\title{
Highly resolved thermal analysis as a tool for simultaneous quantification of total carbon, organic carbon, inorganic carbon and soil organic carbon fractions in landscapes
}

Dissertation

zur Erlangung des mathematisch-naturwissenschaftlichen

Doktorgrades

"Doctor rerum naturalium" der Georg-August-Universität Göttingen

im Promotionsprogramm Geowissenschaften / Geographie der Georg-August University School of Science (GAUSS)

\author{
vorgelegt von \\ Vuong Truong Xuan \\ aus Thai Nguyen Stadt, Vietnam \\ Göttingen 2015
}




\section{Betreuungsausschuss:}

1. Prof. Dr. Gerhard Gerold, Abteilung Landschaftsökologie, Geographisches Institut, Georg-August-Universität Göttingen.

2. Prof. Dr. Hermann F. Jungkunst, Abteilung Geoökologie und Physische Geographie, Universität Koblenz-Landau.

\section{Mitglieder der Prüfungskommission}

$\underline{\text { Referent: }}$

- $\quad$ Prof. Dr. Gerhard Gerold, Abteilung Landschaftsökologie, Geographisches Institut, Georg-August-Universität Göttingen.

Korreferent:

- $\quad$ Prof. Dr. Hermann F. Jungkunst, Abteilung Geoökologie und Physische Geographie, Universität Koblenz-Landau.

\section{Weitere Mitglieder der Prüfungskommission:}

1 Prof. Dr. von Eynatten, Abteilung Sedimentologie und Umweltgeologie, Geowissenschaftliches Zentrum, Georg-August-Universität Göttingen.

2 Prof. Dr. Volker Thiel, Abteilung Geobiologie, Geowissenschaftliches Zentrum, Georg-August-Universität Göttingen.

3 Dr. Andreas Reimer, Abteilung Geobiologie, Geowissenschaftliches Zentrum, Georg-August-Universität Göttingen.

4 Dr. Felix Heitkamp, Abteilung Landschaftsökologie, Geographisches Institut, Georg-August-Universität Göttingen.

\section{Tag der mündlichen Prüfung:}

\subsubsection{5}




\section{Acknowledgements}

I would like to thank my supervisor Prof. Dr. Gerhard Gerold for his indispensable advice and supervision during my doctoral studies that helped me a lot to complete my study. I also would like to thank my second supervisor Prof. Dr. Hermann F. Jungkunst for his guidance and understanding during my research. I am deeply indebted and appreciate to Dr. Felix Heitkamp for his guidance and practical support throughout the doing of my thesis, which helped me a lot and make things easier during the difficult moments of my study.

Many thanks to Dr. Jürgen Grotheer, Anja Södje and Petra Voigt for supporting and helping me in the labor. I also thank Dr. Shafique Maqsood for helping me in improving the language.

I would like to acknowledge the project 322 of Vietnamese Ministry of Training and Education for financing my research abroad.

Finally, sincerely I would deeply like to take this opportunity to thank my family: my parents, my older sister and brother for their motivation and support. To my wife and my children, for their patient support and encouragement.

\section{Vuong Truong Xuan}

Göttingen, 2015 


\section{Preface}

This thesis was funded by the project 322 of Vietnamese Ministry of Training and Education, and supported by the German Academic Exchange Service (DAAD). The thesis is submitted to the Faculty of Geoscience and Geography, Georg-August-Universität Göttingen to fulfill the requirements for the degree "Doktor der Naturwissenschaften" (Dr. rer. nat.).

The cumulative dissertation is based on three papers as first author, which are published in or submitted to international refereed journals. The manuscripts are included in chapters II, III and IV.

The focus of the general introduction (chapter I) is on theoretical and methodological issues, whereas specific introductions on thermal gradient, standard methods and soil samples were given in the following manuscripts (chapters II, III and IV).

Chapter II:

Simultaneous measurement of soil organic and inorganic carbon: Evaluation of a thermal gradient analysis.

Truong Xuan Vuong, Felix Heitkamp, Hermann F. Jungkunst, Andreas Reimer and Gerhard Gerold (2013). Journal of Soils Sediments. 13: 1133-1140.

Chapter III:

Simultaneous measurement of organic and inorganic carbon in dolomite-containing soils.

Truong Xuan Vuong, Jörg Prietzel and Felix Heitkamp.

CATENA Journal (submitted).

Chapter IV:

Highly resolved thermal analysis as a tool for soil organic carbon fractionation in landscapes.

Truong Xuan Vuong, Hermann F. Jungkunst, Andreas Reimer, Gerhard Gerold and Felix Heitkamp.

European Journal of Soil Science (submitted). 


\section{AUTHOR'S CONTRIBUTIONS}

1. Truong Xuan Vuong, Felix Heitkamp, Hermann F. Jungkunst, Andreas Reimer, Gerhard Gerold. 2013. Simultaneous measurement of soil organic and inorganic carbon: Evaluation of a thermal gradient analysis. Journal of Soils Sediments. 13: 1133-1140. (Published).

2. Truong Xuan Vuong, Jörg Prietzel and Felix Heitkamp. Simultaneous measurement of organic and inorganic carbon in dolomite-containing soils. CATENA Journal of Elsevier. (submitted).

3. Truong Xuan Vuong, Jungkunst H.F, Reimer A, Gerold G, Heitkamp F. Highly resolved thermal analysis as a tool for soil organic carbon fractionation in landscapes. European Journal of Soil Science . (submitted).

I am responsible for writing the introduction and synthesis of this thesis. I am the first author of all three articles. I performed measurements, developed the setup of the MCD analysis and analyzed data in paper 1 . For paper 2, I cooperated with colleagues who are working in TU München, Germany. I was responsible for conducting all the laboratory analysis and analyzing data in Göttingen. For paper 2, I was also the corresponding author who drafted the manuscript and contributed significantly to the final text. I did most of the experiments, analyzed most of the data, and contributed in writing the manuscript of the article 3. 


\section{Table of contents}

I Introduction..

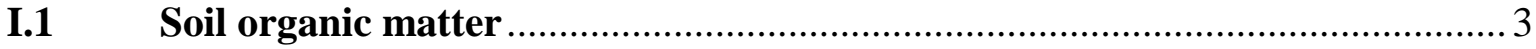

I.2 Soil organic matter stabilization - the geo-ecological need for fractionation.. 5

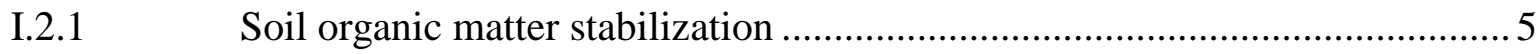

I.2.2 The geo-ecological need for SOM fractionation ..................................... 6

I.3 Methods to analyze SOM pools and fractions ......................................... 8

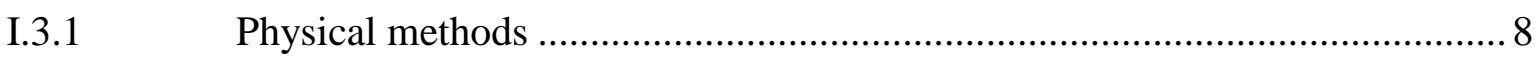

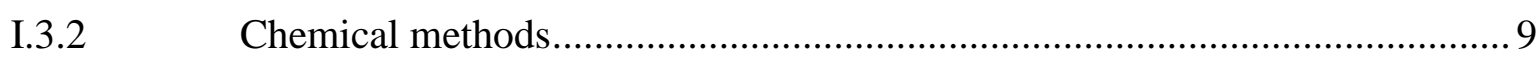

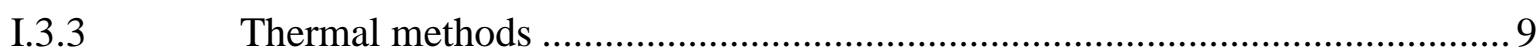

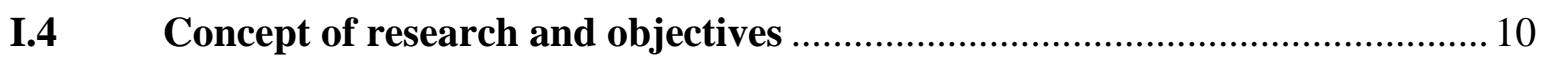

II Simultaneous measurement of soil organic and inorganic carbon: Evaluation of a

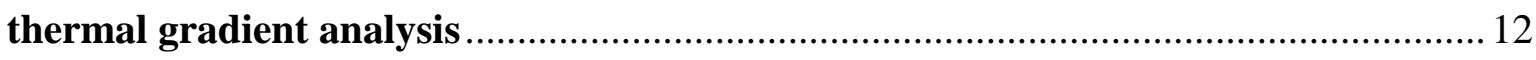

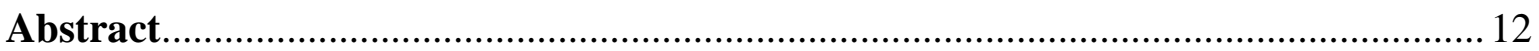

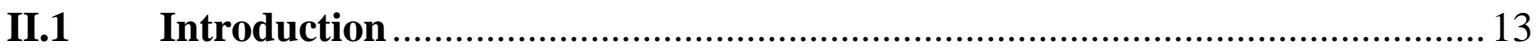

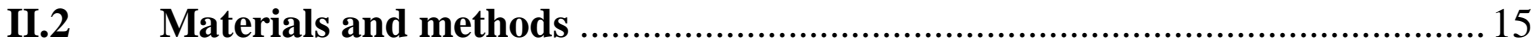

II.2.1 Samples and sample preparation............................................................ 15

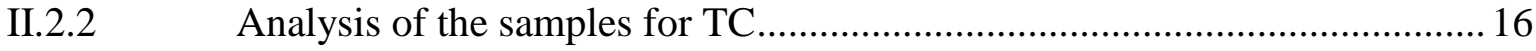

II.2.3 Analysis of SIC with the calcimeter ........................................................ 17

II.2.4 Analysis of TC, SOC and SIC in one subsample ...................................... 18

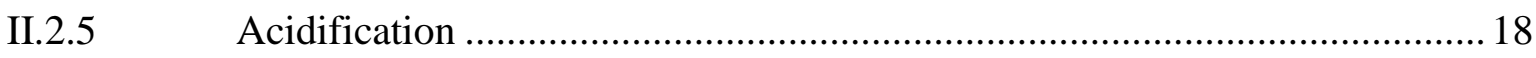

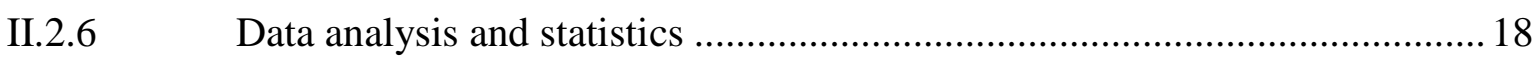

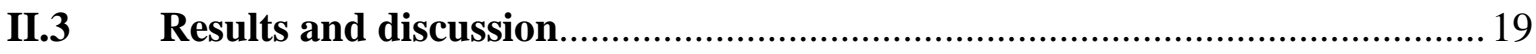

II.3.1 Precision and bias of standard material ................................................ 19

II.3.2 Precision and bias of the replicated subset ................................................ 20

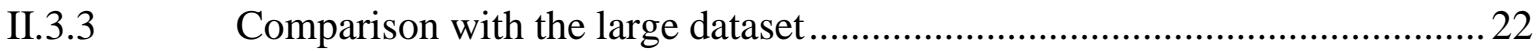

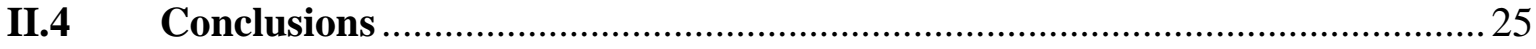


III Multaneous measurement of organic and inorganic carbon in dolomite-

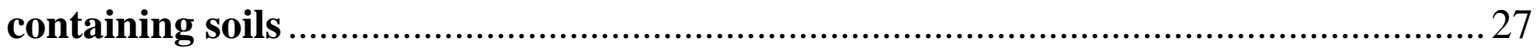

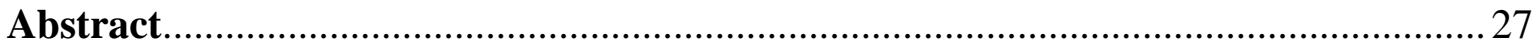

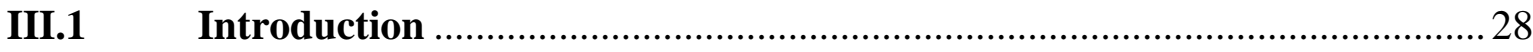

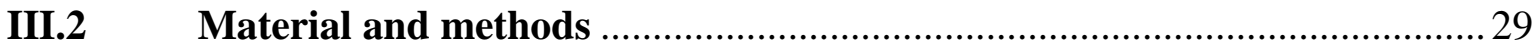

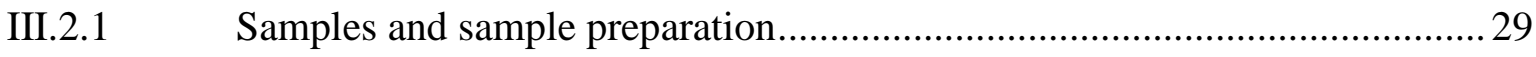

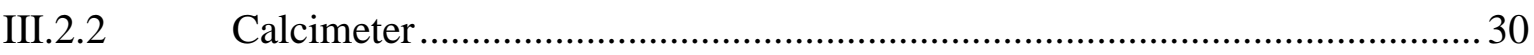

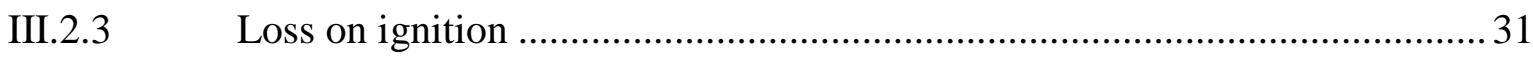

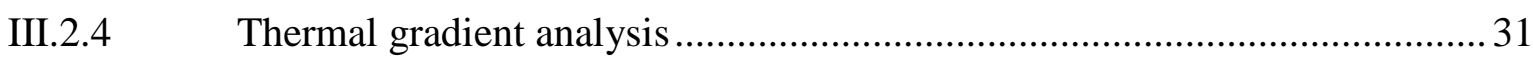

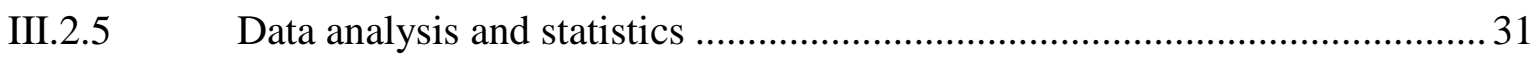

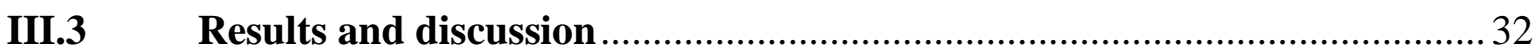

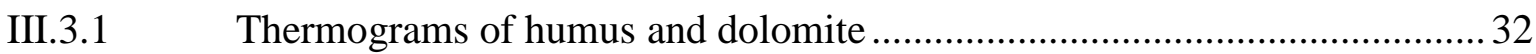

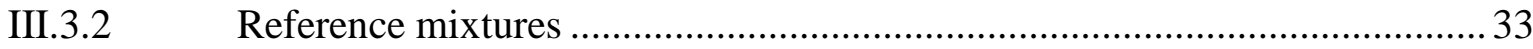

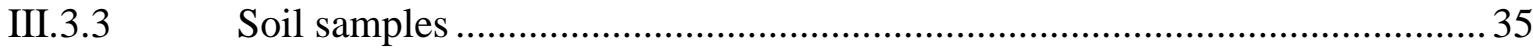

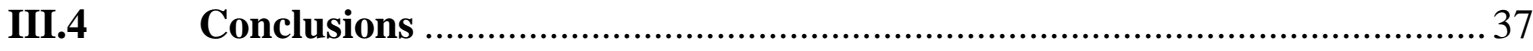

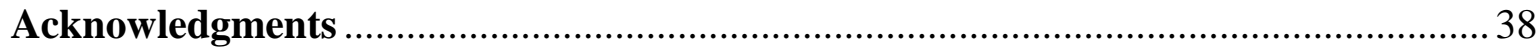

IV Highly resolved thermal analysis as a tool for soil organic carbon fractionation

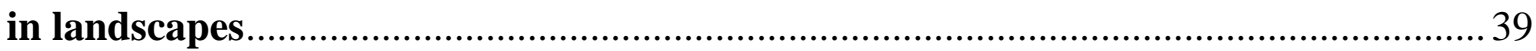

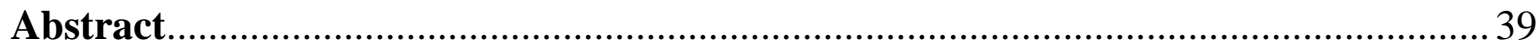

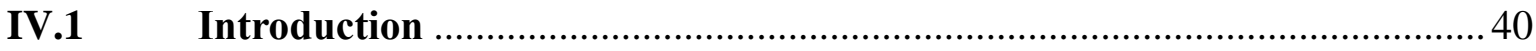

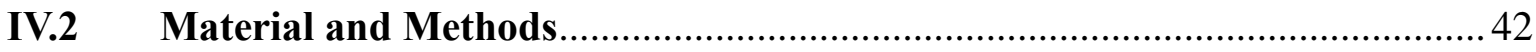

IV.2.1 Setting of the thermal gradient method................................................. 42

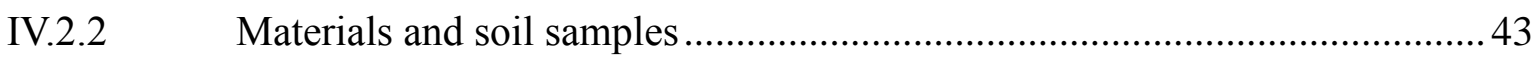

IV.2.3 Description of established methods ........................................................... 46

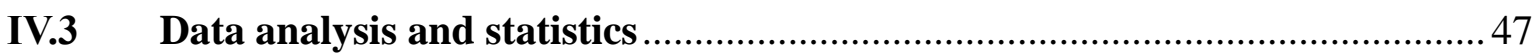

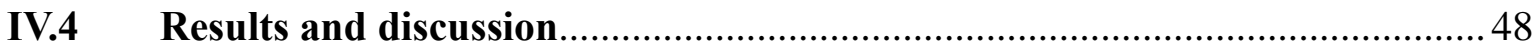

IV.4.1 Thermal fractions of material and soil samples ........................................ 48 


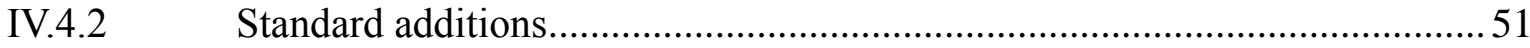

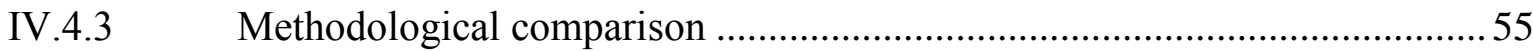

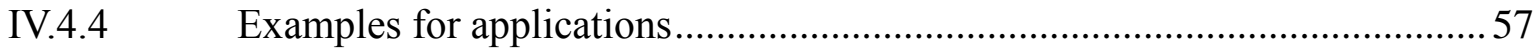

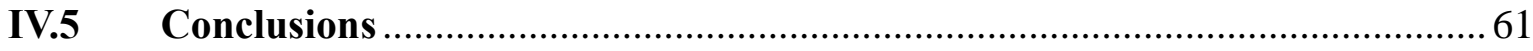

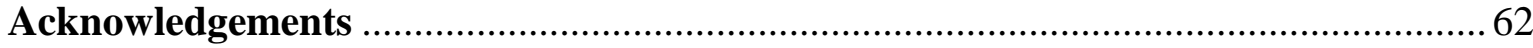

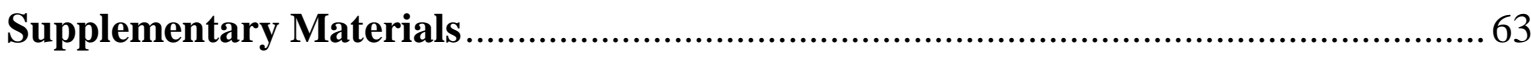

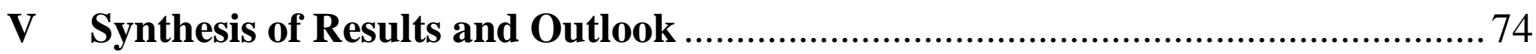

V.1 ThG: direct method for soil carbon characterization: ................................. 74

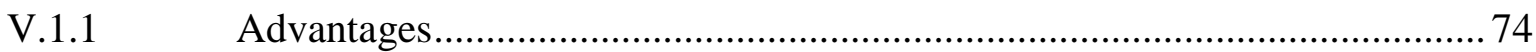

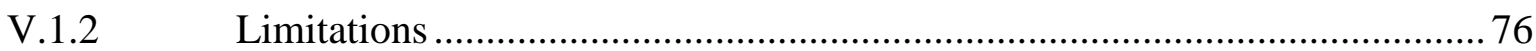

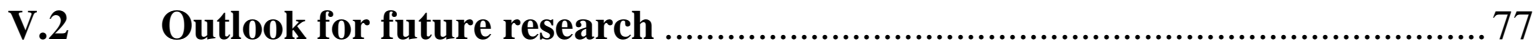

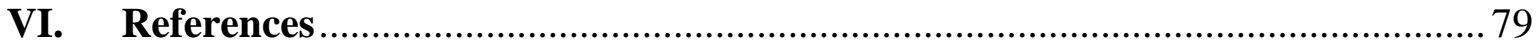




\section{List of tables}

Table I.1 'Pools' (or types) of soil organic matter (Broos and Baldock. 2008; GRDC. 2009; PIRSA. 2010).

Table II.1 Description of sampling sites with ranges of $\mathrm{pH}$-values and contents of total carbon (TC) and the proportion of soil inorganic carbon (SIC)

Table II.2 Regression equations with standard errors for the carbonate standards as quality control for the used instruments. The theoretically calculated C-content was used as independent and the measured $\mathrm{C}$-content as independent variable. A t-test was performed to check if the intercept was significantly $(\mathrm{p} \leq 0.05)$ different from zero and the slope from one. Calculated t-values were compared to the critical t-value. The null hypothesis assumed no differences. Bold figures were used in the case the null-hypothesis was rejected. For abbreviations see text or Fig. II.1 ................................................

Table II.3 Statistics for the comparison of the calcimeter (CALC) and acidification (ACI) method against the thermal gradient method (ThG). The F-test is indicative for the precision and the t-test for the bias of the methods. The condition for accepting the null-hypothesis (i.e., no difference between methods) is given in brackets behind the names of the tests. Bold figures indicate significant differences $(\mathrm{p} \leq 0.05)$ between two methods

Table II.4 The contents of soil inorganic carbon (SIC) and soil organic carbon (SOC) in seven soil samples as determined by three different methods. Mean values of three analytical replicates and coefficients of variation $(\mathrm{CV})$ in brackets. Bold figures indicate a significant difference ( $\mathrm{p} \leq 0.05$, $\mathrm{t}$-test) to the corresponding figure measured by ThG. For abbreviations, see text and Fig. II.1

Table II.5 Regression equations with standard errors for comparison of methods with the different dataset. $\mathrm{SIC}_{\mathrm{CALC}}$ or $\mathrm{SOC}_{\mathrm{CALC}}$ values were used as independent and $\mathrm{SIC}_{\mathrm{ThG}}$ or SOC $_{\text {ThG }}$ values were used as dependent variables. A t-test was performed to check if the intercept was significantly $(\mathrm{p} \leq 0.05)$ different from zero and the slope from one. Calculated $\mathrm{t}$-values were compared to the critical t-value. The null hypothesis assumed no differences. Bold figures were used in the case the null-hypothesis was rejected. For abbreviations and explanation of the sample subsets see text or Fig. II.1 
Table III.1 Mixing ratio of the dolomite-humus mixtures and the resulting theoretical concentrations of inorganic and organic carbon. Measured $\mathrm{C}$ content of humus and dolomite was $419.5 \mathrm{~g} \mathrm{~kg}^{-1}$ and $129.3 \mathrm{~g} \mathrm{~kg}^{-1}$, respectively

Table III.2 Regression equations with standard errors for comparison of methods in the different datasets (reference mixtures: Figure III.2; soil samples: Figure III.3). Bold figures were used in the case that intercept or slope differed significantly $(\mathrm{p} \leq 0.05)$ from zero or one, respectively. For abbreviations and explanation of the sample subsets, see text or Fig. III. 2 and III.3.

Table IV.1 Settings of the temperature profile of the MCD RC-412 with abbreviations of the corresponding fractions.

Table IV.2 Abbreviations, as well as contents of organic carbon, inorganic carbon and the $\mathrm{C} / \mathrm{N}$-ratio of the used soil samples and materials 48

Table IV.3 Organic carbon concentrations in thermal fractions of four soil samples and changes in the concentrations in comparison to the unspiked sample after starch spiking. Mean values and standard errors $(n=3)$ .55

Table IV.4 Organic carbon concentrations in thermal fractions of four soil samples and changes in the concentrations as compared to the unspiked sample after wood char spiking. Mean values and standard errors $(n=3)$

Table IV.5 Mean concentrations (with standard errors, $n=3$ ) of hot water extractable carbon (with starch spike) and oxidisable carbon (with wood char spike) including the respective recovery rates. The letters indicate differences at a level of significance of $p \leq 0.05$ and are entered for convenience. Results of the ANOVA are given in the supporting information. .58

Table IV.6 Thermal characterisation of light $\left(\rho \leq 2.0 \mathrm{~g} \mathrm{~cm}^{-3}\right)$ and heavy $\left(\rho>2.0 \mathrm{~g} \mathrm{~cm}^{-3}\right)$ fractions of soil samples from sites with different fertilisation history. Means of four field replicates with standard deviations in brackets (upper part of the table). The lower part of the table presents the $p$-values obtained by the mixed model (factors Type, Rate and their interaction) and the t-test (comparison between light and heavy fractions) 
Table S1 Statistical parameters for the relationship between the peak areas of different ramps as well as for hold and continuous ramp. Standard errors of intercept and slope are given in brackets. T-statistics show the probability (p-value) that the null-hypothesis (no difference) is accepted.

Table S2 Statistical parameters for the relationship between the sample weight and measured concentrations for the Histosol and Anthrosol. Measurements with holds and a ramp of $35^{\circ} \mathrm{C}$ $\min ^{-1}$. Standard errors of intercept and slope are given in brackets

Table S3 F- and t-statistics ( $\mathrm{n}=3,2$ degrees of freedom) for Table 3 of the main manuscript.

Table S4 F- and t-statistics ( $\mathrm{n}=3,2$ degrees of freedom) for Table 4 of the main manuscript.

Table S5 Results of the one-way ANOVA calculated for the dataset of hot water extractable carbon with starch spike (Table IV.5)

Table S6 Results of the one-way ANOVA calculated for the dataset of oxidisable carbon with wood char spike (Table IV.5) 73

Table S7a Results of the one-way ANOVA calculated for the dataset of absolute Cconcentrations under different land-use (Figure IV.4).

Table S7b Results of the one-way ANOVA calculated for the dataset of absolute Cconcentrations under different land-use (Figure IV.4). . .76

S: supplementary 


\section{List of figures}

Figure I.1 The global carbon cycles (1990s)

Figure I.2 A simple diagram of the soil organic carbon cycle in connection with SOC pools.

Figure II.1 Comparison by linear regressions of total, soil organic and soil inorganic carbon contents as measured and calculated by different methods. (a) Soil organic carbon (SOC) contents as measured by the thermal gradient $\left(\mathrm{SOC}_{\mathrm{ThG}}\right)$ method were compared to calculated

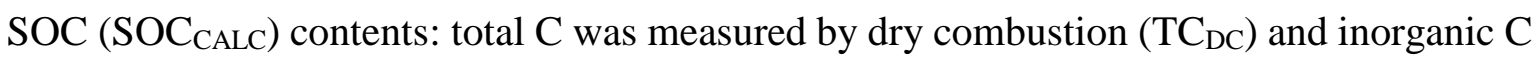
by a calcimeter $\left(\mathrm{SIC}_{\mathrm{CALC}}\right), \mathrm{SOC}_{\mathrm{CALC}}$ was obtained by difference. (b) Soil inorganic carbon contents as measured by the calcimeter $\left(\mathrm{SIC}_{\mathrm{CALC}}\right)$ and the $\mathrm{ThG}$ method $\left(\mathrm{SIC}_{\mathrm{ThG}}\right)$. (c) Total carbon in acidic, carbonate-free samples $(\mathrm{pH}<6)$ as measured by the $\mathrm{CN}$ analyser $\left(\mathrm{TC}_{\mathrm{DC}}\right)$ and the ThG method ( $\mathrm{TC}_{\mathrm{ThG}}$ ). (d) As in (a) but with a set of samples with $\mathrm{pH}>6$. Parameters are given \pm standard error. An uppercase asterisk after the parameter indicates that it is significantly different ( $t$-test, $\mathrm{p} \leq 0.05)$ from zero (intercept) or one (slope); "ns" denotes no significant difference

Figure III.1 Thermo-gram of humus (long-dash) and dolomite (solid line) samples. The short-dashed line is the temperature and the vertical grey line indicates the division of inorganic and organic carbon .35

Figure III.2 Scatter plots of different methods as compared to the reference mixtures ( $\mathrm{n}=$ 25). The dashed line is the $1: 1$ line and the thick black line is the linear regression. IC: inorganic carbon; OC: organic carbon; CALC: calcimeter; LOI: loss-on-ignition; ThG: thermal gradient; REF: reference mixtures of humus and dolomite.

Figure III.3 Comparison of contents of organic (OC) and inorganic carbon (IC) quantified by the thermal gradient method (ThG), calcimeter (CALC) and loss-on-ignition (LOI). Set of soil samples $(n=17)$. Long-dashed thin line: theoretical 1:1 line; thick solid line: regression with all samples; short-dashed thick line: regression without outliers

Figure IV.1 Thermograms of material and soil samples. The peak above $600^{\circ} \mathrm{C}$ was proven to be inorganic carbon and is therefore delimited by the dashed grey line. The numbers represent the temperatures for peaks and shoulders. 
Figure IV.2 Thermograms of different samples spiked with $16 \mathrm{~g} \mathrm{~kg}^{-1}$ wheat starch or wood char in comparison to the blank samples. The peak above $600^{\circ} \mathrm{Cwas}$ proven to be inorganic carbon and is therefore delimited by the dashed line

Figure IV.3 Scatter plots of spiked samples for comparison of (left) labile carbon evolved between 140 and $300^{\circ} \mathrm{C}\left(\mathrm{C}_{140-300}\right)$ and hot water extractable carbon (HWC) and (right) stable carbon evolved between 450 and $600^{\circ} \mathrm{C}\left(\mathrm{C}_{450-600}\right)$ and wet oxidation resistant carbon $\left(\mathrm{C}_{\mathrm{OX}}\right)$

Figure IV.4 Land use effects on soil total carbon, inorganic carbon organic carbon and its four thermal fractions. Left: absolute values, right: fractions in relation to organic carbon (mean values and standard deviations, $n=9$ ). The letters indicate differences at a level of significance of $\mathrm{p} \leq 0.05$ and are entered for convenience. Results of the ANOVA are given in the supporting information 60

Figure S1 Examples for thermograms recorded with different ramps $\left(12^{\circ} \mathrm{C} \min ^{-1}\right.$ : dashed line; $35^{\circ} \mathrm{C} \mathrm{min}^{-1}$ : solid line). Left side: Histosol, right side: Anthrosol. Note that temperature is on the $\mathrm{x}$-axis, whereas time is on the $\mathrm{x}$-axis in the main manuscript.

Figure S2 Relationships between the peak areas of different ramps (left) as well as of hold and continuous ramp (right). Comparison of different ramps without hold and comparison of hold and continuous ramp at $35^{\circ} \mathrm{C} \mathrm{min}^{-1}$. The $1: 1$ line is dashed and $95 \%$ confidence intervals are visualized.

Figure S3 Comparison of thermograms with holds (solid line) and continuous ramp (dashed line). The ramp was $35^{\circ} \mathrm{C} \min ^{-1}$. The figure is the equivalent of Figure 1 in the main manuscript, but temperature instead of time is used on the x-axis. This may lead in the holdregions to apparently clinched signals .68

Figure S4 Scatter plots showing results for organic carbon concentrations in different thermal fractions as well as total carbon concentrations in relation to sample amount. Analysis with hold and ramp of $35^{\circ} \mathrm{C} \mathrm{min}^{-1}$. Analysis was done in duplicate. 


\section{List of abbreviation}

ACI Acidification

CALC Calcimeter

CON Control sample (quartz sand)

CR

$\mathbf{C R}_{\text {sand }} \quad$ Cropland soil classified as sandy soil

CV Coefficient of variation

DC Dry combustion

DSC Differential scanning calorimetry

DTA Differential thermal analysis

DTG Derivative thermogravimetry

EDTA Ethylene diamine tetra

EGA Evolved gas analysis

FOR Forest soil

FYM Farmyard manure

HWC Hot-water extractable C

IC Inorganic carbon

LC Labile carbon

LF Light fraction

LOI Loss on ignition

MCD Multiphase carbon determinator

MSI Mineral fertilizer with straw incorporation

NMR Nuclear magnetic resonance

OC Organic carbon

POM Particulate organic matter

SC Stable carbon

SE Standard error

SIC Soil inorganic carbon

SOC Soil organic carbon

SOM Soil organic matter

TC Total carbon

ThG Thermal gradient

WE Wetland soil WOX: wet oxidation 


\section{Summary}

To quantify and evermore qualify carbon in soils have become highly timely task in landscape ecology. However, separating soil organic carbon (SOC) into different ecologically relevant fractions is difficult. Particularly for landscape approaches needing high numbers of samples, it is necessary to find a simple, economic and suitable method that can quantify total carbon, organic carbon and inorganic carbon as well as separate SOC fractions, preferably with a single method and a single run for each sample. A thermal gradient method was modified and tested for this purpose. The objective of the present work were to:

To verify the cost-effective method developed by Chichester and Chaison (1992) with a larger set of samples representing a much wider range of soil properties (carbonate and noncarbonated soils) and with a new generation of the analyzer.

To test the ability to quantify dolomite-derived IC by ThG in dolomite soil samples.

(iii) Assessing the suitability of ThG for the quantification of ecological meaningful differences in organic carbon fractions of soil and material samples with different carbon stability.

Topsoil samples were collected from cropland, forest, grassland and wetland in temperate, subtropical and tropical regions in order to represent a wide range of soil properties. Standard materials with different thermal stabilities were used for testing as well.

The main findings were:

All methods (ThG, Calcimeter and acidification methods) were suitable to separate soil carbon into SIC and SOC. However, Calcimeter and acidification methods resulted in lower estimates of SOC contents due to the use of acid. When comparing soil samples with differing carbonate concentrations, the use of the ThG method was more reliable. Moreover, ThG was as suitable as standard methods ( $\mathrm{CN}$ analyser or dry combustion) to measure total carbon (TC).

(ii) Compared to Calcimeter (CALC) and Loss on ignition (LOI) in quantifying OC and IC in dolomite soil samples, the ThG method was the most accurate method in the reference sample set, especially when dolomite contents were high. On the soil sample set, ThG and CALC performed equally, but only when two outliers were eliminated. LOI was not satisfactory in any case on the sample set. Overall, ThG was the most reliable method for measuring IC and OC in dolomite-containing samples over the wide range of concentrations, but the more widespread CALC method is also acceptable. 
(iii) By using ThG for isolation SOC fractions, four main peaks of organic carbon fractions were recorded at the temperature ranges: $140-300^{\circ} \mathrm{C}, 300-400^{\circ} \mathrm{C}, 400-450^{\circ} \mathrm{C}$ and $450-600^{\circ} \mathrm{C}$. By testing with different materials with different thermal stabilities (e.g. grass char, wood char and wheat starch), results showed that the thermal fractions are ecologically relevant. Thermal fractions are various with different materials and relevant to different turnover rate of SOM. Therefore, thermal gradient analysis can be effectively used in routine measurement to determine organic, inorganic and total carbon as well as the stability of organic matter in a single analytical run. Care has to be taken when samples with high C-concentrations are analysed. In any case, first examples like comparing different land use within a region according to their soil organic carbon fraction revealed that much more information with a single analysis (i.e. TC, SOC, SIC, thermal fractions of SOM) can be achieved from the presented thermal gradient method in comparison to regular bulk $\mathrm{C}$ measurement (providing only TC value).

Overall, ThG can be used to quantify TC, IC and OC as a simple, precise and economic method without complicated pretreatment. Moreover, it can effectively measure the organic, inorganic and total carbon as well as the stability of organic matter in a single analytical run. It can be applied to landscape scale, particularly for larger scale analyses on land use systems and land use change. 


\section{Introduction}

Soil is the largest terrestrial reservoir of carbon (C), which has three times amount of $\mathrm{C}$ compared to terrestrial plants (Schlesinger. 1990) and twice as much as the atmosphere (Jungkunst et al. 2012). Therefore, soil carbon plays a vital role in global carbon cycle and climate change (Lal R. 2002), and has a complicated links to the climate system via the carbon global cycle (Brevik EC. 2012). The atmospheric $\mathrm{CO}_{2}$ and $\mathrm{CH}_{4}$ concentrations are linked to climate warming that may enhance $\mathrm{C}$ release from soils (see Fig.I.1).

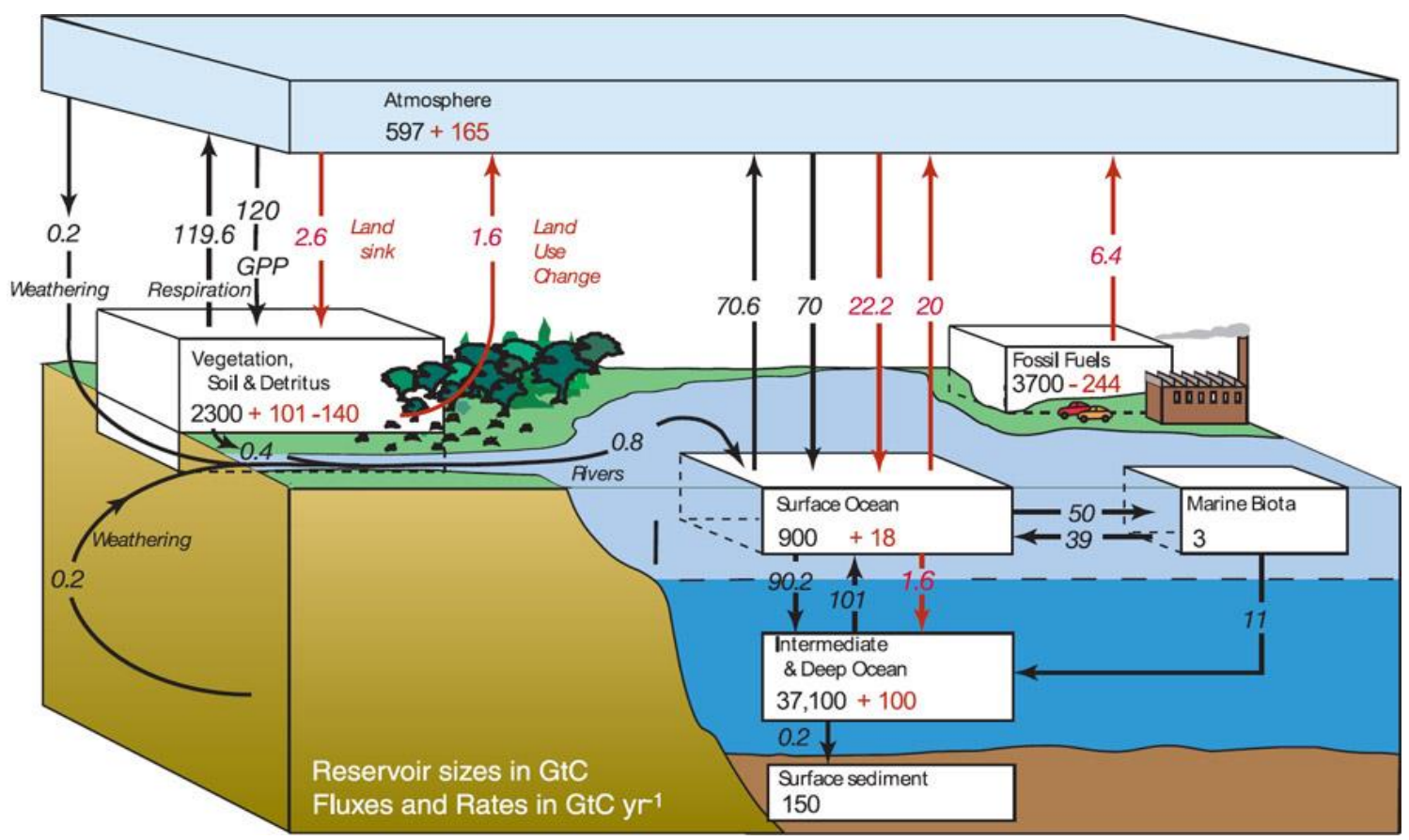

Fig. I.1 The global carbon cycle (1990s) (IPCC (2007) Climate change report. chapter 7)

The increase in greenhouse gases (GHGs) like carbon dioxide $\left(\mathrm{CO}_{2}\right)$, nitrous oxide $\left(\mathrm{N}_{2} \mathrm{O}\right)$ and methane $\left(\mathrm{CH}_{4}\right)$ in the atmosphere is closely linked to Global warming (IPCC. 2007; Jungkunst and Fiedler. 2007). The main sources that enhance the concentration of the anthropogenic greenhouse gases are human activities such as burning of fossil fuels and biomass, industrial processes and land use changes (e.g. land-clearing, burning, deforestation and tillage). About $75 \%$ of the anthropogenic emissions are caused by fossil

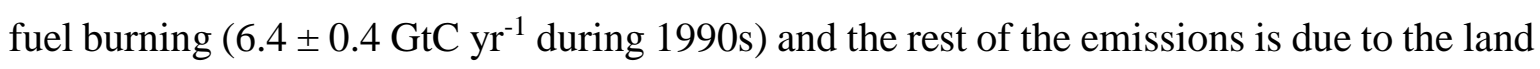
use changes (deforestation and agricultural development, around 1.6 GtC) (IPCC. 2007; Schimel et al. 2001). Every year, the flux of carbon dioxide $\left(\mathrm{CO}_{2}\right)$ from the soil surface to the atmosphere is approximate ten times more than the $\mathrm{CO}_{2}$ emitted from anthropogenic burning of fossil fuels (Cao and Woodward. 1998; IPCC. 2007). Changes in the size of soil 
carbon pools or their exchange rates will influence significantly the concentration of $\mathrm{CO}_{2}$ in the atmosphere (Cao and Woodward. 1998).

Generally, total soil carbon includes soil organic carbon (SOC) and may include inorganic carbon (SIC). SOC includes "residues of animals, plants, or microorganisms at various states of decomposition" (Bisutti et al. 2004; Bastjes and Sombroek. 1997) whereas SIC consists of carbonates. Carbonate minerals play a vital role in soil quality due to their special properties of solubility, alkalinity and $\mathrm{pH}$-buffering; hence they influence strongly the biochemical properties of soils (Bisutti et al. 2004). Quantifying SOC and SIC separately is essential for our understanding about carbon cycle from regional to global scales (Chichester and Chaison. 1992; Bisutti et al. 2007).

In most of the soils, SOC is the crucial part of C in soil (Batjes and Sombroek. 1997). The changes in SOC can have significant impacts on soil fertility (Brevik. 2012) and climate change (Lal. 2004). Since changes in the turnover rate of SOC can influence concentration of atmospheric $\mathrm{CO}_{2}$ significantly (Karhu. 2010). Vegetation, dead plant litter, roots and roots exudates are carbon inputs to soil carbon. $\mathrm{C}$ is mainly cumulated in the soil from plant debris decomposed by the oxidation of microorganism (Schmidt et al. 2011). The carbon output of soil carbon is respiration of $\mathrm{CO}_{2}$ from decomposition process, soil erosion and leaching of dissolved organic carbon (GRDC. 2004; Heimann and Reichstein. 2008). Changes of carbon stocks and SOC-composition are dependent on the balance of carbon input and output (Karhu. 2010; GRDC. 2004). Therefore, factors that limit the amount of C input or output will change the amount of carbon stored in soils. Moreover, the SOC decomposition is more sensitive to temperature than net carbon fixation of plants and has much more $\mathrm{C}$ than that of plants (1550 GtC of SOC and $550 \mathrm{GtC}$ of biotic pool) (Lal. 2004). Therefore, the rise of $\mathrm{CO}_{2}$ respiration from soil caused by global warming can easily be more than the $\mathrm{CO}_{2}$ uptake of plant (Karhu. 2010; Kirschbaum. 2000). Consequently, only a slight change of soil organic carbon will affect climate change (Karhu 2010; Kirschbaum. 2006).

SOC plays several vital ecological functions with strong impacts on "soil structure, storing nutrients, cation exchange and water-holding capacity" (van Keulen. 2001). SOC serves as nutrients source for plant growth, promotes biological and physical health and the structure of soil, and is a strong buffer and binding agent against organic pollutants and non-ionic compounds (Murphy. 2014; van Keulen. 2001; Batjes and Somboek. 1997). Furthermore, SOC plays a key role in the crop sustainability by enhancing the "fertility and tillage of soil" 
(Reeves. 1997). Thus, quantification and characterization of OC is important for our understanding of soil ecological processes, especial for soil carbon fluxes and storage.

The following chapter of this introduction will focus on the background knowledge as well as with theoretical and methodological consideration of SOC, SOC fractions and its measurability. The remaining issues will be covered by the introductions of different manuscripts (chapter II, III and IV).

\section{I.1 Soil organic matter}

There are many different ways to define organic constituents of SOM (GRDC ${ }^{1}$. 2013). According to Baldock and Skjemstad (1999), SOM was defined as "all organic materials found in soils irrespective of origin or state of decomposition”. SOM is a mixture of organic substances of different forms that have various turnover times from year to thousands of years (GRDC ${ }^{1}$. 2013). It includes a mixture of plant and animal residues at various stages of decomposition of substances, synthesized microbiologically and chemically from the breakdown products, microorganisms, small animals and their decomposing products' (Schnitzer. 1991; Batjes and Sombroek. 1997).

According to von Lützow et al (2008), SOM is separated into at least three conceptual pools based on the different turnover rates. They include (i) a labile or active pool with turnover times of up to 10 years, (ii) a slow or intermediate pool with turnover times between 10 and 100 years and (iii) a stable or passive pool with slower turnover times (>100 years). SOC can also be differentiated in four pools with various properties and turnover rates based on the different layers of pools (see table I.1) (GRDC ${ }^{1}$. 2013).

SOM is different form SOC because it includes all the elements which are components of organic compounds (GRDC ${ }^{1}$. 2013). Because SOM consists of $\mathrm{C}, \mathrm{H}, \mathrm{O}, \mathrm{N}, \mathrm{P}$ and $\mathrm{S}$, it is challenging to quantify directly the SOM content. It can merely be quantified indirectly by measurement of SOC and estimate through a conversion factor. SOM is assumed to contain $50-58 \%$ carbon (Chaudhari et at. 2013). To do so, a factor of 1.72 is regularly used to convert organic carbon to organic matter as in equation (1) (Baldock and Skjemstad. 1999)

$$
\mathrm{SOM}=1.72 * \operatorname{SOC}(1)
$$

SOM is a key indicator for soil quality (Reeves. 1997). It has three main groups of functions. They include: (i) Biological functions (e.g. providing source of energy, reservoir of nutrients 
and contributing to resilience of soil-plant system), (ii) Physical functions (e.g. improving structural stability of soils at various scales, influencing water holding capacity of soils and altering soil thermal properties), (iii) Chemical functions (e.g. to contribute to the cation exchange capacity, to strengthen ability of soil to pH-buffer changes) (GRDC ${ }^{1}$. 2013). Therefore, it plays an important role in the "fertility, productivity and sustainability of agricultural and non-agricultural ecosystems" (Crawell and Lefroy. 2001). Moreover, SOM acts as a vital key component in the global $\mathrm{C}$ balance. Management of SOM can influence remarkably on the global $\mathrm{C}$ balance and the increased atmospheric $\mathrm{CO}_{2}$ on climate change (Crawell and Lefroy. 2001).

Table I.1 'Pools' of soil organic matter (Broos and Baldock. 2008; GRDC. 2009; PIRSA. 2010).

\begin{tabular}{|c|c|c|c|c|}
\hline $\begin{array}{l}\text { Organic carbon } \\
\text { pool }\end{array}$ & Size & Stability & $\begin{array}{c}\text { Turnover } \\
\text { time }\end{array}$ & Key functions \\
\hline Crop residue & & & & Provide energy and \\
\hline $\begin{array}{l}\text { Shoot and root } \\
\text { residues on and in } \\
\text { the soil }\end{array}$ & $>2 \mathrm{~mm}$ & Labile & Days & $\begin{array}{l}\text { nutrients to biological } \\
\text { processes; readily broken } \\
\text { down supporting } \\
\text { microbial life in soils. }\end{array}$ \\
\hline $\begin{array}{l}\text { Particulate } \\
\text { organic matter } \\
\text { (POM) }\end{array}$ & & & & $\begin{array}{l}\text { These are broken down } \\
\text { relatively quickly in } \\
\text { suitable conditions but }\end{array}$ \\
\hline $\begin{array}{l}\text { Smaller plant } \\
\text { debris }\end{array}$ & $0.05-2 \mathrm{~mm}$ & & & $\begin{array}{l}\text { more slowly than crop } \\
\text { residues. Important for } \\
\text { soil structure, provision of } \\
\text { energy for biological } \\
\text { processes and nutrients. }\end{array}$ \\
\hline \multicolumn{5}{|l|}{ Humus } \\
\hline $\begin{array}{l}\text { Decomposed } \\
\text { material } \\
\text { dominated by } \\
\text { molecules stuck } \\
\text { to soil minerals }\end{array}$ & $<0.05 \mathrm{~mm}$ & & & $\begin{array}{l}\text { This plays a role in all key } \\
\text { soil functions, but is } \\
\text { particularly important in } \\
\text { the retention and } \\
\text { provision of nutrients (e.g } \\
\text { the majority of available } \\
\mathrm{N} \text { is found in the humus } \\
\text { fraction). }\end{array}$ \\
\hline $\begin{array}{l}\text { Recalcitrant } \\
\text { organic matter }\end{array}$ & & & & \multirow{2}{*}{$\begin{array}{l}\text { Decomposes very slowly } \\
\text { and if present in large } \\
\text { enough quantities can } \\
\text { contribute to cation } \\
\text { exchange capacity as well } \\
\text { as controlling soil } \\
\text { temperature. }\end{array}$} \\
\hline $\begin{array}{l}\text { Biologically } \\
\text { stable, dominated } \\
\text { by pieces of } \\
\text { charcoal. }\end{array}$ & Variable & $\begin{array}{l}\text { Very stable/ } \\
\text { relatively } \\
\text { inert }\end{array}$ & $\begin{array}{l}\text { Hundreds } \\
\text { of years }\end{array}$ & \\
\hline
\end{tabular}




\section{I.2 Soil organic matter stabilization - the geo-ecological need for fractionation}

\section{I.2.1 Soil organic matter stabilization}

Sollins et al. (1996) defined SOM stabilization as the "protection of organic matter from mineralization". According to von Lützow et al. (2006), SOM is stabilized by three main mechanisms: (i) recalcitrance, (ii) spatial inaccessibility, and (iii) interaction with soil minerals and metal ions.

(i) Recalcitrance is the selective preservation of SOM because of its structural composition or molecular-level characteristics of organic substances (Sollin et al. 1996). It can be divided as two kinds of recalcitrance such as primary and secondary recalcitrance. Primary recalcitrance is the recalcitrance combined with plant litter and rhizodeposits, whereas secondary recalcitrance is the recalcitrance of microbial products, humic polymers and charred material that are slowly decomposed by microbes and enzymes (Sollins et al. 1996; von Lutzow et al. 2006; von Lutzow et al. 2008; Breulmann. 2011; Heitkamp. 2010). However, according to von Lützow (2006), recalcitrance is merely significant in active surface of soils and during the beginning decomposition of OM.

(ii) Spatial inaccessibility refers to various processes that is caused by occlusion of SOM, rendering it inaccessible to microbes and degradative enzymes. These include interactions with aggregates, intercalation into "phyllosilicates", "hydrophobicity" and “encapsulation” in organic macromolecules (von Lützow. 2006; Breulmann. 2011). Occluded $O M$ is spatially protected against decomposition because occlusion of $\mathrm{OM}$ reduced access for the microorganisms and their enzymes, restricted aerobic decomposition owing to reduced diffusion of oxygen and reduced diffusion of enzymes into the intra-aggregate space. Intercalation within phyllosilicates of organic ligands from enzymes, proteins, fatty acids or organic acids is dependent on the $\mathrm{pH}$ values. Organic ligands can intercalate within phyllosilicates only at a $\mathrm{pH}<5$. Hydrophobicity reduces water providing for living conditions of microorganisms and therefore decreases decomposition rates of $\mathrm{OM}$ and the accessibility of $\mathrm{OM}$ for microorganisms. Encapsulation in organic macromolecules is a process, in which labile organic matter is protected from decomposition by encapsulation in the network of recalcitrant polymers or humic pseudo-macromolecules (von Lützow. 2006).

(iii) Interactions between the SOM and minerals or metal ions that reduce the ability in decomposing SOM by microorganisms and enzymes, and therefore change the decomposed rate of SOM. It is suggested that after binding to mineral surface, OM 
becomes stabilized. It consists of various processes of ligand exchange, polyvalent cation bridges and complexation of SOM with metal ions (von Lützow. 2006). Clay minerals or amorphous hydroxides or iron (Fe) and aluminum (Al) play an important role in interaction between $\mathrm{OM}$ and minerals. Because amorphous hydroxides have active hydroxyl groups and $\mathrm{OM}$ has active groups such as $\mathrm{COOH}, \mathrm{OH}$ or $\mathrm{NH}_{2}$ that can exchange cation or anion and create stabile complex between $\mathrm{OM}$ and clay minerals by complexation reactions (Sollin et al. 1996; von Lützow. 2006).

\section{I.2.2 The geo-ecological need for SOM fractionation}

Total organic carbon of soil can only provide the amount of organic carbon in a soil. It does not supply information about characteristics, function or stability of SOM (GRDC 2.2013 ). It is necessary to understand how SOM fractions change in soils that can supply important information on sequestration potential, carbon balances, nutrient storage, turnover rate, biological function, soil properties and carbon dynamics in soils (see figure 2) (GRDC ${ }^{2}$. 2013; von Lützow. 2008).

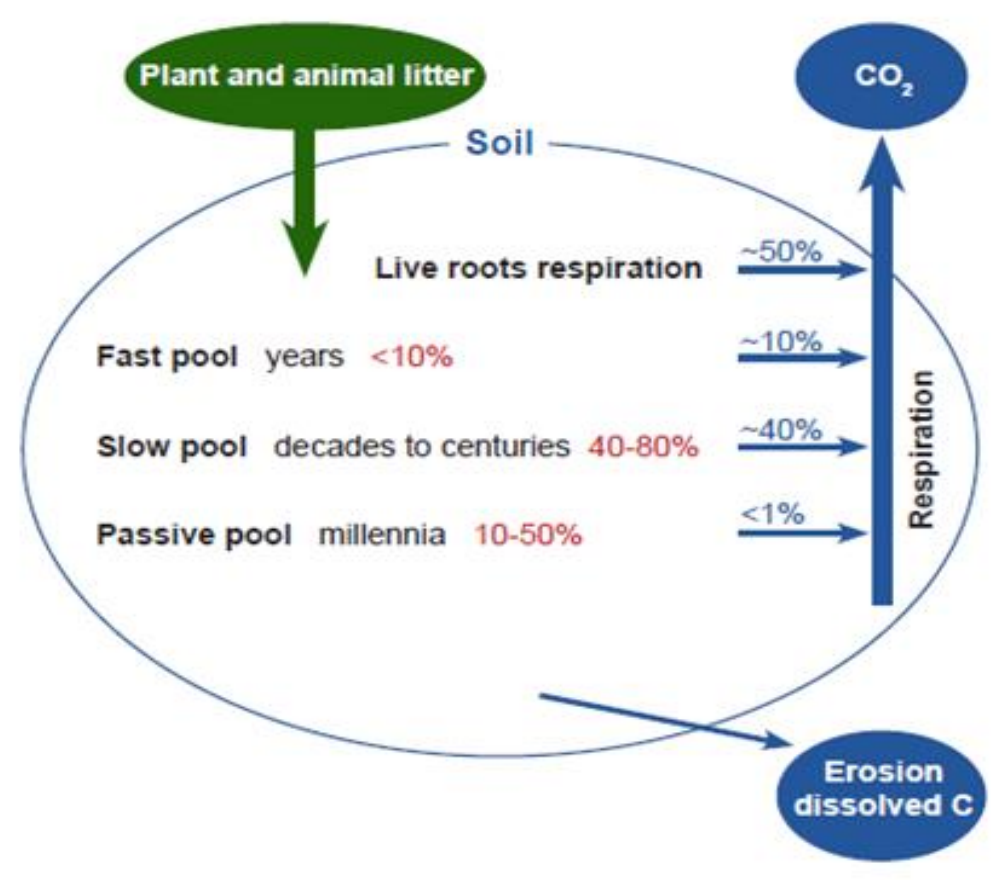

Fig. I.2 A simple diagram of the soil organic carbon cycle in connection with SOC pools. (Soil Carbon Management and Carbon Trading. 2009)

Moreover, SOM fractions also provide a vital contribution to evaluate the changes in landuse or management practices on soil carbon (Leifeld and Kögel-Knabner. 2004). Understanding about the amount and the contribution and of labile and stable OM fractions 
to total OC would be useful in modeling SOC dynamics, in predicting the SOC changes with the changes of environmental and management conditions (Ludwig et al. 2005). Besides, it is also helpful to know about labile and stable OC fractions in estimating short-term (labile OC) and long-term (stable OC) effects of changes in land use (Helfrish. 2007). It is necessary to quantify SOM fractions in order to understand the dynamics of accumulation and turnover of organic carbon of SOM and to know more about global $\mathrm{C}$ cycle and climate change (Trumbore et al. 1996). Therefore, it is important to measure SOM fractions of different residence time to understand and predict the sequestration and stabilization of SOC (Helfrich. 2006). Thus finding fractionation procedures to isolate and quantify SOM fractions is crucial to understand more about landscape ecology. However, quantification SOM fractions is challenging since SOM is a continuum of organic substances with turnover rate from days to million years and has three main complicated mechanisms as aforementioned above. SOM interacts with both inorganic and organic compounds (Sollin et al. 1996; von Lützow et al. 2006; Kiem. 2002). One of the challenges in isolation of SOM fractions is the considerable variety of the soil environment with its complicated stabilization mechanisms. (von Lützow et al. 2006; Helfrich. 2006). SOM fractions change with the alteration of environmental conditions. For example, in fired soils, organic matters in the top layer were burnt that reduces labile OC fraction and increases recalcitrant OC fraction by enhancing mineralization. Moreover, mechanisms of recalcitrance, interaction and accessibility operate concurrently. In addition, the mechanisms take place variously in different types of soil and soil horizons. Stabilization of interaction consists of some mechanisms such as ligand exchange, polyvalent cation bridges and interaction of metal ions with organic substances. These mechanisms operate simultaneously in acid soil, but with various intensities in different soil. Ligand exchange operates mainly in acid subsoil soil that is rich in oxides when interaction of metal ions with organic substances occurs primarily in acid soil, calcareous soil or heavy metals contaminated soil (von Lützow et al. 2006). Therefore, it is difficult to find SOM fractionation methods or any procedures that are specific enough for all stabilization mechanisms and generate completely homogeneous SOM pools (von Lützow et al. 2008; von Lützow et al. 2007; Helfrich. 2006). For more detail, see von Lützow et al. (2006, 2007). 


\section{I.3 Methods to analyze SOM pools and fractions}

The analysis of SOM methodologically can be devided into physical and chemical fractionsmethods (von Lützow et al. 2007). In the following sections, the basic principles of these methods will be briefly described.

\section{I.3.1 Physical methods}

Physical fraction methods are based on the premise that the SOM dynamic is dependent on the structure of soil. Physical fractionation methods established in soil science consist of particle size, aggregate and density fractionation (von Lützow et al. 2007).

\section{a) Aggregate fractions}

Aggregate fractionation is based on the separation of free and protected SOM that is isolated from bulk soil by dry or wet sieving and slaking of different mesh size. The purpose of having different aggregate fractions is to separate active/labile from intermediate and passive SOM pools. (von Lützow et al. 2007). In general, soil aggregates are divided into two classifies such as macro- (> $250 \mu \mathrm{m})$ and micro-aggregates $(<250 \mu \mathrm{m})($ Oades. 1984). There are more SOM in macro-aggregates than in micro-aggregates and the turnover rate of $\mathrm{OM}$ in macro-aggregates (15-50 years) is faster than that of micro-aggregates (100-300 years) (von Lützow et al. 2007; Heitkamp. 2010).

\section{b) Particle size fractions}

This fractionation technique is based on the concept that SOM associated with particles of different sizes, which differ in their structure and function (Christensen. 1992; von Lützow et al. 2007). In general, the amount of OC in sand, silt and clay fractions increase in the following order sand < silt < clay. In fact, $50-75 \%$ of total OC was combined with claysized particles $(<2 \mu \mathrm{m})$, about $20-40 \%$ with silt-sized particles $(2-63 \mu \mathrm{m})$ and $<10 \%$ with sand-sized particles (> $63 \mu \mathrm{m}$ ) in temperate arable soils (Christensen. 2001; von Lützow et al. 2007; Helfrich. 2006). Generally, active OC distributed more in sand fraction, whereas more intermediate and passive OC distributed in silt and clay fractions (von Lützow et al. 2007).

c) Density fractionation 
Density fraction is based on the concept that SOM can be divided into light fraction (weakly associated with soil minerals) and heavy fraction (organo-mineral complexes). The aim of using density fractionation is to isolate active, intermediate and passive $\mathrm{OM}$ pools individually (von Lützow et al. 2007) by flotation or sedimentation SOM in soils in heavy organic liquids or inorganic salt solutions with specific densities ranging from 1.6-2.2 $\mathrm{g} \mathrm{ml}^{-}$ ${ }^{1}$ (Christensen. 1992). The optimal density of the solutions might be dependent on the soil types (Gregorich et al. 2006). Comprehensive reviews on density fractionation can be found in Lützow et al. (2007) and in Christensen (1992).

\section{I.3.2 Chemical methods}

According to von Lützow et al. (2007), chemical fractionation procedures rely on the extraction of SOM in various solutions such as aqueous solutions (with and without electrolytes), inorganic solvents or acids. Various chemical fractionation procedures have been used to isolate stable SOM by extraction with aqueous solvents, hydrolysability (e.g. $\mathrm{HCl}$ ) or oxidizability (e.g. $\mathrm{H}_{2} \mathrm{O}_{2}, \mathrm{NaOCl}$ or $\mathrm{Na}_{2} \mathrm{~S}_{2} \mathrm{O}_{8}$ ) of SOM (von Lützow et al. 2007; Helfrich et al. 2007).

Oxidative treatment is one of the most common used methods to isolate stable SOM pool. Two oxidative treatments, which were most successful in isolating a stable pool of organic, were used with hydrogen peroxide $\left(\mathrm{H}_{2} \mathrm{O}_{2}\right)$ and disodium peroxodisulfate $\left(\mathrm{Na}_{2} \mathrm{~S}_{2} \mathrm{O}_{8}\right)$ (Helfrich et al. 2007). By using $\mathrm{H}_{2} \mathrm{O}_{2}$, younger SOC was removed effectively and therefore achieved more stable SOC fraction. The ${ }^{14} \mathrm{C}$ age of residues (stable SOC) were more than 10000 years (Helfrich et al. 2007). Nonetheless, using $\mathrm{H}_{2} \mathrm{O}_{2}$ has a disadvantage that it might dissolve some soil minerals (Mikutta et al. 2005). Besides, it is necessary to isolate light fraction (LF) material before using oxidation with $\mathrm{H}_{2} \mathrm{O}_{2}$ to soils (von Lützow et al. 2007). In contrast to $\mathrm{H}_{2} \mathrm{O}_{2}$, oxidation with disodium peroxodisulfate did not dissolve soil minerals. A disadvantage of $\mathrm{Na}_{2} \mathrm{~S}_{2} \mathrm{O}_{8}$ oxidation is that it may cause an interference of the $\mathrm{NaHCO}_{3}$ buffer with ${ }^{14} \mathrm{C}$ analysis (von Lützow et al. 2007). However, that problem can be solved by using a solution of $0.01 \mathrm{M} \mathrm{HCl}$ (Helfrich et al. 2007). Generally, both methods have potential for isolating a very old and passive pool of SOM (Helfrich et al. 2007; von Lützow et al. 2007).

\section{I.3.3 Thermal methods}

During the first half of the 20th century, thermal analysis was applied frequently in clay mineralogy. Since then, it has been applied widely in analysis SOM, black carbon or charcoal in soil science (Plante et al. 2009). Thermal methods have been currently applied to isolate 
carbon fractions in soils. According to the International Confederation for Thermal Analysis and Calorimetry (ICTAC), thermal methods is a group of techniques programmed to detect the change of a physical or chemical property of a sample against temperature of the sample in a special atmosphere (e.g. pure $\mathrm{N}_{2}$ or $\mathrm{O}_{2}$ ) (Plante et al. 2009). Thermal analysis includes four major thermal analysis techniques (thermogravimetry (TG), derivative thermogravimetry (DTG), differential thermal analysis (DTA) and differential scanning calorimetry (DSC)). More detail of these thermal techniques can be found in Plante et al. (2009). Thermal analysis has been applied for analyzing the mineral soil and the organic carbon fractions, for instance, analyzing humic substances (Provenzano M.R and Senes.N. 1999; Dell' Abate et al. 2002), black carbon (Elmquist et al. 2006; Leifeld J. 2007; Nguyen et al. 2004) and soil samples (Lopez-Capel et al. 2005; Plante et al. 2011). These thermal techniques were also used as a combination with each other or with other devices to separate organic carbon fractions in soils such as DSC-TG-MS (Dell' Abate et al. 2003), TG-DSC (Lopez-Capel et al. 2006a), TG-DSC-isotope (Kuzyakov et al. 2006; Dorodnikov et al. 2007) and TG-DSC-EGA (evolved gas analysis) (Fernández et al. 2012). However, these techniques are quite expensive and unavailable in many labors. Moreover, they are not suitable for quantitative analysis of organic carbon (OC), inorganic carbon (IC) and TC.

\section{I.4 Concept of research and objectives}

Summarizing the findings above, there is neither single physical nor chemical fractionation technique that describes sufficiently the complete continuum of SOM existed in nature (Paul et al. 2006). However, there are some thermal analysis techniques, which were applied to characterize soil humic substances in the past (e.g., Schnitzer and Hoffman. 1964; Schnitzer et al. 1966; Shurygina et al. 1971) and whole soils or physical fractions recently (e.g., LopezCapel et al. 2005; Plante et al. 2005; De la Rosa et al. 2008; Plante et al. 2011). They all have shown promising results in isolating SOM fractions. Consequently, the concept of research for this thesis was to find a suitable thermal method in quantifying OC, IC, TC and separate OC fractions. The main objective of this current dissertation is to find a rapid, costeffective, simple thermal method, which can isolate organic carbon (OC) and inorganic carbon (IC), as well as organic carbon fractions in soils simultaneously and can be applied at the landscape scale, where high sample numbers are needed. To achieve it, a large range of soil samples and material with various properties were used to test with ThG. Moreover, the results of thermal gradient method were compared to conventional methods (see detail of samples and methods in chapter 2, 3 and 4). 
This dissertation specially focuses on the methodology. Therefore, the following questions will be considered:

Objective 1: The first objective was to verify the cost-effective method developed by Chichester and Chaison (1992) with a much larger sample set containing a larger range of soil properties and with a new generation of the analyser.

In the second chapter, a thermagradient (ThG) was used to compare with standard methods in analyzing total carbon (TC), soil organic carbon (SOC), soil inorganic carbon (SIC) in soil samples with and without calcite. Measurements of SOC and SIC contents by ThG were compared with (1) the measurement of SIC (calcimeter) and TC (dry combustion), SOC content calculation and (2) measurement of SOC (acidification) and TC (dry combustion) and quantification of SIC contents.

Objective 2: To test the ability to quantify dolomite-derived IC by ThG in dolomite soil samples.

In the third chapter, the prior study (Vuong et al. 2013) showed that total carbon, organic carbon and inorganic carbon in the form of calcite could be quantified precisely and accurate by a thermal gradient method (ThG). In the third chapter, we focus on the ability to quantify dolomite-derived IC by ThG. The aims of this study were to compare the accuracy of ThG with standard methods such as calcimeter (CALC) and loss on ignition (LOI) on a sample set with known proportions of OC and IC present as dolomite. After that, we compare the results of the different methods on a set of soil samples.

Objective 3: Assessing the suitability of ThG for the quantification of ecological meaningful differences in organic carbon fractions of soil and material samples with different carbon stability.

In the fourth chapter, ThG was used to test if the presented ThG is suitable for the quantification of ecological meaningful differences in organic carbon fractions for both soil and material samples of different carbon stability. Moreover, we used a standard addition approach to compare ThG method with established methods for measuring labile and stable OC. Afterward, we tested the applications of the proposed method for process studies and particular landscape and other larger scale approach. 


\title{
II Simultaneous measurement of soil organic and inorganic carbon: Evaluation of a thermal gradient analysis
}

\author{
Truong Xuan Vuong, Felix Heitkamp, Hermann F. Jungkunst, Andreas Reimer, \\ Gerhard Gerold
}

(Published in Journal of Soil and Sediment, 2013)

\begin{abstract}
Purpose The best method for determining soil organic carbon (SOC) in carbonate-containing samples is still open to debate. The objective of this work was to evaluate a thermal gradient method (ThG), which can determine simultaneously inorganic carbon (SIC) and SOC in a wide range of soil samples.

Materials and methods The determination of $\mathrm{SOC}$ by $\mathrm{ThG}$ ( $\mathrm{SOC}_{\mathrm{ThG}}$ ) was compared to widespread standard methods (1) acidification as pre-treatment and subsequent dry combustion (ACI, SOC $\mathrm{ACI}_{\text {) }}$ and (2) volumetric quantification of SIC by a calcimeter and subtraction of the total carbon content as determined by dry combustion (CALC, SOC $_{\text {CALC }}$ ). Precision (F-test) and bias (t-test) was tested on a subset of seven samples $(n=3)$. Comparison of the ThG and CALC methods was performed by regression analysis $(n=76)$ on samples representing a wide range of SOC (5.5 to $\left.212.0 \mathrm{~g} \mathrm{~kg}^{-1}\right)$ and SIC contents ( 0 to $\left.59.2 \mathrm{gkg}^{-1}\right)$.

Results and discussion: Tests on the replicated subset showed that the precision of ThG was not significantly different from ACI or CALC (F values $<39, \mathrm{n}=3$ ) for SOC and SIC measurements. However, $\mathrm{SOC}_{\mathrm{ACI}}$ and $\mathrm{SOC}_{\mathrm{CALC}}$ contents were systematically and significantly lower compared to $\mathrm{SOC}_{\mathrm{ThG}}$ contents. The positive bias for $\mathrm{SOC}_{\mathrm{ThG}}$ relative to SOC $_{\text {CALC }}$ contents appeared also in the regression analysis (given numbers \pm standard errors) of the whole dataset $\left(y=[4.67 \pm 0.70]+[0.99 \pm 0.01] x ; R^{2}=0.99 ; n=76\right)$. When performing a regression with carbonate-free samples, the bias between the methods was negative $(-2.90$ $\pm 0.63, \mathrm{n}=29)$, but positive in the set with carbonate-containing samples $(3.95 \pm 1.41, \mathrm{n}=$ 47). This observation corroborated the suspicion that the use of acid for carbonate decomposition can lead to an underestimation of SOC.

Conclusions: All methods were suitable for differentiation between SIC and SOC, but the use of acid resulted in lower estimates of SOC contents. When comparing soil samples with differing carbonate concentrations the use of the ThG method is more reliable.
\end{abstract}

Keywords: Calcimeter, Dry combustion, Soil carbon, Thermal gradient analysis, Carbonate 


\section{II.1 Introduction}

Soil organic carbon (SOC) has been recognised as an important ecosystem property since the late $18^{\text {th }}$ century (Manlay et al. 2007). SOC affects soil structure and most biogeochemical cycles and is therefore one of the most important properties determining soil fertility (Lal 2004). Furthermore, soils act as source or sink of atmospheric $\mathrm{CO}_{2}$, which is stored or released from SOC (Heitkamp et al. 2012).

In the absence of inorganic carbon (SIC) in soils dry combustion (DC) at temperatures above $900^{\circ} \mathrm{C}$ is the preferred method for quantification of carbon in soil samples (Skjemstad and Baldock. 2008; ISO 10694. 1995). In this case, contents of total carbon (TC) equal those of SOC. However, if SIC is present, measurement of SOC is still not straightforward (Kalbitz et al. 2012), and especially challenging when the portion of SIC on TC is high (Schmidt et al. 2012). Three fundamentally different approaches for measuring SOC in carbonate containing soils exist: (1) removing SIC by acid treatments before quantifying TC contents, (2) determining TC and SIC contents separately and calculating SOC contents, and (3) measuring only the fraction of SOC and leaving the fraction of SIC intact. All of the mentioned approaches have their specific drawbacks and advantages.

\section{(1) Removing SIC by acid treatments}

Different kinds of acid at various concentrations are used to remove SOC prior to DC. Commonly, $\mathrm{HCl}, \mathrm{H}_{3} \mathrm{PO}_{4}$ or $\mathrm{H}_{2} \mathrm{SO}_{3}$ are used for SIC decomposition (Bisutti et al. 2004). For soils containing low amounts of $\mathrm{CaCO}_{3}$, while the use of acids is without greater problems (Schmidt et al. 2012), some carbonates (e.g. dolomite, magnetite) may decompose incompletely or need very long times for removal. For example, Midwood and Boutton (1998) reported that it took up to three days to remove SIC with $0.5 \mathrm{M} \mathrm{HCl}$ until the $\delta^{13} \mathrm{C}$ signature of SOC was unaffected by presence of SIC. Other concerns are dissolution and removal of SOC during the pre-treatment and the effects of the ionic solutions or halides on the $\mathrm{CO}_{2}$-detectors (Bisutti et al. 2004; Chatterjee et al. 2009; Midwood and Boutton. 1998). These problems were solved in part with the acid fumigation method (Harris et al. 2001; Walthert et al. 2010), where samples are exposed to $\mathrm{HCl}$ vapour under low pressure. Nevertheless, the method is laborious and needs experience and careful handling. Until now, removal of SIC by acidification is the only method applicable in mass spectrometry of SOC (Midwood and Boutton. 1998). 


\section{(2) Calculation of SOC}

The most common method for quantification of SIC is the use of a volumetric calcimeter. A soil sample is acidified with $\mathrm{HCl}$; the evolved gas volume is measured and SIC is calculated as $\mathrm{CaCO}_{3}$-equivalents (Williams. 1948; Martin and Reeve. 1954; Loeppert and Suarez. 1996). Problems may arise due to incomplete decomposition of dolomite, evolution of different gas volumes from different carbonates or the presence of sulphides which react to form $\mathrm{H}_{2} \mathrm{~S}$ (Bisutti et al. 2004). Inaccurate quantification of SIC contents is especially likely in highly carbonaceous soils (Schmidt et al. 2012), leading to erroneous calculation of SOC contents. Furthermore, the calculation of SOC contents cannot be used in carbon mass spectrometry due to different ${ }^{13} \mathrm{C}$ values of SOC and SIC (Harris et al. 2001; Midwood and Boutton. 1998).

\section{(3) Direct measurement of SOC}

Direct measurement of SOC involves several methodological drawbacks until now. Wet combustion of a soil sample by $\mathrm{K}_{2} \mathrm{Cr}_{2} \mathrm{O}_{7}$ was the standard method for determining SOC since the early $20^{\text {th }}$ century. The method is still applied in many laboratories worldwide and there are several modifications to it (for details, see Chatterjee et al. 2009). The principle is oxidation of SOC, while leaving SIC undecomposed. Problems arise from incomplete oxidation of SOC and the exact value of correction factors depend on land-use, soil depths and texture (Tivet et al. 2012). Furthermore, most of the fire-derived carbon will not be oxidised by wet combustion (Hammes et al. 2007). Therefore, correction factors for SOC determination by wet oxidation have to be determined independently for different samples sets. This, again, leads to the challenge to determine SOC in carbonate-containing soils.

Loss-on-ignition (LOI) is another method for determination of organic matter in soils (SOM) (Wang et al. 2012). The sample is heated up to a temperature where SOM is oxidised but SIC will remain in the sample. The gravimetrically determined mass loss is assumed to be SOM, which can be divided by a correction factor (1.72) to obtain SOC values (Chatterjee et al. 2009). The choice of the appropriate temperature and duration is open to question, since mass losses can occur from different sources. Furthermore, the correction factor of 1.72 is only a rule of thumb and varies between different samples (Wang et al. 2012). These problems were solved by directly measuring $\mathrm{CO}_{2}$ evolution by infrared detection in the same sample at different temperatures (Bisutti et al. 2007; Chichester and Chaison. 1992). Measuring $\mathrm{CO}_{2}$-evolution across a thermal gradient (ThG) is advantageous, because this can 
be done subsequently in one sample and losses of other material besides $\mathrm{C}$ can be ignored. Bisutti et al. (2007) showed that by using mixtures of pure materials, the ThG method is suitable for separating organic and inorganic substances. Chichester and Chaison (1992) successfully used a similar method with soil samples and showed the comparability with standard methods. However, their sample set was relatively small and only three samples exceeded SOC contents of $2 \%$.

The objective of this work was to verify the cost-effective method developed by Chichester and Chaison (1992) with a much larger sample set containing a larger range of soil properties and with a new generation of the analyser. Measurements of SOC and SIC contents by ThG were compared with (1) measurement of SIC (calcimeter) and TC (dry combustion), SOC contents were calculated and (2) measurement of SOC (acidification) and TC (dry combustion) and quantification of SIC contents.

\section{II.2 Materials and methods}

\section{II.2.1 Samples and sample preparation}

For the comparisons three sample sets were used:

(1) Mixtures (C-contents between 0 and $120 \mathrm{~g} \mathrm{~kg}^{-1}$ ) of C-free silica-sand (p.a., Merck, Darmstadt) and calcium carbonate standard (Leco, part no 501-034, lot 1016; Leco Corporation, St. Joseph, MI, USA) were used to quantify precision and bias (see 2.6) of the $\mathrm{CN}$ analyser, the Multiphase Carbon Determinator (MCD) and the calcimeter by regression analysis. This was done to test if the methods were able to reproduce the "true" C-concentrations of the standard mixtures.

(2) A replicated $(n=3)$ subset of seven soil samples was used to compare precision and bias of the ThG method against ACI and CALC methods, respectively. A smaller number of samples was chosen because we already suspected that the ACI method was disadvantageous (see references in the introduction). Furthermore, replication of the same samples was necessary to prove general suitability of the methods. The subset covers the range of properties of the large sample set.

(3) After proving the potential suitability of the CALC and ThG methods, for routine analysis, a large sample set $(n=76)$ was used to compare the ThG against the CALC method. CALC was chosen as the reference method, because it is most widely used. 
Soil samples were collected from cropland, forest, grassland and wetland in temperate, subtropical and tropical regions in order to represent a wide range of soil properties (Table II.1). Contents (measured by ThG) of TC, SOC and SIC were in the range of 5.5 to 212.0, 5.5 to 212.0 and 0 to $59.2 \mathrm{~g} \mathrm{~kg}^{-1}$ respectively (Table II.1). Collected soils were air-dried $\left(45^{\circ} \mathrm{C}\right)$, passed through a $2-\mathrm{mm}$ sieve, and stored at room temperature. Samples were ground with a planetary ball mill for homogenisation and to reduce the time needed for full carbonate removal with the calcimeter. Subsamples were dried at $105^{\circ} \mathrm{C}$ to correct results for residual water contents. Drying of a subsample is another potential source of uncertainty. However, some components of SOC could be lost when drying at $105^{\circ} \mathrm{C}$ (Bisutti et al. 2004). Soil pH was measured in a 1:5 soil-solution (v/v) suspension of the $2 \mathrm{~mm}$-sieved material in $0.01 \mathrm{M}$ $\mathrm{CaCl}_{2}$ (ISO 10390. 2005).

Table II.1 Description of sampling sites with ranges of $\mathrm{pH}$-values and contents of total carbon (TC) and the proportion of soil inorganic carbon (SIC)

\begin{tabular}{|c|c|c|c|c|c|}
\hline Location & $\begin{array}{l}\begin{array}{c}\text { Number } \\
\text { of } \\
\text { samples }\end{array}\end{array}$ & pH & $\underset{\left(\mathrm{g} \mathrm{kg}^{-1}\right)}{\mathrm{TC}}$ & $\begin{array}{c}\text { SIC } \\
(\% \text { of TC) }\end{array}$ & Land use/land cover \\
\hline $\begin{array}{l}\text { Sierra Madre } \\
\text { Oriental, } \\
\text { Mexico }\end{array}$ & 5 & $5.7-7.7$ & $29.2-132.1$ & $0-42$ & $\begin{array}{l}\text { Forest with different } \\
\text { fire intensities }\end{array}$ \\
\hline $\begin{array}{l}\text { Aterro Jacare' } \\
\text { Brazil }\end{array}$ & 13 & $8.1-9.2$ & $34.4-77.4$ & $16-43$ & $\begin{array}{l}\text { Secondary forest, } \\
\text { ancient Anthrosol }\end{array}$ \\
\hline $\begin{array}{l}\text { Drakensberg, } \\
\text { Republic } \\
\text { South Africa }\end{array}$ & 8 & $4.0-4.3$ & $\begin{array}{l}135.8- \\
212.0\end{array}$ & 0 & $\begin{array}{l}\text { Wet- and upland, } \\
\text { grass/shrub vegetation }\end{array}$ \\
\hline $\begin{array}{l}\text { Göttingen, } \\
\text { Germany }\end{array}$ & 32 & $6.0-7.6$ & $20.1-110.3$ & $1-77$ & $\begin{array}{l}\text { Forest, grassland and } \\
\text { cropland, soil } \\
\text { developed on } \\
\text { limestone }\end{array}$ \\
\hline $\begin{array}{l}\text { Hainich } \\
\text { Nationalpark, } \\
\text { Germany }\end{array}$ & 18 & $3.5-5.4$ & $5.5-75.7$ & 0 & $\begin{array}{l}\text { Deciduous forest, } \\
\text { Luvisol developed on } \\
\text { loess over limestone }\end{array}$ \\
\hline
\end{tabular}

\section{II.2.2 Analysis of the samples for TC}

Dry combustion with a CN analyser (Truspec CHN LECO, St Joseph, MI, USA) was conducted for measurement of TC. An amount of 20 to $200 \mathrm{mg}$ of ground sample was scaled into a tin foil capsule and combusted in a resistance furnace at $950^{\circ} \mathrm{C}$. After passing an 
oxidising column $(\mathrm{CuO}) \mathrm{CO}_{2}$ is measured by an infrared detector (ISO 10694. 1995; Skjemstad and Baldock. 2008). Calibration was done with certified standards (Leco, part no 502-062, lot 1014; Leco Corporation, St. Joseph, MI, USA) over a range of 1 to $17 \mathrm{mg}$ carbon. This method will be abbreviated by DC. Contents of TC measured by this method will be abbreviated by $\mathrm{TC}_{\mathrm{DC}}$.

\section{II.2.3 Analysis of SIC with the calcimeter}

The calcimeter method is based on the reaction of SIC with $\mathrm{HCl}$ to $\mathrm{CO}_{2}$. The volume of evolved gas is measured by displacement of a water column. The method is extensively described in Horváth et al. (2005) and in ISO 10693 (1995). Between one and $10 \mathrm{~g}$ were scaled, depending on the reaction of the sample with $10 \% \mathrm{HCl}$ in a preliminary test.

Samples were transferred into the glass reaction vessels $(250 \mathrm{ml})$ and were wetted with 20 $\mathrm{ml}$ of distilled water. Wetting was necessary to avoid evolution of entrapped gas, which would have led to an overestimation of SIC. A plastic cup was filled with $5 \mathrm{ml}$ of $10 \% \mathrm{HCl}$ and placed into the reaction vessel. The reaction vessel was connected to the water column. The volume of displaced water was checked after 15 minutes of stirring. If the volume was not constant, stirring was continued until the volume was stable, but not longer than one hour. The displaced volume was measured in the calibrated tube with an accuracy of $0.1 \mathrm{ml}$. This corresponds to ca. $0.4 \mathrm{~g} \mathrm{~kg}^{-1}$ SIC when using $1 \mathrm{~g}$ and $0.04 \mathrm{~g} \mathrm{~kg}^{-1}$ SIC when using $10 \mathrm{~g}$ in weigh. Calibration was done with calcium carbonate (Reag. Ph. Eur, Merck, Darmstadt, Germany). Soil inorganic C $\left(\mathrm{g} \mathrm{kg}^{-1}\right)$ was measured as carbonate equivalents and calculated as

$$
S I C=P V \times 0.1204 / T W
$$

where $P$ is the air pressure $(\mathrm{hPa}), V$ the volume of displaced water column $(\mathrm{ml}), T$ is temperature $(\mathrm{K})$ and $W$ is the weight of the sample $(\mathrm{g})$. The method will be abbreviated by CALC. The abbreviations SOC $\mathrm{CALC}_{\mathrm{L}}$ and $\mathrm{SIC}_{\mathrm{CALC}}$ will be used for calculated SOC values $\left(\mathrm{TC}_{\mathrm{DC}}-\mathrm{SIC}_{\mathrm{CALC}}=\mathrm{SOC} \mathrm{CALC}\right)$ and measured SIC values by the CALC method, respectively. The standard deviation for SOC $\mathrm{CALC}_{\mathrm{LC}}$ contents was calculated by error propagation (van Reeuwijk and Houba. 1998). 


\section{II.2.4 Analysis of TC, SOC and SIC in one subsample}

A Multiphase Carbon Determinator (MCD, RC-412, Leco, St.Joseph, MI, USA) was used for simultaneous analysis of TC, SIC and SOC by ThG (Bisutti et al. 2007; Chichester and Chaison. 1992). An amount of 10-25 mg of ground sample was scaled. The temperature of the $\mathrm{MCD}$ rose from $140^{\circ} \mathrm{C}$ to $900^{\circ} \mathrm{C}$ during 30 minutes, using $\mathrm{O}_{2}$ as carrier gas. The amount of $\mathrm{CO}_{2}$ evolved was measured by infrared detection three times per second. Due to the isolated peaks, $\mathrm{CO}_{2}$ evolved above $600^{\circ} \mathrm{C}$ was assigned as SIC. Calibration was done with certified EDTA (Leco, part no 502-012, lot 1035; Leco Corporation, St. Joseph, MI, USA) and $\mathrm{CaCO}_{3}$ standards (part no 501-034, lot 1016) over a range of 1 to $4 \mathrm{mg}$ carbon. The method will be abbreviated by ThG. Contents of TC, SOC and SIC analysed by ThG will be abbreviated by $\mathrm{TC}_{\mathrm{ThG}}, \mathrm{SOC}_{\mathrm{ThG}}$ and $\mathrm{SIC}_{\mathrm{ThG}}$, respectively.

\section{II.2.5 Acidification}

Because acidification is up to now a required pre-treatment applicable in mass spectrometry of SOC (Midwood and Boutton. 1998) and is used as standard method (ISO 10694. 1995) we also quantified SOC and SIC contents by this method in a subset of seven samples. Carbonate was removed by adding $200 \mu \mathrm{L}$ of $1 \mathrm{M} \mathrm{HCl}$ to the ground samples in a tin foil (approximately $25 \mathrm{mg}$ ). The acidified sample was dried at $45^{\circ} \mathrm{C}$ in an oven connected to a vacuum. This was repeated one time with $200 \mu \mathrm{L}$ of $1 \mathrm{M} \mathrm{HCl}$ and several times with $100 \mu \mathrm{L}$ of $1 \mathrm{M} \mathrm{HCl}$, depending on the carbonate concentration. After acidification, DC was applied and SIC was calculated by subtracting SOC (acidified sample) from TC (not acidified, different subsample). Results from the acidification method were compared to the ThG method. The contents of SOC and SIC quantified by acidification will be abbreviated by $\mathrm{SOC}_{\mathrm{ACI}}$ and $\mathrm{SIC}_{\mathrm{ACI}}$, respectively. The standard deviation for $\mathrm{SIC}_{\mathrm{ACI}}$ contents was calculated by error propagation (van Reeuwijk and Houba. 1998).

\section{II.2.6 Data analysis and statistics}

To quantify precision and bias, seven samples out of the whole set were analysed three times. The F-test was performed to test if precision (i.e., equal variances) of the ThG method was equal to the CALC and ACI methods, respectively. Each of the two methods was tested separately against the ThG method. To test for bias (i.e., significant differences of means), a Student's t-test was performed. The F- and t-values were calculated with Excel (Microsoft corporation) and compared to the critical F- and t-values (two-sided tests) given by van 
Reeuwijk and Houba (1998). The null hypothesis assumed no difference in either variances or mean values.

For a large number of samples $(n=76)$, a comparison of the CALC and ThG methods was performed. A linear regression was carried out with values of the CALC method as independent and those of the ThG method as dependent variables (van Reeuwijk and Houba. 1998). T-values were calculated to test if the intercept of the regression was different from zero and if the slope was different from one. The following sample sets were compared: (1) the whole dataset of SOC values $(n=76)$, (2) the whole dataset of SIC values $(n=58$, the acidic Hainich samples were omitted), (3) samples with $\mathrm{pH}$-values $<6$ ( $\mathrm{n}=29$, Hainich, Drakensberg, parts of the Sierra Madre Oriental set) and (4) samples with $\mathrm{pH}$ values $>6$ (n =47). Linear regression was performed by using SigmaPlot 10.0 (Systat). A significance level of $\mathrm{p} \leq 0.05$ was used for all statistical calculations.

\section{II.3 Results and discussion}

\section{II.3.1 Precision and bias of standard material}

Comparing theoretical and measured amounts (range of 0 to $120 \mathrm{mg} \mathrm{C} \mathrm{kg}^{-1}$ ) of the mixtures of C-free silica-sand and carbonate standard gave highly satisfactory results for the calcimeter, the $\mathrm{CN}$-analyser and the $\mathrm{MCD}$.

Table II.2 Regression equations with standard errors for the carbonate standards as quality control for the used instruments.

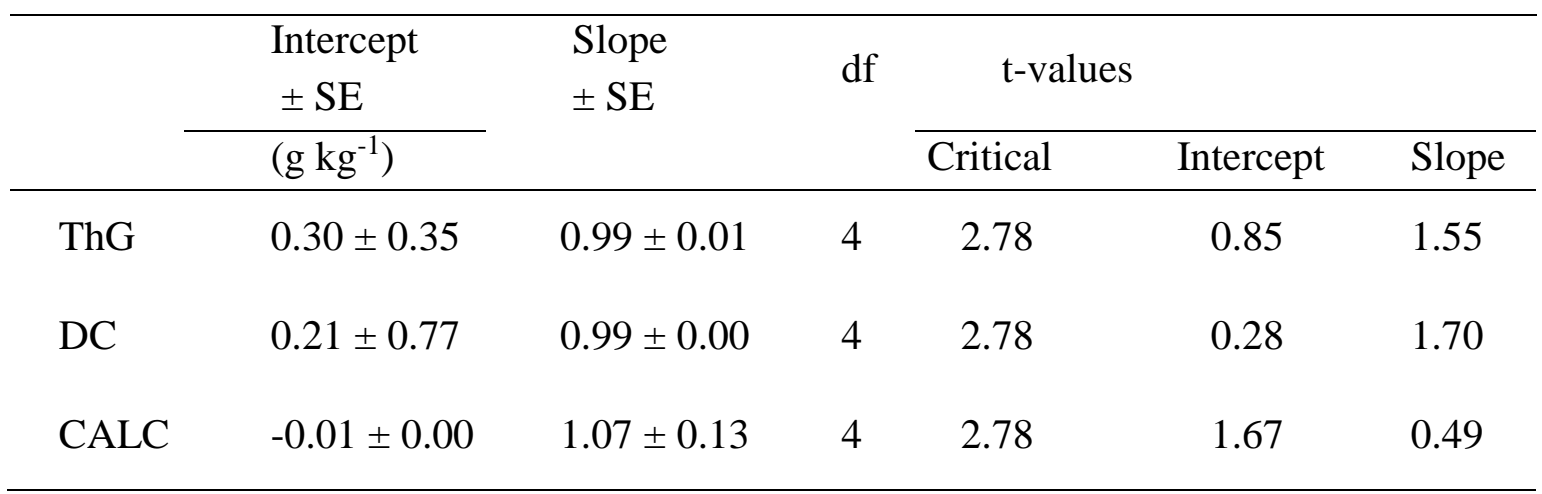

The theoretically calculated C-content was used as independent and the measured C-content as independent variable. A t-test was performed to check if the intercept was significantly ( $p$ $\leq 0.05$ ) different from zero and the slope from one. Calculated t-values were compared to the critical t-value. The null hypothesis assumed no differences. Bold figures were used in the case the null-hypothesis was rejected. For abbreviations see text or Fig. II.1

SE: Standard error; df: Degrees of freedom ( $n-2)$ 
Table II.2 showed the results of the regression and their statistical evaluation. None of the intercepts differed significantly $(\mathrm{p} \leq 0.05)$ from zero and neither did the slopes differed significantly from one. Therefore, all methods were generally suitable for routine laboratory analysis.

\section{II.3.2 Precision and bias of the replicated subset}

Results of the F-test showed that in soil samples, the determination of $\mathrm{SIC}_{\mathrm{ThG}}$ and $\mathrm{SOC}_{\mathrm{ThG}}$ contents was as precise as determination of $\mathrm{SIC}_{\mathrm{CAL}}, \mathrm{SIC}_{\mathrm{ACI}}, \mathrm{SOC}_{\mathrm{CAL}}$ and $\mathrm{SOC}_{\mathrm{ACI}}$ contents (Table II.3). Only two exceptions occurred, in one case ACI was the less precise and in the other case the more precise method as compared to ThG. The $\mathrm{CV}$ of sample 1 for $\mathrm{SIC}_{\mathrm{ACI}}$ contents was unacceptably high (23.1\%, Table II.4). This was a consequence of the high variation of the $\mathrm{SOC}_{\mathrm{ACI}}$ content $(\mathrm{CV}=9.8 \%)$, and subsequent propagation of the error to the relatively low $\mathrm{SIC}_{\mathrm{ACI}}$ content. In general, all methods were precise and could be used to reproducibly determine SIC and SOC contents. However, not only precision (i.e., small errors), but also accuracy (i.e., representing the "true" value) is essential for high quality laboratory analysis.

Table II.3 Statistics for the comparison of the calcimeter (CALC) and acidification (ACI) method against the thermal gradient method (ThG). The F-test is indicative for the precision and the t-test for the bias of the methods. The condition for accepting the null-hypothesis (i.e., no difference between methods) is given in brackets behind the names of the tests. Bold figures indicate significant differences $(\mathrm{p} \leq 0.05)$ between two methods.

\begin{tabular}{|c|c|c|c|c|c|}
\hline \multirow[t]{2}{*}{ Sample } & \multicolumn{2}{|l|}{ SIC } & \multicolumn{3}{|l|}{ SOC } \\
\hline & \multicolumn{2}{|c|}{ ThG vs. CALC ThG vs. ACI } & ThG vs. & CALC & ThG vs. ACI \\
\hline \multicolumn{6}{|c|}{$F$-test $(F<39.0)$} \\
\hline 1 & 3.09 & 26.96 & 22.90 & & 3.65 \\
\hline 2 & 1.59 & 1.06 & 5.08 & & 732.00 \\
\hline 3 & 17.07 & 39.03 & 1.65 & & 26.46 \\
\hline 4 & 1.17 & 15.20 & 1.82 & & 4.81 \\
\hline 5 & 11.05 & 2.82 & 1.53 & & 11.27 \\
\hline 6 & 1.06 & 13.39 & 5.16 & & 3.04 \\
\hline 7 & 1.15 & 17.58 & 2.21 & & 6.87 \\
\hline \multicolumn{6}{|c|}{$T$-test $(t<2.78)$} \\
\hline 1 & 4.89 & 1.17 & 4.20 & & 2.08 \\
\hline 2 & 3.80 & 1.66 & 2.46 & & 3.73 \\
\hline 3 & 23.42 & 2.68 & 5.37 & & 5.98 \\
\hline 4 & 3.37 & 1.68 & 7.41 & & 8.37 \\
\hline 5 & 0.82 & 2.56 & 7.49 & & 18.08 \\
\hline 6 & 9.50 & 2.85 & 2.14 & & 11.78 \\
\hline 7 & 1.49 & 3.61 & 7.68 & & 7.25 \\
\hline
\end{tabular}


Results of the student's t-test showed that most of the $\mathrm{SIC}_{\mathrm{ThG}}$ and $\mathrm{SOC}_{\mathrm{ThG}}$ contents were significantly different as compared to the corresponding contents determined by the two other methods (Table II.3 and Table II.4). Whereas SIC CALC $_{\text {and }}$ SIC $_{\text {ThG }}$ contents did not systematically differ, SIC $_{\mathrm{ACI}}$ contents were higher as compared to the $\mathrm{SIC}_{\mathrm{ThG}}$ contents: six out of seven mean values differed significantly and in five out of six significant cases the SIC $_{\mathrm{ACI}}$ content was higher. Therefore, $\mathrm{SIC}_{\mathrm{ACI}}$ contents were likely to be overestimated. The case was clearer for determination of SOC contents. In all cases of significantly different mean values (five for $\mathrm{SOC}_{\mathrm{CALC}}$ and six for $\mathrm{SOC}_{\mathrm{ACI}}$ ), the $\mathrm{SOC}_{\mathrm{ThG}}$ contents were higher as compared to the contents determined by one of the two other methods. This corroborates the assumption that a part of SOC can get lost due to the acid treatments (Bisutti et al. 2004; Midwood and Boutton. 1998).

Table II.4 The contents of soil inorganic carbon (SIC) and soil organic carbon (SOC) in seven soil samples as determined by three different methods. Mean values of three analytical replicates and coefficients of variation $(\mathrm{CV})$ in brackets. Bold figures indicate a significant difference ( $\mathrm{p} \leq 0.05$, t-test) to the corresponding figure measured by ThG. For abbreviations, see text and Fig.II.1

\begin{tabular}{|c|c|c|c|c|c|c|}
\hline \multirow[t]{2}{*}{ Sample } & SIC $_{\text {CALC }}$ & $\mathrm{SIC}_{\mathrm{ThG}}$ & $\mathrm{SIC}_{\mathrm{ACI}}$ & $\mathrm{SOC}_{\mathrm{CALC}}$ & $\mathrm{SOC}_{\mathrm{ThG}}$ & $\mathrm{SOC}_{\mathrm{ACI}}$ \\
\hline & \multicolumn{6}{|c|}{$\left(\mathrm{g} \mathrm{kg}^{-1}\right)$} \\
\hline 1 & $15.7(2.6)$ & $13.4(5.3)$ & $15.9(23.1)$ & $37.6(1.1)$ & $42.4(4.5)$ & $37.4(9.8)$ \\
\hline 2 & $18.5(3.0)$ & $20.1(2.2)$ & $19.5(2.2)$ & $16.8(4.1)$ & $19.2(8.1)$ & $15.8(0.4)$ \\
\hline 3 & $20.3(1.0)$ & $17.4(0.3)$ & $17.9(1.8)$ & $13.2(10.6)$ & $18.7(5.8)$ & $14.9(1.4)$ \\
\hline 4 & $23.3(1.1)$ & $24.0(1.0)$ & $25.0(3.8)$ & $19.0(2.8)$ & $21.8(1.8)$ & $17.3(4.9)$ \\
\hline 5 & $36.1(0.7)$ & $36.5(2.4)$ & $38.0(1.4)$ & $14.9(3.9)$ & $18.2(2.6)$ & $13.0(1.1)$ \\
\hline 6 & $49.0(0.5)$ & $51.1(0.5)$ & $52.8(1.9)$ & $18.1(4.6)$ & $19.2(1.9)$ & $14.3(4.5)$ \\
\hline 7 & $60.2(2.5)$ & $62.0(2.3)$ & 74.7 (7.9) & 70.7 (2.1) & $82.8(2.7)$ & $56.3(10.5)$ \\
\hline
\end{tabular}




\section{II.3.3 Comparison with the large dataset}

The comparison of $\mathrm{SOC}_{\mathrm{ThG}}$ and $\mathrm{SOC}_{\mathrm{CALC}}$ contents is shown in Fig. II.1a. A high $\mathrm{R}^{2}$ value $\left(\mathrm{R}^{2}=0.99\right)$ was obtained for the regression and the slope $(b=0.99 \pm 0.01)$ was not significantly different from one (Table II.5). Despite the close relation, the intercept of the regression between $S O C_{C A L C}$ and $S_{\text {SOC }}$ indicated a significant bias of $4.67 \mathrm{~g} \mathrm{~kg}^{-1}$. This bias is more pronounced in samples with low SOC values, such as cropland soils where management affects SOC contents only to a small extent (Körschens et al. 1998; Heitkamp et al. 2011). Furthermore, changes in the methodology for measuring SOC contents can lead to erroneous conclusions for time series.

The bias between the methods in the whole dataset is shown in Fig. II.1b. In this case, the slope of the regression between SIC $_{\mathrm{CALC}}$ and $\mathrm{SIC}_{\mathrm{ThG}}$ contents was significantly lower than one $(b=0.91 \pm 0.02)$. Consequently, the gap in measured contents of SIC CALC $_{\text {and }}$ SIC $_{\mathrm{ThG}}$ increased with increasing carbonate contents. This problem also appeared in other studies using different methods (Schmidt et al. 2012). Since most samples with high SIC contents had SOC contents $<30 \mathrm{~g} \mathrm{~kg}^{-1}$ the intercept of the regression for SOC contents in Fig. II.1a was affected more than the slope. It is likely that the reason for the slope $>1$ was incomplete decomposition of carbonates by $\mathrm{HCl}$ after one hour in samples containing more than $30 \mathrm{~g}$

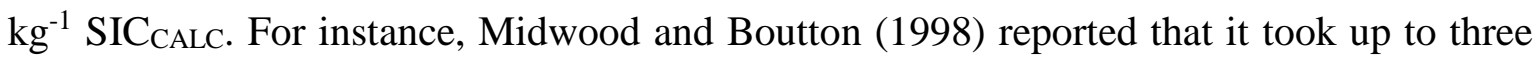
days to completely remove SIC from samples by acid treatments. The observation that the bias of the SIC $_{\text {CALC }}$ contents depended on the concentration range has important implications for studies using e.g. chronosequence approaches (Kabala and Zapart. 2012; Kalbitz et al. 2012). If SIC contents change over time, e.g., by decalcification, calculation of SOC and SIC balance using chronosequence approaches will be erroneous. Of course, the same concern applies for any comparison of samples with differing SIC $_{\text {CALC }}$ concentrations, e.g., comparisons of top- and subsoil samples. 

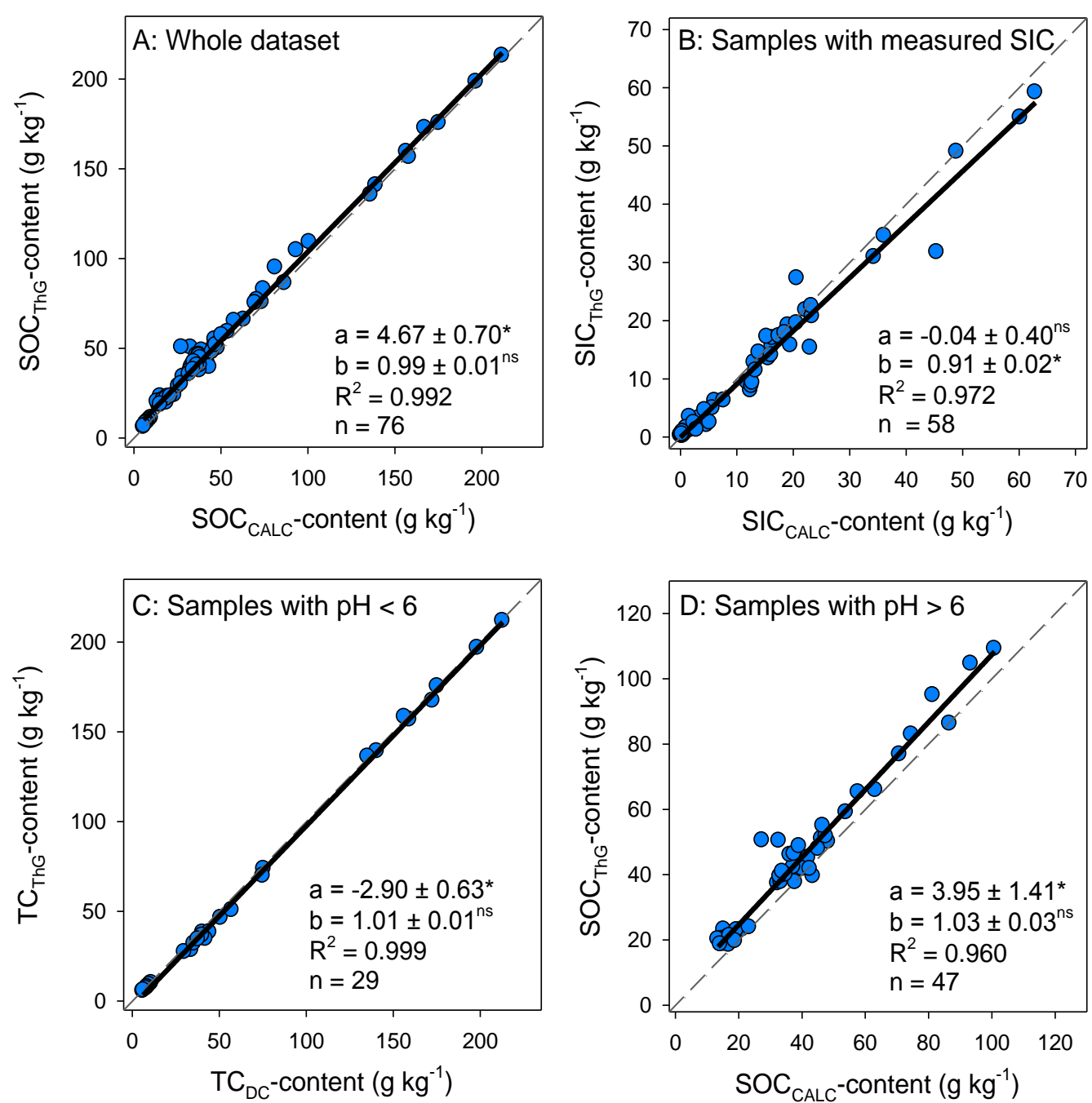

Fig. II.1 Comparison by linear regressions of total, soil organic and soil inorganic carbon contents as measured and calculated by different methods. (a) Soil organic carbon (SOC) contents as measured by the thermal gradient $\left(\mathrm{SOC}_{\mathrm{ThG}}\right)$ method were compared to calculated SOC (SOC $\mathrm{CALC}_{\mathrm{C}}$ ) contents: total $\mathrm{C}$ was measured by dry combustion $\left(\mathrm{TC}_{\mathrm{DC}}\right)$ and inorganic $\mathrm{C}$ by a calcimeter $\left(\mathrm{SIC}_{\mathrm{CALC}}\right)$, $\mathrm{SOC}_{\mathrm{CALC}}$ was obtained by difference. (b) Soil inorganic carbon contents as measured by the calcimeter ( $\mathrm{SIC}_{\mathrm{CALC}}$ ) and the $\mathrm{ThG}$ method $\left(\mathrm{SIC}_{\mathrm{ThG}}\right)$. (c) Total carbon in acidic, carbonate-free samples $(\mathrm{pH}<6)$ as measured by the $\mathrm{CN}$ analyser $\left(\mathrm{TC}_{\mathrm{DC}}\right)$ and the ThG method $\left(\mathrm{TC}_{\mathrm{ThG}}\right.$ ). (d) As in (a) but with a set of samples with $\mathrm{pH}>6$. Parameters are given \pm standard error. An uppercase asterisk after the parameter indicates that it is significantly different ( $t$-test, $\mathrm{p} \leq 0.05$ ) from zero (intercept) or one (slope); "ns" denotes no significant difference. 
Table II.5 Regression equations with standard errors for comparison of methods with the different dataset. SIC $\mathrm{CALC}$ or SOC $\mathrm{CALC}$ values were used as independent and $\mathrm{SIC}_{\mathrm{ThG}}$ or $\mathrm{SOC}_{\mathrm{ThG}}$ values were used as dependent variables. A t-test was performed to check if the intercept was significantly $(\mathrm{p} \leq 0.05)$ different from zero and the slope from one. Calculated $\mathrm{t}$-values were compared to the critical $\mathrm{t}$-value. The null hypothesis assumed no differences. Bold figures were used in the case the null-hypothesis was rejected. For abbreviations and explanation of the sample subsets, see text or Fig. II.1.

\begin{tabular}{|c|c|c|c|c|c|c|}
\hline & \multirow{2}{*}{$\begin{array}{l}\text { Intercept } \\
\pm \mathrm{SE} \\
\left(\mathrm{g} \mathrm{kg}^{-1}\right)\end{array}$} & \multirow[t]{2}{*}{$\begin{array}{l}\text { Slope } \\
\pm \text { SE }\end{array}$} & \multirow[t]{2}{*}{ df } & \multicolumn{3}{|l|}{ t-values } \\
\hline & & & & Critical & Intercept & Slope \\
\hline SIC & $-0.04 \pm 0.40$ & $0.91 \pm 0.02$ & 56 & 2.00 & 0.11 & 4.13 \\
\hline SOC, whole set & $4.67 \pm 0.70$ & $0.99 \pm 0.01$ & 74 & 1.99 & 6.71 & 0.81 \\
\hline $\mathrm{SOC}, \mathrm{pH}>6$ & $3.95 \pm 1.41$ & $1.04 \pm 0.03$ & 45 & 2.01 & 2.81 & 1.10 \\
\hline SOC, $\mathrm{pH}<6$ & $-2.90 \pm 0.63$ & $1.01 \pm 0.01$ & 27 & 2.05 & 4.61 & 0.76 \\
\hline
\end{tabular}

SE: Standard error; df: Degrees of freedom (n -2)

Since the "true" values are unknown, it was necessary to further elucidate reasons for the observed bias between the SOC contents measured using the different methods. The dataset was divided into subsets containing samples with $\mathrm{pH}<6$ (carbonate-free) and $\mathrm{pH}>6$ (potentially containing carbonate, Walthert et al. 2010). Fig. 1c shows the relation between the $\mathrm{TC}_{\mathrm{ThG}}$ and $\mathrm{TC}_{\mathrm{DC}}$ contents. Since no SIC should be present, the $\mathrm{TC}$ contents are regarded as being equal to SOC contents. Using the carbonate-free subset still revealed a significant bias (intercept of $-2.90 \pm 0.63$ was significantly different from zero, Table II.5). The bias had a different sign, but the modulus was not significantly smaller (t-value of the intercept's modulus: 1.45 ; t-value of the intercept: $6.20 ; \mathrm{df}=101$; critical t-value: 1.98 ) as compared to that of the whole dataset (Fig. II.1a). The significantly negative bias of the carbonate-free subset indicated that the source of the positive bias in the whole dataset were the carbonatecontaining samples. Consequently, we presume that $\mathrm{SOC}_{\mathrm{CALC}}$ values were underestimated, when containing carbonate.

The presumption that the source of the significant positive bias between $\mathrm{SOC}_{\mathrm{CALC}}$ and $\mathrm{SOC}_{\mathrm{ThG}}$ contents was underestimation of $\mathrm{SOC}_{\mathrm{CALC}}$ contents was corroborated by Figure II.1d. In the dataset containing carbonaceous samples $(\mathrm{pH}>6)$ the bias $(\mathrm{a}=3.95 \pm 1.41)$ was not significantly different from that of the whole dataset ( $\mathrm{t}$-value $=0.50 ; \mathrm{df}=119$; critical $\mathrm{t}$ value $=1.98)$. It is likely that parts of $\mathrm{SOC}$ evolved in gaseous form $\left(\right.$ as $\mathrm{CO}_{2}$ or volatile 
organic C) due to the acid treatment (Bisutti et al. 2004). Any evolved gas will be measured as carbonate equivalent by the CALC method and will lead to an underestimation of

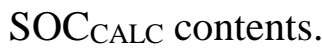

\section{II.4 Conclusions}

Precision of all tested methods confirmed their potential to be used as standard methods. However, use of the thermal gradient method systematically resulted in higher estimates of SOC contents. Thus, the suspicion that acid treatments lead to an underestimation of soil organic carbon contents was further corroborated by this study. When relative results are the focus of the study; e.g., management "A" results in higher $\mathrm{C}$ stocks compared to management "B"; all methods are suitable, provided the carbonate contents are in the same magnitude. Care has to be taken when comparing SOC contents in soil samples with markedly different carbonate contents. In this case the thermal gradient method is more reliable. The chosen method of SOC or SIC determination has to be taken into account in inter-study comparisons and values from different studies should be recalculated by suitable functions.

Acidification of samples is still a required pre-treatment in mass spectrometry when the isotopic signal of SOC is of interest. Coupling an MCD with an isotope ratio mass spectrometer (IRMS) in order to assign isotopic signatures to SIC and SOC may be a valuable future advancement of the thermal gradient method. 


\section{Acknowledgement}

Excellent technical assistance from Petra Voigt and Anja Södje is greatly acknowledged. We are thankful to Dr. Jürgen Grotheer for fruitful discussion. Truong Xuan Vuong was supported by the German Academic Exchange Service (DAAD) and project 322 of the Vietnamese Ministry of Training and Education. The comments of an anonymous reviewer significantly improved the content of the manuscript and Dr. Alphonce Guzha improved the language. 
III. Simultaneous measurement of soil organic and inorganic carbon in dolomite-containing soils

\title{
III Multaneous measurement of organic and inorganic carbon in dolomite-containing soils
}

\author{
Truong Xuan Vuong, Jörg Prietzel and Felix Heitkamp \\ (Submitted to CATENA)
}

\begin{abstract}
It is still open to question, which method is the best to quantify organic carbon (OC) and inorganic carbon (IC) in soils containing dolomite. Aims of this study were (1) to compare the accuracy of a novel thermal gradient (ThG), the classical calcimeter (CALC) and losson-ignition (LOI) methods on a reference sample set with known proportions of OC present as soil organic matter (SOM) and IC present as dolomite, and (2) compare the results of the different methods on a set of soil samples with different dolomite and SOM contents. The CALC and LOI methods rely on separate quantification or removal of IC by acid or heat, whereas IC and OC can be quantified in a single run by the ThG analysis. The ThG method was the most accurate method in the reference sample set, especially when dolomite contents were high. On the soil sample set, ThG and CALC performed equally, but only when two outliers were eliminated. LOI was not satisfactory in any case on the sample set. Overall, ThG was the most reliable method for measuring IC and OC in dolomite-containing samples over the wide range of concentrations, but the more widespread CALC method is also acceptable.
\end{abstract}

Keywords: Carbonate, Organic carbon, Dolomite, Calcimeter, Thermal gradient analysis, Loss on ignition 


\section{III.1 Introduction}

The differentiation of inorganic carbon (IC) and organic carbon (OC) is still challenging (Chatterjee et al., 2009). Accurate quantification of OC, however, is important regarding climate change and soil quality (Lal. 2004). Calcite and dolomite are the main forms of carbonate in soils (Bisutti et al. 2004). Several methods for the measurement of soil carbonate content exist (Loeppert and Suarez. 1996). Most of them base on the reaction of carbonate with acid. The most common method to analyse the carbonate content of soil samples is to treat the samples with $\mathrm{HCl}$ and conduct a volumetric determination of the released $\mathrm{CO}_{2}$. This method is called "Scheibler" or calcimeter (CALC) method. CALC is a cheap, simple and reliable method to determine inorganic carbon (IC), at least in samples containing mainly calcite (Horváth et al. 2005; Tatzber et al. 2007; Vuong et al. 2013). Dolomite, however, reacts more slowly than calcite; therefore it needs very long times to be removed by acid. Loeppert and Suarez (1996) reported that it takes up to 2 hour for dolomite samples to be completely dissolved by $\mathrm{HCl}$. And Midwood and Boutton (1998) reported that it took up to 3 days to remove dolomite-derived IC with $0.5 \mathrm{M} \mathrm{HCl}$. Effects of the different reaction speed may potentially be minimized by calibrating the CALC system with dolomite instead of calcite (Prietzel and Christophel. 2014). This, however, requires knowledge of the type of IC present in the sample, which may be critical in some regions lacking detailed geological information. Moreover, samples containing sulphide, will volatise $\mathrm{H}_{2} \mathrm{~S}$ and, thus, induce an overestimate of $\mathrm{CO}_{2}$ volatilization (Hafner and Bisobni. 2007; Rozzi and Brunetti. 1981); hence it causes a positive bias in measurement of IC (Hafner and Bisobni. 2007). Consequently, calculation of OC as the difference between total carbon (TC) and IC will be erroneous, too (Vuong et al. 2013). In some soils, the magnitude of this error may result in substantially different estimates for total SOC stocks (Kalbitz et al. 2013).

Loss-on-ignition (LOI) is another method, which is widely used to determine OC. The total carbon concentration of a sample is measured, the sample is exposed to heat and the carbon concentration is measured a second time. After correction of weight loss during heating, the OC concentration is obtained (Chatterjee et al. 2009; Wang et al. 2011; Wang et al. 2012). There is however, no consensus on the appropriate cut-off temperature or duration of heat exposure. Temperature between 300 and $550^{\circ} \mathrm{C}$ and durations between 2 and 18 hours were reported (summarised in Chatterjee et al. 2009). Moreover, information about the performance of LOI in soils containing dolomite, not only calcite, seem to be missing. 
III. Simultaneous measurement of soil organic and inorganic carbon in dolomite-containing soils

In a prior study (Vuong et al. 2013), we could show that total carbon, organic carbon and inorganic carbon in the form of calcite could be quantified precisely and accurate by a thermal gradient method (ThG). In this study we focus on the ability to quantify dolomitederived IC by ThG. The aims of this study were (1) to compare the accuracy of ThG, CALC and LOI on a sample set with known proportions of OC and IC present as dolomite, and (2) compare the results of the different methods on a set of soil samples.

\section{III.2 Material and methods}

III.2.1 Samples and sample preparation

\section{a. $\quad$ Reference mixtures}

Natural dolomite and natural humus of the Bavarian Alps were used for analysis. Dolomite samples were retrieved from the Hauptdolomit formation from Guggenauer Koepfl (Biermayer and Rehfuess. 1985). Tangelhumus, which was free of inorganic carbon was collected for organic carbon samples which originated from the Guggenauer Koepfl as well (Prietzel et al. 2013). The recovered dolomite boulder was washed to remove external contamination and then crushed, sieved and ground to a particle size of $<0.2 \mathrm{~mm}$. The tangelhumus was also ground. Mixtures of dolomite, humus and quartz sand were prepared with various fixed mass ratios for artificial samples (see Table III.1). The mixtures were weighed and delivered directly in the grinding bowl of a planetary mill and ground to achieve good homogeneity and uniform grain size. The $\mathrm{C}$ contents of the dolomite (IC) and tangelhumus (OC) samples were measured by dry combustion (Euro-EA 3000, HEKAtech $\mathrm{GmbH}$, Wegberg, Germany) and are abbreviated as $\mathrm{IC}_{\mathrm{REF}}$ and $\mathrm{OC}_{\mathrm{REF}}$ in the following.

\section{b. $\quad$ Soil samples}

Seventeen soil samples of different sources on dolomitic parent material were collected, airdried $\left(45^{\circ} \mathrm{C}\right)$ and passed through a 2-mm sieve. Samples were ground with a planetary ball mill for homogenisation and to reduce the time needed for complete dolomite removal with the calcimeter. Soil samples were dried at $105^{\circ} \mathrm{C}$ to correct results for residual water contents. The samples are described in detail in Prietzel et al. (2013). 
III. Simultaneous measurement of soil organic and inorganic carbon in dolomite-containing soils

Table III.1 Mixing ratio of the dolomite-humus mixtures and the resulting theoretical concentrations of inorganic and organic carbon. Measured $\mathrm{C}$ content of humus and dolomite was $419.5 \mathrm{~g} \mathrm{~kg}^{-1}$ and $129.3 \mathrm{~g} \mathrm{~kg}^{-1}$, respectively

\begin{tabular}{|c|c|c|c|c|c|}
\hline Humus & Dolomite & Quartz & TC & IC & $\mathbf{O C}$ \\
\hline \multicolumn{3}{|c|}{$(\%)$} & \multicolumn{3}{|c|}{$\left(\mathrm{g} \mathrm{kg}^{-1}\right)$} \\
\hline 0 & 100 & 0 & 129.3 & 129.3 & 0.0 \\
\hline 1 & 99 & 0 & 132.2 & 128.0 & 4.2 \\
\hline 5 & 95 & 0 & 143.8 & 122.8 & 21.0 \\
\hline 10 & 90 & 0 & 158.3 & 116.4 & 42.0 \\
\hline 25 & 75 & 0 & 201.9 & 97.0 & 104.9 \\
\hline 33 & 67 & 0 & 225.1 & 86.6 & 183.4 \\
\hline 50 & 50 & 0 & 274.4 & 64.7 & 209.8 \\
\hline 67 & 33 & 0 & 323.7 & 42.7 & 281.1 \\
\hline 75 & 25 & 0 & 347.0 & 32.3 & 314.6 \\
\hline 90 & 10 & 0 & 390.5 & 12.9 & 377.6 \\
\hline 95 & 5 & 0 & 405.0 & 6.5 & 398.5 \\
\hline 99 & 1 & 0 & 416.5 & 1.3 & 415.3 \\
\hline 100 & 0 & 0 & 419.5 & 0.00 & 419.5 \\
\hline 0 & 75 & 25 & 97.0 & 97.0 & 0.00 \\
\hline 7.5 & 67.5 & 25 & 118.7 & 87.3 & 31.5 \\
\hline 37.5 & 37.5 & 25 & 205.8 & 48.5 & 157.3 \\
\hline 67.5 & 7.5 & 25 & 292.9 & 9.7 & 283.2 \\
\hline 0 & 50 & 50 & 64.7 & 64.7 & 0.0 \\
\hline 5 & 45 & 50 & 79.2 & 58.2 & 21.0 \\
\hline 25 & 25 & 50 & 137.2 & 32.3 & 104.9 \\
\hline 45 & 5 & 50 & 195.2 & 6.5 & 188.8 \\
\hline 0 & 25 & 75 & 32.3 & 32.3 & 0.0 \\
\hline 2.5 & 22.5 & 75 & 39.6 & 29.1 & 10.5 \\
\hline 12.5 & 12.5 & 75 & 68.6 & 16.2 & 52.4 \\
\hline 22.5 & 2.5 & 75 & 97.6 & 3.2 & 94.4 \\
\hline
\end{tabular}

\section{III.2.2 Calcimeter}

The calcimeter (CALC) method is based on the reaction of carbonates with $\mathrm{HCl}$ to $\mathrm{CO}_{2}$. The volume of evolved gas is measured by the displacement of a water column. The method is extensively described in (Horváth et al. 2005) and in ISO 10693 (1995). A defined amount of sample ( 0.2 to $1.2 \mathrm{~g})$, depending on the estimated carbonate content was transferred into the glass reaction vessel and wetted with $2 \mathrm{ml}$ of distilled water. Seven $\mathrm{ml}$ of $4 \mathrm{M} \mathrm{HCl}$ were added. The sample was mixed with the $\mathrm{HCl}$ and stirred until the volume of the water column remained stable. The water volume displaced by the formed $\mathrm{CO}_{2}$ was measured in the calibrated tube. Calibration was done with dolomite, which was collected as described above. In the following, the calcimeter method will be abbreviated by CALC and IC measured by this method by $\mathrm{IC}_{\mathrm{CALC}}$. 
III. Simultaneous measurement of soil organic and inorganic carbon in dolomite-containing soils

Total carbon was measured by dry combustion $\left(\mathrm{TC}_{\mathrm{DC}}\right)$ and $\mathrm{OC}$ was calculated as the difference of $\mathrm{IC}_{\mathrm{CALC}}\left(\mathrm{TC}_{\mathrm{DC}}-\mathrm{IC}_{\mathrm{CALC}}=\mathrm{OC}_{\mathrm{CALC}}\right)$.

\section{III.2.3 Loss on ignition}

This method is based on the principle that OC is decomposed at lower temperatures as IC. One gram of soil sample $\left(m_{0}\right)$ with already known total carbon content $\left(\mathrm{TC}_{\mathrm{DC}}\right.$ analyzed by dry combustion) was placed in a ceramic crucible, heated in a muffle oven at $500^{\circ} \mathrm{C}$ for four hours, and left to cool in a desiccator. Afterward, the sample was re-weighed $\left(m_{500}\right)$. Total carbon of the completely burnt (at $500{ }^{\circ} \mathrm{C}$ ) sample was measured again and corrected by the weight loss obtained by the amount of inorganic carbon:

$$
I C_{L O I}=\frac{m_{0} \times T C_{D C}}{m_{500}}
$$

Organic carbon $\left(\mathrm{OC}_{\mathrm{LOI}}\right)$ content is the difference of total carbon content $\left(\mathrm{TC}_{\mathrm{DC}}\right)$ and inorganic carbon ( $\left.\mathrm{IC}_{\mathrm{LOI}}\right)$ content.

\section{III.2.4 Thermal gradient analysis}

A multiphase carbon determinator (RC-412, Leco, St. Joseph, MI, USA) was used for analysis of IC and OC by ThG (Chichester and Chaison. 1992; Vuong et al. 2013). An amount of 10-20 mg of ground sample was scaled in quartz crucibles. The temperature ramp was programmed to rise from 140 to $900^{\circ} \mathrm{C}$ in ca. 20 min using pure $\mathrm{O}_{2}$ as carrier gas. The amount of $\mathrm{CO}_{2}$ evolved was measured by infrared detection three times per second (Figure 1). Due to the isolated peaks, $\mathrm{CO}_{2}$ that evolved at temperatures higher than $600^{\circ} \mathrm{C}$ was assigned to inorganic carbon (Vuong et al. 2013). Calibration was done with certified EDTA (Leco, part no. 502-012, lot 1035; Leco Corporation, St. Joseph, MI, USA) and $\mathrm{CaCO}_{3}$ standards (part no. 501-034, lot 1016) over a range of 1 to $4 \mathrm{mg}$ carbon. The method will be abbreviated by ThG. Contents of TC, OC and IC analyzed by ThG will be abbreviated as $\mathrm{TC}_{\mathrm{ThG}}, \mathrm{OC}_{\mathrm{ThG}}$ and $\mathrm{IC}_{\mathrm{ThG}}$, respectively.

\section{III.2.5 Data analysis and statistics}

Comparisons of the ThG with CALC as well as of LOI methods were performed. Linear, bivariate regression analysis was carried out with values of $\mathrm{IC}_{\mathrm{CALC}}, \mathrm{OC}_{\mathrm{CALC}}, \mathrm{IC}_{\mathrm{LOI}}, \mathrm{OC}_{\mathrm{LOI}}$, $\mathrm{IC}_{\mathrm{ThG}}$ and $\mathrm{OC}_{\mathrm{ThG}}$ as dependent variables and $\mathrm{IC}_{\mathrm{REF}}$ and $\mathrm{OC}_{\mathrm{REF}}$ values were used as independent variables (Fig. III.2; Webster. 1997). Similarly, linear bivariate regression analysis was carried out with values of $\mathrm{IC}_{\mathrm{CALC}}, \mathrm{OC}_{\mathrm{CALC}}, \mathrm{IC}_{\mathrm{LOI}}, \mathrm{OC}_{\mathrm{LOI}}$ as independent 
variables and $\mathrm{IC}_{\mathrm{ThG}}$ and $\mathrm{OC}_{\mathrm{ThG}}$ were used as dependent variables (Fig. III.3). T-values were calculated to test if the intercept of the regression was different from zero and if the slope was different from one. Linear regression was performed by using SigmaPlot 10.0 (Systat). A significance level of $\mathrm{p} \leq 0.05$ was used for all statistical calculations.

\section{III.3 Results and discussion}

III.3.1 Thermograms of humus and dolomite

Fig. 1 shows the thermograms of humus and dolomite. ThG graphs illustrated that dolomite is decomposed at temperatures above $600^{\circ} \mathrm{C}$ and humus is decomposed in the temperature range below $600^{\circ} \mathrm{C}$. This is in accordance with results from Plante et al. (2011) and Maharaj et al. (2007), who analysed soil samples with thermal analysis and reported that soil organic carbon and inorganic mineral carbon generally have been oxidized at temperatures below and above $600^{\circ} \mathrm{C}$, respectively. There is, however, a small peak at temperatures below $600^{\circ} \mathrm{C}$ in the dolomite samples, which represents $3.8 \%$ of $\mathrm{TC}_{\mathrm{DC}}\left(4.8 \mathrm{~g} \mathrm{C} \mathrm{kg}^{-1}\right)$ in the sample. It is likely, that this amount is OC bound in the Hauptdolomit bedrock. For instance, Köster et al. (1988) reported that OC contents of 3-15 $\mathrm{g} \mathrm{kg}^{-1}$ are common in carbonaceous rocks of the Hauptdolomit formation. The OC value as calculated for the dolomite from the Guggenauer Köpfl by ThG is well within this range. That OC in the dolomite sample can be detected by ThG is an important advantage, especially compared to the CALC method, where due to the lack of commercially available lab-synthesized pure dolomite, bedrock dolomite has been used for calibration and assumed to consist exclusively of IC. Similarly, the small peak (2.4 $\mathrm{g} \mathrm{C} \mathrm{kg}^{-1}$ or $5.6 \%$ of total $\mathrm{C}$ ) above $600^{\circ} \mathrm{C}$ in the humus sample probably indicates small amounts of dolomite present in the sample. For instance, Mutsch (2001) reported a carbonate content of $19 \mathrm{~g} \mathrm{~kg}^{-1}$ (ca. $2.4 \mathrm{~g} \mathrm{C} \mathrm{kg}^{-1}$ ) in a top soil sample with a $\mathrm{pH}\left(\mathrm{CaCl}_{2}\right)$ of 5.8 from the Mühlegger Köpfl, which is only two kilometres away from the Guggenauer Köpfl). 


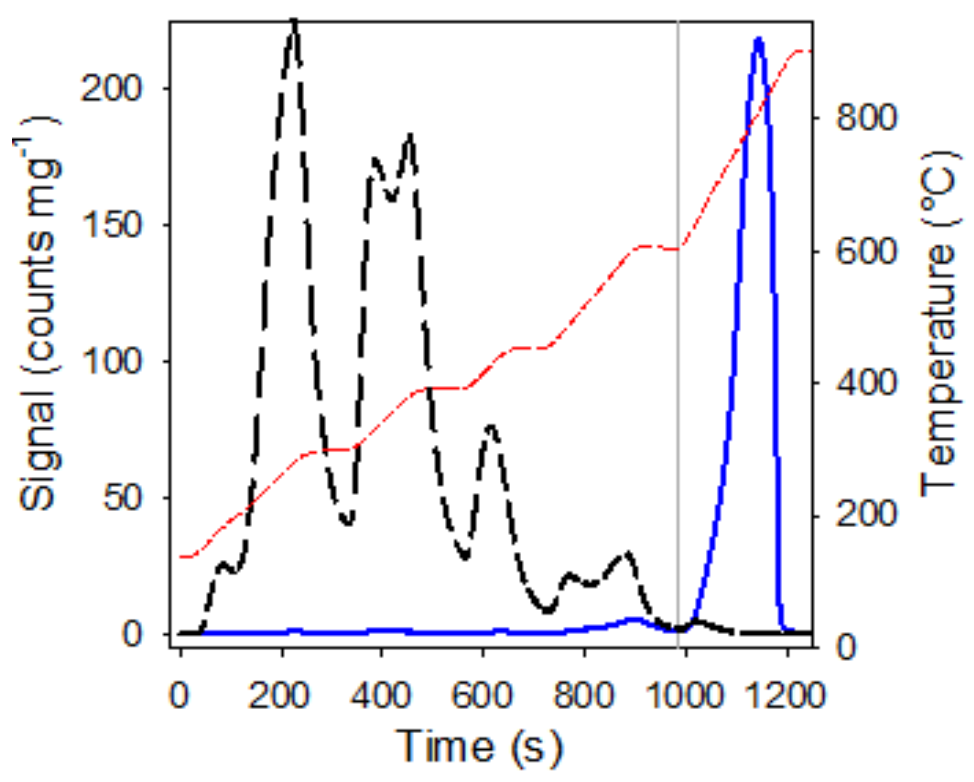

Fig. III.1 Thermo-gram of humus (long-dash) and dolomite (solid line) samples. The shortdashed line is the temperature and the vertical grey line indicates the division of inorganic and organic carbon.

\section{III.3.2 Reference mixtures}

For measurements of IC, both CALC and ThG showed a high precision, as indicated by high $\mathrm{R}^{2}$-values (0.998 and 0.995 for CALC and ThG, respectively, Fig. III.2). The LOI method showed a high scatter, and the $\mathrm{R}^{2}$ of 0.848 shows that the method is not suitable to routinely analyse IC in dolomite-humus-mixtures with satisfying precision. Furthermore, the high intercept (18.28, Table III.2) indicates a strong overestimation of $\mathrm{IC}_{\mathrm{LOI}}$ contents, particularly at low concentrations. An overestimation, but less scatter, was also reported by Wang et al. (2012) for soils containing calcite. From the comparison of our reference samples with humus and dolomite, we conclude that the CALC and ThG methods are superior over LOI. Both methods (CALC and ThG), however, had slopes significantly lower than one (0.82 and 0.87 for CALC and LOI, respectively) and $\mathrm{IC}_{\mathrm{ThG}}$ had a significantly positive intercept (Table III.2). Contents of $\mathrm{IC}_{\mathrm{THG}}$, however, seem to be biased especially above $\mathrm{IC}_{\mathrm{REF}}$ contents above $70 \mathrm{~g} \mathrm{~kg}^{-1}$, whereas deviation from the 1:1 line occurred much earlier for $\mathrm{IC}_{\mathrm{CALC}}$ (Fig. III.2). Therefore, the ThG method should be preferred when dolomite contents are very high. However, $\mathrm{IC}_{\mathrm{CALC}}$ contents did not have a significant intercept, indicating that the method is preferable for samples with low dolomite contents (ca. $<20 \mathrm{~g} \mathrm{C} \mathrm{kg}^{-1}$, Fig. III.2). In many studies, however, IC is determined to quantify OC contents in samples (Kalbitz et al. 2013; Vuong et al. 2013; Wang et al. 2012). 

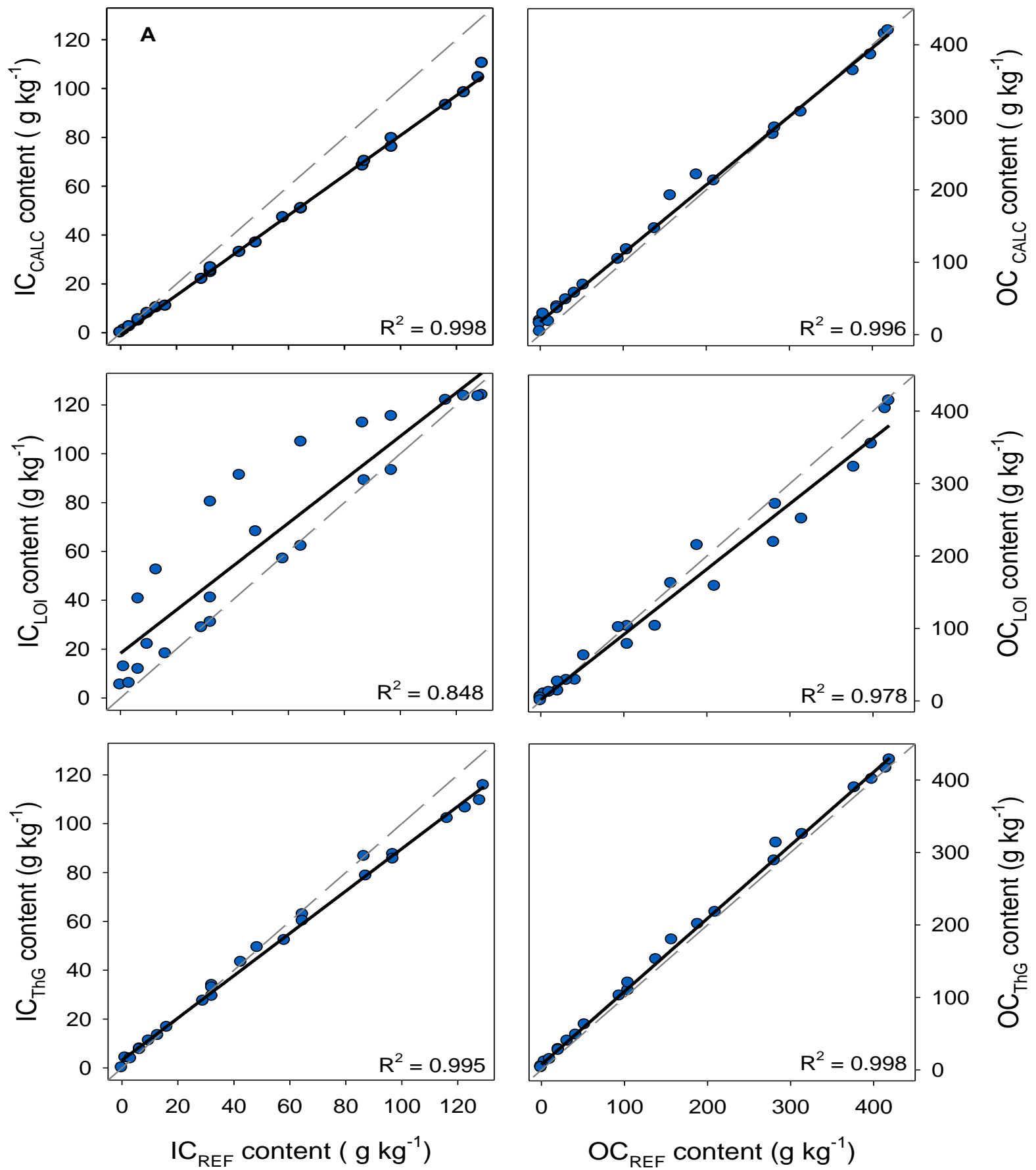

Fig. III.2 Scatter plots of different methods as compared to the reference mixtures $(n=25)$. The dashed line is the 1:1 line and the thick black line is the linear regression. IC: inorganic carbon; OC: organic carbon; CALC: calcimeter; LOI: loss-on-ignition; ThG: thermal gradient; REF: reference mixtures of humus and dolomite.

Coefficients of determination for OC measurements were high for all three methods $\left(\mathrm{R}^{2} \geq\right.$ 0.978), although lowest for $\mathrm{OC}_{\mathrm{LOI}}$ (Fig. III.2). Interestingly, the latter method performed much better for OC as compared to IC determination. The slope, however, was significantly lower than one (0.90, Table III.2). Although there was a significant positive bias (intercept $=7.36 \mathrm{~g} \mathrm{~kg}^{-1}$, Table III.2) in $\mathrm{OC}_{\mathrm{ThG}}$, this method still showed the highest accuracy. There was a positive bias $\left(17.93 \mathrm{~g} \mathrm{~kg}^{-1}\right)$ for $\mathrm{OC}_{\mathrm{CALC}}$ and the slope was significantly smaller than 
one. The very high intercept can probably be attributed, at least in part, to the nature of the reference samples: in case $\mathrm{OC}_{\mathrm{REF}}$ contents were small, $\mathrm{IC}_{\mathrm{REF}}$ contents were high. As discussed above, this causes underestimation of $\mathrm{IC}_{\mathrm{CALC}}$ and hence overestimation of OC $\mathrm{CALC}_{\mathrm{C}}$ From the reference sample set, we conclude that ThG is the most reliable method for measuring OC in dolomite containing samples over a wide range of OC and IC contents. The finding that ThG is suitable to quantify OC in reference mixtures was also demonstrated by Bisutti et al. (2007) for calcite and magnesite.

Table III.2 Regression equations with standard errors for comparison of methods in the different datasets (reference mixtures: Fig. III.2; soil samples: Fig. III.3). Bold figures were used in the case that intercept or slope differed significantly $(\mathrm{p} \leq 0.05)$ from zero or one, respectively. For abbreviations and explanation of the sample subsets, see text or Fig. III.2 and III.3.

\begin{tabular}{|c|c|c|c|c|c|}
\hline & \multicolumn{2}{|c|}{ Intercept $\pm \mathrm{SE}$ Slope $\pm \mathrm{SE}$} & \multicolumn{3}{|l|}{ t-values } \\
\hline & \multicolumn{2}{|l|}{$\left(\mathrm{g} \mathrm{kg}^{-1}\right)$} & \multirow[t]{2}{*}{ Critical } & \multirow[t]{2}{*}{ Intercept } & \multirow[t]{2}{*}{ Slope } \\
\hline \multicolumn{3}{|c|}{ Reference mixtures $(\mathrm{df}=23)$} & & & \\
\hline $\mathrm{IC}_{\mathrm{CALC}} \mathrm{vs} \mathrm{IC}_{\mathrm{REF}}$ & $-0.99 \pm 0.52$ & $0.82 \pm 0.01$ & 2.06 & 1.92 & 22.75 \\
\hline $\mathrm{IC}_{\mathrm{LOI}} \mathrm{vs} \mathrm{IC}_{\mathrm{REF}}$ & $18.28 \pm 5.34$ & $0.89 \pm 0.08$ & 2.06 & 3.24 & 1.42 \\
\hline $\mathrm{IC}_{\mathrm{ThG}} \mathrm{vs} \mathrm{IC}_{\mathrm{REF}}$ & $3.34 \pm 0.87$ & $0.86 \pm 0.01$ & 2.06 & 3.87 & 10.64 \\
\hline $\mathrm{OC}_{\mathrm{CALC}} \mathrm{vs} \mathrm{OC}_{\mathrm{REF}}$ & $17.93 \pm 2.61$ & $0.95 \pm 0.01$ & 2.06 & 6.84 & 4.23 \\
\hline OC $C_{\text {LOI VS }} O C_{\text {REF }}$ & $1.05 \pm 5.87$ & $0.90 \pm 0.03$ & 2.06 & 0.18 & 3.50 \\
\hline $\mathrm{OC}_{\mathrm{ThG}} \mathrm{vs} \mathrm{OC}_{\mathrm{REF}}$ & $7.36 \pm 1.82$ & $1.01 \pm 0.01$ & 2.06 & 4.04 & 1.00 \\
\hline \multicolumn{6}{|c|}{ Soil samples $(\mathrm{df}=15)$} \\
\hline $\mathrm{IC}_{\mathrm{ThG}} \mathrm{vs} \mathrm{IC}_{\mathrm{CALC}}$ & $16.69 \pm 9.11$ & $0.81 \pm 0.16$ & 2.13 & 1.83 & 1.22 \\
\hline $\mathrm{IC}_{\mathrm{ThG}}$ vs $\mathrm{IC}_{\mathrm{LOI}}$ & $-0.57 \pm 1.79$ & $0.88 \pm 0.02$ & 2.13 & 0.32 & 5.21 \\
\hline $\mathrm{OC}_{\mathrm{ThG}} \mathrm{VS} \mathrm{OC}_{\mathrm{CALC}}$ & $11.60 \pm 8.49$ & $0.78 \pm 0.10$ & 2.13 & 1.37 & 2.31 \\
\hline $\mathrm{OC}_{\mathrm{ThG}} \mathrm{vs} \mathrm{OC}_{\mathrm{LOI}}$ & $7.97 \pm 3.33$ & $1.11 \pm 0.05$ & 2.13 & 2.40 & 2.27 \\
\hline \multicolumn{6}{|c|}{ Soil samples without outliers $(\mathrm{df}=13)$} \\
\hline $\mathrm{IC}_{\mathrm{ThG}} \mathrm{vs} \mathrm{IC}_{\mathrm{CALC}}$ & $3.67 \pm 2.58$ & $0.94 \pm 0.04$ & 2.16 & 1.42 & 1.60 \\
\hline $\mathrm{OC}_{\mathrm{ThG}} \mathrm{vs} \mathrm{OC}_{\mathrm{CALC}}$ & $4.92 \pm 3.25$ & $0.97 \pm 0.04$ & 2.16 & 1.51 & 0.75 \\
\hline
\end{tabular}

SE: Standard error; df: Degrees of freedom $(n-2)$

\section{III.3.3 Soil samples}

When soil samples are analysed, the "true" values are unknown and, therefore, it can only be tested if different methods are consistent with each other. Since CALC and LOI are established methods, we compare them to the novel ThG approach. When comparing both 
thermal methods (LOI and ThG) it became obvious, that for both IC and OC significant differences occurred (Fig. III.3, Table III.2). Taking into account the results of the reference mixtures, we conclude that the ThG method is more reliable as compared to LOI. Most likely, this is the case because evolved gas is measured directly by ThG and scaling and repeated measurements are avoided. The relationship between CALC and ThG methods was poor ( $\mathrm{R}^{2}$ of 0.638 and 0.817 for IC and OC, respectively; Fig. III.3) when the whole dataset was included in the statistical analysis.
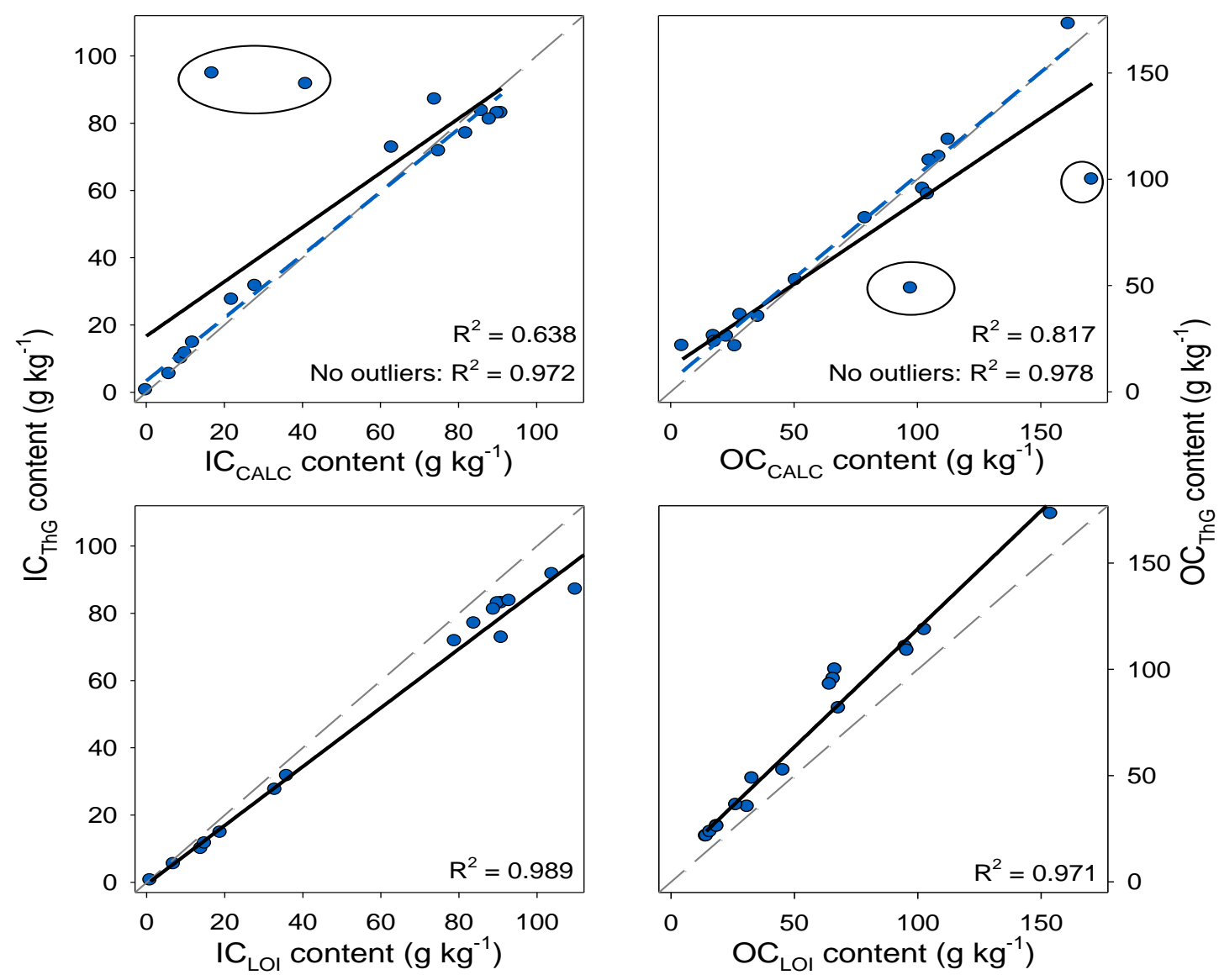

Fig. III.3 Comparison of contents of organic (OC) and inorganic carbon (IC) quantified by the thermal gradient method (ThG), calcimeter (CALC) and loss-on-ignition (LOI). Set of soil samples $(n=17)$. Long-dashed thin line: theoretical 1:1 line; thick solid line: regression with all samples; short-dashed thick line: regression without outliers.

The strong pronounced difference between CALC and ThG was surprising, since Vuong et al. (2013) showed relatively close relationships of these methods when using sample sets containing calcite. In our study, the deviation could be attributed mainly to the presence of two outliers. Eliminating the outliers yielded close relations, with no significant differences to zero (intercept) or one (slope) in the regression equations (Table III.2). Unfortunately, there is no explanation why the two outliers occurred in the CALC, but not in the thermal (ThG, LOI) methods. Increasing the reaction time may help in this issue (Loeppert and 
III. Simultaneous measurement of soil organic and inorganic carbon in dolomite-containing soils

Suarez. 1996; Midwood and Boutton. 1998), but this would be a serious drawback concerning the standardisation of the CALC method.

\section{III.4 Conclusions}

Concerning the reference mixtures, no method was able to determine the theoretical values perfectly. The ThG method, however, performed best of all three methods, especially in determining organic carbon, where a part of the significant offset may be explained by the presence of minor amounts of $\mathrm{OC}$ in the investigated dolomite used as reference material for IC. When using soil samples, both ThG and CALC performed equally, with the exception of two outliers. "Outliers", however, are an inherent feature of natural samples. Therefore and under consideration of the reference mixtures, we conclude that the ThG method is the best option when analysing samples containing dolomite, because results were the most accurate over the wide range of different contents of OC and IC. Since an RC-412 may not be available in many laboratories, use of the CALC method is still a reasonable choice, especially when dolomite contents are low or when performing comparisons. In the latter case, the relatively small error applies to each treatment, rendering relative values valid. Loss on ignition should be avoided when analysing samples containing dolomite. 
III. Simultaneous measurement of soil organic and inorganic carbon in dolomite-containing soils

\section{Acknowledgments}

We acknowledge the following people who helped with the study: Daniel Helm (TU München) performed analysis with the calcimeter and muffle oven; Andreas Reimer (GAUG) granted access to the LECO equipment; Hermann Jungkunst (University KoblenzLandau) and Gerhard Gerold (GAUG) commented on an earlier version of the manuscript. Truong Xuan Vuong was supported by the German Academic Exchange Service (DAAD) and project 322 of the Vietnamese Ministry of Training and Education. JP designed the study; TXV and FH wrote the manuscript; JP contributed with significant comments. 


\title{
IV Highly resolved thermal analysis as a tool for soil organic carbon fractionation in landscapes
}

\author{
Truong Xuan Vuong, Hermann F. Jungkunst, Andreas Reimer, Gerhard Gerold, \\ Felix Heitkamp. \\ (Submitted in European Journal of Soil Science)
}

\begin{abstract}
Evolved gas analysis during ramped combustion increased the value of thermal methods, but it could not yet be used to quantify carbon contents in soil organic matter and its fractions. The presented thermal gradient method overcomes these problems and it was shown by means of standard additions and methodological comparisons that it also can be used to measure the stability of soil organic matter. Four main peaks of organic carbon fractions were recorded at the temperature ranges: $140-300^{\circ} \mathrm{C}, 300-400^{\circ} \mathrm{C}, 400-450{ }^{\circ} \mathrm{C}$ and 450 $600^{\circ} \mathrm{C}$. Indications are shown that the thermal fractions are ecologically relevant. Therefore, thermal gradient analysis has the potential to be used in routine measurement to determine organic, inorganic and total carbon as well as the stability of organic matter in a single analytical run. Care has to be taken when samples with high C-concentrations are analyzed. Here, some methodological adjustments are necessary. In any case, small examples like comparing different land use within a region according to their soil organic carbon fraction revealed that much more information can be withdrawn from the presented thermal gradient method in comparison to regular bulk $\mathrm{C}$ measurement. The high sample throughput is an advantage particularly for larger scale analyses on land use systems and land use change.
\end{abstract}

Keywords: Thermal analysis, Soil carbon, Carbon fraction, Labile carbon, Stable carbon, Land use change 


\section{IV.1 Introduction}

Soil organic matter (SOM) is a key component in ecosystems due to its importance for nutrient cycling, soil structure, soil fertility and as sink or source of atmospheric $\mathrm{CO}_{2}$ (Lal. 2004). SOM is a continuum of molecules with different properties regarding chemistry and turnover (Amundson. 2001; Baldock et al. 2004). Being the primary source for energy for heterotrophic organisms, both the properties of SOM as well as its association to the mineral phase are key to biochemical cycling in soils. Therefore, there is demand for fractionation methods (von Lützow et al. 2007), particurlarly for larger scales like landscapes that require larger numbers of samples (Herbst et al. 2012).

Physical, chemical, biological, and thermal methods have been proposed to separate different SOM fractions (Christensen. 2001; von Lützow et al. 2007; Plante et al. 2009; Heitkamp et al. 2012). Generally, at least three fractions are proposed and termed labile, intermediate and stable, according to their different turnover times (Amundson. 2001; von Lützow et al. 2008). Physical methods include fractionation according to primary particle size, specific density and aggregate size. It is assumed that sorption to primary particles and physical occlusion within aggregates are relevant mechanisms to stabilise SOM (Baldock and Skjemstad. 2000; Heitkamp et al. 2012). Among wet chemical methods, hot water extractable carbon (HWC) was shown to be a reliable measurement for labile C (Leinweber et al. 1995; Ghani et al. 2003). Various chemicals were tested to isolate stable SOM fractions, of which $\mathrm{H}_{2} \mathrm{O}_{2}$ and $\mathrm{Na}_{2} \mathrm{~S}_{2} \mathrm{O}_{8}$ proved to be most suitable (Helfrich et al. 2007; Jagadamma et al. 2010). von Lützow et al. (2007) recommended to use a combination of different methods, but this approach has the drawback that some methods may isolate overlapping fractions. Therefore, a single method, which is capable to isolate several SOM fractions will be an important advancement for fractionation methods.

For the latter a group of methods, thermal methods are promising for SOM fractionation. Thermal methods and their applicability for SOM fractionation were reviewed in detail by Plante et al. (2009) and the potential for using thermograms as a base for SOM modelling is dicussed in Bruun et al. (2010). All thermal methods have in common, that properties of a certain material are monitored during exposure to heat in a specified atmosphere. The underlying principle in SOM research is that the liberation of organic compounds in relation to increasing temperature should be directly related to their bioavailability or recalcitrance (Rovira et al. 2008), which is directly related to microbial decomposability (Leifeld and von Lützow. 2014). One subgroup of thermal methods (differential thermal analysis, DTA and 
differential scanning calorimetry, DSC) is used to characterise endothermic or exothermic reactions at certain temperatures. These methods were often applied in decomposition studies to indicate changes in the energy content of organic materials (Rovira et al. 2008; Plante et al. 2009). Thermogravimetry (TG) is the continuous measurement of mass loss during constant heating. A general challenge for this application encompasses the multiple sources of mass loss at different temperatures (water, changes in the mineral matrix). Thermal methods were markedly improved by evolved gas analysis (EGA) (Plante et al. 2009; Fernández et al. 2012; Plante et al. 2013). For this technique, a $\mathrm{CO}_{2}$ analyzer is coupled with the combustion unit and, thus, $\mathrm{CO}_{2}$ evolution can be related to mass loss. Fernández et al. (2012) coupled TG, DSC and EGA and concluded that especially DSC profiles were highly correlated $(\mathrm{r}>0.90)$ with $\mathrm{CO}_{2}$ evolution. The recovery of total $\mathrm{C}(\mathrm{TC})$ of samples was, however, only slightly higher than $80 \%$. Moreover, the resolution of the thermograms is not always suitable to calculate SOM fractions from clearly distinct peaks. This means that DSC-EGA provides valuable information on the overall stability of SOM (Peltre et al. 2013; Marin-Spiotta et al. 2014), but is not suitable for quantitative analysis of organic carbon (OC), inorganic carbon (IC) and TC.

The quantitative determination of TC, OC and IC in a single run by thermal analysis was proven by Vuong et al. (2013). They tested a multiphase carbon determination (ramped combustion with highly resolved infrared $\mathrm{CO}_{2}$-detection), and concluded that this thermal gradient method (ThG) is even advantageous over classical methods for OC and IC differentiation and also accurate in quantifying TC. Moreover, the thermograms revealed the presence of several peaks below $600^{\circ} \mathrm{C}$, i.e. the range where $\mathrm{OC}$ was detected. Therefore, the ThG measurements may even provide additional information on the stability of SOM, potentially resulting in a powerful tool, especially when a high sample throughput is required.

In the present study, our objectives are to (1) test if the presented ThG is suitable for the quantification of ecological meaningful differences in organic carbon fractions for both soil and material samples of different carbon stability; (2) corroborate the findings by using a standard addition approach; (3) compare the ThG method with established methods for measuring labile and stable $\mathrm{C}$ and (4) test applications of the proposed method for process studies and particular landscape and other larger scale approaches. 


\section{IV.2 Material and Methods}

IV.2.1 Setting of the thermal gradient method

The used device is a Multiphase Carbon Determinator (RC-412, Leco, St. Joseph, MI, USA), which consist of a furnace which can be programmed for ramping (increase of temperature per unit of time) and a coupled IR-detector for $\mathrm{CO}_{2}$ quantification (three times per second). During the analysis of the thermograms, it was apparent that the region assigned as OC $(<$ $600^{\circ} \mathrm{C}$ ) consisted of several overlapping peaks (Fig. IV.1), which showed similar patterns for different soils and materials. After reviewing the literature (see introduction) and deconvolving the peaks (Peakfit 4.12, Saytat Software Inc., San Jose, CA, USA; see appendix), temperature ramps were added to divide the most obvious existing peaks. It was done to achieve a better separation of the peaks (Fig. IV.1). Organic carbon evolved as $\mathrm{CO}_{2}$ was classified into four ranges: $140-300^{\circ} \mathrm{C}\left(\mathrm{C}_{140-300}\right) ; 300-400^{\circ} \mathrm{C}\left(\mathrm{C}_{300-400}\right) ; 400-450^{\circ} \mathrm{C}\left(\mathrm{C}_{400}\right.$ $450)$ and $450-600^{\circ} \mathrm{C}\left(\mathrm{C}_{450-600}\right)$, respectively (see also Supplementary Information Table S1 and Figures S2 and S3). $\mathrm{CO}_{2}$ evolved above $600^{\circ} \mathrm{C}$ was proven to originate from IC (Maharaj et al. 2007; Fernández et al. 2012; Vuong et al. 2013). To convert the signal into C concentrations, the total area within each defined temperature range was used. Sometimes, less clear peaks were overlapping. To guarantee reproducibility, only the most clearly defined peaks which appeared in all tested samples were differentiated.

Calibration was done with $\mathrm{CaCO}_{3}$ and EDTA standards (Leco Corporation, St. Joseph, MI, USA). These standards were also analysed every fifth sample as a quality control. An amount of 10 to $20 \mathrm{mg}$ finely ground sample material was scaled into quartz crucibles. The amount of sample may affect the results (Fernández et al. 2011). We tested two different soils having different $\mathrm{C}$ contents with sample amounts in the range of 10-40 mg. In the sample with high C-contents. Therefore, the optimal sample weight was in the range of 10-20 mg (supporting information, Table S2, Figure S4).

The parameters of the heating program are given in Table IV.1. The ramp (increase in temperature per minute) was tested with 12 and $35^{\circ} \mathrm{C} \mathrm{min}^{-1}$ (see supporting information). Since there was no significant or relevant difference between the results of both ramps, the faster setup was chosen to increase sample throughput to be designed for landscape approaches. In addition, we tested two setups, having the same heating rate of $35^{\circ} \mathrm{C} \mathrm{min}^{-1}$ with and without plateau holds. Again, the results showed that there was no significant difference in fraction size between two setups (see supporting information, Table S1, Figures $\mathrm{S} 2$ and S3). Moreover, the peaks of the setup with heating rate $35^{\circ} \mathrm{C} \mathrm{min}^{-1}$ with holds were 
separated better than that of heating rate $35^{\circ} \mathrm{C} \mathrm{min}^{-1}$ without holds. Therefore, we chose the parameter of the heating program as an optimal setup given in table IV.1. With this setup analysis time was 20 minutes. Another 20 minutes are needed until the oven cools down, increasing analysis time to ca. 40 minutes per sample.

Analysis of TC, OC and IC was proven to be precise and accurate (Table IV.1; Vuong et al. 2013). Unfortunately, there are no standards, which can be used for specific temperature ranges. To test reproducibility, five different soil samples were measured in three repetitions. The pooled coefficient of variation $(\mathrm{CV})$ was $7.9 \%, 6.4 \%, 4.8 \%$ and $7.2 \%$ for the organic fractions. The CVs were slightly lower when using relative values ( $\%$ of TC; Table IV.1).

Table IV.1 Settings of the temperature profile of the MCD RC-412 with abbreviations of the corresponding fractions

\begin{tabular}{|c|c|c|c|c|c|}
\hline \multirow[t]{2}{*}{ Temperature } & \multirow[t]{2}{*}{ Abbreviation } & \multirow[t]{2}{*}{ Ramp } & \multirow[t]{2}{*}{ Hold } & \multicolumn{2}{|c|}{$\mathrm{CV}$} \\
\hline & & & & absolute & relative \\
\hline$/{ }^{\circ} \mathbf{C}$ & & ${ }^{\circ}{ }^{\circ} \mathrm{C}$ min $^{-1}$ & $/ \mathbf{s}$ & $/ \%$ & $/ \%$ \\
\hline $140-300$ & $\mathrm{C}_{140-300}$ & 35 & 100 & 7.9 & 6.2 \\
\hline $300-400$ & $\mathrm{C}_{300-400}$ & 35 & 120 & 6.4 & 5.3 \\
\hline $400-450$ & $\mathrm{C}_{400-450}$ & 35 & 100 & 4.8 & 4.1 \\
\hline $450-600$ & $\mathrm{C}_{450-600}$ & 40 & 120 & 7.2 & 5.3 \\
\hline $600-900$ & IC & 60 & 100 & 2.5 & 1.4 \\
\hline $140-600$ & $\mathrm{OC}$ & $\mathrm{n} / \mathrm{a}$ & $\mathrm{n} / \mathrm{a}$ & 4.8 & 1.9 \\
\hline $140-900$ & $\mathrm{TC}$ & $\mathrm{n} / \mathrm{a}$ & $\mathrm{n} / \mathrm{a}$ & 3.4 & $\mathrm{n} / \mathrm{a}$ \\
\hline
\end{tabular}

$\mathrm{CV}$ : coefficient of variation

\section{IV.2.2 Materials and soil samples}

Three different sample sets were used to indicate the suitability of the method for carbon fractionation. The first sample set includes different organic materials and samples differing in their decomposability and/or stage of decomposition. We assumed that wood char consisted mainly of stable, grass char of intermediate stable and starch of labile material. This set is mainly used to explore if the general pattern of the ThG method fits the expectations (see descriptions below). The second sample set reflects top soils with different properties spiked with fixed amount of reference materials (wood char and wheat starch). The set was used to test the recovery rate of wheat starch and wood char in OC fractions of different soil samples analysed by the ThG method. The second sample set was also used to compare ThG with established laboratory methods in determining labile and stable organic 
carbon fractions in spiked soil samples. The third sample set was used to give examples for application of the method.

Sample set 1. Starch, charred rice straw (grass char) and charred wood were used as samples with different stabilities. Charred straw and wood were obtained from M.W.I. Schmidt, University Zürich and were described by Hammes et al. (2008). In addition, three different types of soil samples were selected for the present study and for demonstration of the thermogram:

(1) Anthrosol from the Brazilian Pantanal. This soil type is similar to the Amazonian "terra preta" (Glaser and Birk. 2012) and developed under influence of anthropogenic input of organic material, such as charcoal, manure and bio wastes. A high proportion of stable $\mathrm{C}$ was expected due to a high degree of humification and char addition (Glaser and Birk. 2012).

(2) Sandy Cambisol with high sand content under cropland use. Due to the land use, the labile $\mathrm{C}$ pool should be depleted. The stable $\mathrm{C}$ pool should be relatively small, due to a lack of stabilisation by organo-mineral associations in the sandy soil (for a detailed description, see Heitkamp et al. 2011).

(3) Wetland soil, classified as Histosol. Water logging hampers mineralisation of organic matter. Therefore, it is expected that a high proportion of labile $\mathrm{C}$ was preserved, due to environmental conditions (Krüger et al. 2013).

(4) Light and heavy fraction material from a density fractionation of the sandy Cambisol was used. A major difference between the fractions is the mineral association of carbon in the heavy fraction, whereas light fraction material occurs "free" in soil. The methodology and origin of the samples is described in Heitkamp et al. (2011). Here, the clay and silt fraction $(<53 \mu \mathrm{m})$ of the heavy fraction was used. We tested if differences between the light and heavy fractions occurred. Light fraction material was shown to contain less recalcitrant compounds (Helfrich et al. 2006) and this difference should therefore be detectable by the proposed ThG method.

Sample set 2. Standard additions are often used to evaluate new methods. In this case, however, there is no specific standard for individual fractions available. Therefore, we spiked four soil samples with wheat starch and wood char as surrogates for mainly labile and stable OC, respectively. To deal with the problem that the spiking materials occurred in all four 
thermal fractions, both starch and char were added to quartz sand at the same rates as to soil samples (see below). The measured distribution among fractions of the sand-starch and sandchar mixtures were defined as "standard". Based on the former soil carbon analysis by Vuong et al. (2013), four top soil samples $(0-10 \mathrm{~cm})$, with different contents of organic and inorganic carbon were chosen:

(1) WE: wetland soil, classified as Histosol. Water logging hamper mineralization of organic matter in the Drakensberg mountains, South Africa (for a detailed description, see Krüger et al. 2013).

(2) FOR: forest soil, classified as Rendzic Cambisol developed on limestone near Goettingen, Germany.

(3) $\mathrm{CR}_{\text {loam }}$ cropland soil classified as clay loam Rendzic Cambisol, developed on limestone near Goettingen, Germany.

(4) $\mathrm{CR}_{\text {sand }}$ cropland soil classified as sandy Cambisol soil near Darmstadt, Germany (Heitkamp et al. 2009).

(5) CON: quartz sand (p.a. Merck, Darmstadt, Germany).

Wheat starch and wood char were added with two different rates: 2 and $16 \mathrm{~g} \mathrm{~kg}^{-1}$ soil (amendment with OC: 0.83 and $6.57 \mathrm{~g} \mathrm{~kg}^{-1}$, and 1.49 and $11.75 \mathrm{~g} \mathrm{~kg}^{-1}$ for wheat starch and wood char, respectively), as suggested by Roth et al. (2012). All measurements were repeated three times.

The spiked samples were also used to compare ThG with hot water extraction and wet oxidation with $\mathrm{Na}_{2} \mathrm{~S}_{2} \mathrm{O}_{8}$. Since starch was completely oxidised by $\mathrm{Na}_{2} \mathrm{~S}_{2} \mathrm{O}_{8}$, whereas wood char was not dissolved by the hot water treatment, hot water extraction results are only reported for starch and wet oxidation results only for wood char.

Sample set 3. This sample set was used to demonstrate two potential applications.

The density fractions described in sample set 1 were derived from a fertilisation experiment. These samples were used to test if effects of fertiliser rate and/or type are detectable. Briefly, mineral fertiliser with straw incorporation (MSI) was compared with application of farmyard manure (FYM), each at low and high rates (50 and $\left.150 \mathrm{~kg} \mathrm{~N} \mathrm{ha}^{-1}\right)$. These treatments were applied for 28 years in the long term fertilisation experiment, Darmstadt Germany.

The effect of the major land use categories (forest, meadow, cropland) on different thermal fractions was quantified. Forest (FOR) and cropland $\left(\mathrm{CR}_{\text {loam }}\right)$ samples were already 
described in sample set 2. Land was differently used, but environmental conditions were remarkably equal since climate (mean annual temperature of $8.7^{\circ} \mathrm{C}, 865 \mathrm{~mm}$ annual precipitation), topography (plateau), geology (limestone) and soil type (mosaic of rendzic Cambisols and rendzic Leptosols, texture of loamy clay) were the same. The forest is dominated by European beech (Fagus sylvatica L) and was likely used for grazing and fuel extraction in the past centuries and is now under extensive management. In the $13^{\text {th }}$ century the forest was converted to agricultural use at the meadow site (Müller. 2010). The cropland was used as such at least since 1784 (Preutenborbeck. 2009). Since 1980, the area serves as experimental station for the Georg-August-Universität Göttingen, Germany.

Table IV.2 Abbreviations, as well as contents of organic carbon, inorganic carbon and the $\mathrm{C} / \mathrm{N}$-ratio of the used soil samples and materials

\begin{tabular}{|c|c|c|c|c|}
\hline \multirow[t]{2}{*}{ Sample } & \multirow[t]{2}{*}{ Abbreviation } & OC & IC & \multirow{2}{*}{$\begin{array}{l}\mathrm{C} / \mathrm{N} \\
\text { ratio }\end{array}$} \\
\hline & & \multicolumn{2}{|c|}{$/ \mathrm{g} \mathrm{kg}^{-1}$} & \\
\hline Starch & - & 417.4 & nd & 316 \\
\hline Grass char & - & 586.3 & nd & 47 \\
\hline Wood char & - & 746.8 & nd & 197 \\
\hline $\begin{array}{l}\text { Anthrosol, } \\
\text { rainforest }\end{array}$ & - & 39.9 & 13.5 & 8 \\
\hline Histosol & WET & 157.1 & 0.78 & 17 \\
\hline $\begin{array}{l}\text { Loamy } \\
\text { Cambisol, } \\
\text { beech forest }\end{array}$ & FOR & 94.1 & 2.60 & 12 \\
\hline $\begin{array}{l}\text { Loamy } \\
\text { Cambisol, } \\
\text { cropland }\end{array}$ & $\mathrm{CR}_{\text {loam }}$ & 18.2 & 50.4 & 12 \\
\hline $\begin{array}{l}\text { Sandy } \\
\text { Cambisol, } \\
\text { cropland }\end{array}$ & $\mathrm{CR}_{\text {sand }}$ & 6.7 & 0.2 & 12 \\
\hline Quartz sand & $\mathrm{CON}$ & 0.4 & nd & nd \\
\hline
\end{tabular}

\section{IV.2.3 Description of established methods}

To compare our results with established methods, hot water extractable carbon was selected as a measure for labile $\mathrm{C}$ and a wet oxidation with $\mathrm{Na}_{2} \mathrm{~S}_{2} \mathrm{O}_{8}$ was used as a measure for stable C. 
The hot-water extractable C (HWC) was determined on air dried samples following the method of Ghani et al. (2003). Briefly, $3 \mathrm{~g}$ of soil were extracted for 16 hours at $80^{\circ} \mathrm{C}$ with $30 \mathrm{ml}$ distilled water. The suspension was filtered $(0.45 \mu \mathrm{m})$ after cooling and the organic carbon concentration in the filtrate was determined with a Dima-TOC 100 (Dimatec, Essen, Germany).

Wet oxidation (WOX) with $\mathrm{Na}_{2} \mathrm{~S}_{2} \mathrm{O}_{8}$ was performed according to Helfrich et al. (2007). Briefly, 0.5 gram of soil was dispersed in $250 \mathrm{ml}$ distilled water by ultrasound $\left(440 \mathrm{~J} \mathrm{ml}^{-1}\right)$. Then, $20 \mathrm{~g} \mathrm{Na}_{2} \mathrm{~S}_{2} \mathrm{O}_{8}$ buffered with $22 \mathrm{~g} \mathrm{NaHCO}_{3}$ were added. The oxidative treatment lasted for 48 hours at $80^{\circ} \mathrm{C}$ on a heated magnetic stirrer. The sample residue was washed twice with $40 \mathrm{ml}$ distilled water and traces of the carbonate buffer were removed by adding $20 \mathrm{ml} 0.01$ $\mathrm{M} \mathrm{HCl}$. Afterwards sample was washed until $\mathrm{pH}$ 6-7, freeze-dried and analysed for $\mathrm{C}$ contents (Truspec CHN LECO, St Joseph, MI, USA). The residue represent the oxidationresistant and hence most stable fraction of SOM.

\section{IV.3 Data analysis and statistics}

Probability levels were generally $95 \%$ for all statistical analysis, which were performed with SPSS 20.0.0. (IBM SPSS Statistics). Homogeneity of variances (F-test) and normal distributions (Histograms and Kolmogorov-Smirnoff test) were checked. Pearson correlation coefficients were calculated for the comparison of different methods $(n=15)$. In the case of the correlation between HWC and $\mathrm{C}_{140-300}$, both datasets were log-normal distributed and were transformed correspondingly before analysis.

For the standard addition approach of ThG method, comparisons were performed between the spiked controls (adjusted for "background" concentrations, i.e. the un-spiked sample) as reference and the spiked soil samples (also adjusted for background concentrations). A homo- or heteroscedastic t-test (depending on the results of the F-test, see supporting information) was used for statistical evaluation $(n=3)$. For the standard additions of starch and char the recovery in the control for the hot water extraction and chemical oxidation was not suitable to use the same approach. Here, an ANOVA was calculated. Recovery rates (R) of the spikes were calculated as:

$$
R=\frac{S_{A}-S}{A}
$$


Where $S_{A}$ is the C-concentration $\left(\mathrm{g} \mathrm{kg}^{-1}\right)$ of the spiked sample/fraction, $S$ is the Cconcentration $\left(\mathrm{g} \mathrm{kg}^{-1}\right)$ in the original sample/fraction and $A$ is the amendment rate $\left(\mathrm{g} \mathrm{C} \mathrm{kg}^{-1}\right)$ rate of the spike.

The significance of differences between light and heavy fractions was checked by a student's t-test $(n=16)$. Treatment (fertiliser type and rate) effects $(n=4)$ within light and heavy fractions were analysed by a mixed model with SAS 9.1 (SAS Institute Inc., Cary, USA), where fertiliser type and rate were fixed effects, whereas the spatial structure of the field experiment was included as random effect. Details were described by Heitkamp et al. (2009). The effects of land use on thermal fractions was analysed by a one-way ANOVA, followed by Fisher's least significant difference as post-hoc test $(n=9)$. Detailed results of the statistics are provided in the supporting information.

\section{IV.4 Results and discussion}

IV.4.1 Thermal fractions of material and soil samples

The individual peak maxima for all tested soils and materials were located at similar temperatures having only small deviations (Figure IV.1). These peak positions fit well to positions reported by numerous authors (summarised in Plante et al. 2009) and to the temperature ranges reported by Dorodnikov et al. (2007) as well. These authors used thermogravimetry coupled with differential scanning calorimetry (TG-DSC) to separate OC fractions into four temperature ranges (values of this study in brackets, Table IV.1): 190$310^{\circ} \mathrm{C}\left(140-300^{\circ}\right), 310-390^{\circ} \mathrm{C}\left(300-400^{\circ} \mathrm{C}\right), 390-480^{\circ} \mathrm{C}\left(400-450^{\circ} \mathrm{C}\right)$ and $480-600^{\circ} \mathrm{C}$ $\left(450-600^{\circ} \mathrm{C}\right)$. The small differences are likely a consequence of different resolutions. Only 4 out of 13 studies (compiled in Plante et al. 2009) reported starting temperatures below $200^{\circ} \mathrm{C}$, but our data (Figure IV.3) showed a relevant release of carbon below $200^{\circ} \mathrm{C}$. Demyan et al. (2013) also reported four components of soil organic matter, which they related to organic functional groups. The peak temperature of these groups were close to the ones of this study (Figure IV.1). Moreover, Plante et al. (2013) reported (local) peak maxima near $290,350,420$ and $490^{\circ} \mathrm{C}$. Hence, it is likely that these repeatedly reported OC fractions are meaningful in terms of the ecological function of soil organic carbon stability. This was corroborated by analyzing the chemical composition and the ${ }^{14} \mathrm{C}$ content of these thermal fractions (Plante et al. 2013; Demyan et al. 2014). Consequently, we argue here, that the well resolved four fractions identified within a single analytical run is a progress for more qualitative soil carbon analyses for landscape and other larger scale studies. Wood char revealed peaks in all four OC fractions (Figure IV.1). $300^{\circ} \mathrm{C}$ representing the most labile 
fraction. Thermo-labile wood char carbon may fit to the finding that charcoal is not entirely inert (Hammes et al. 2008; Bruun et al. 2010). Grass char differs in chemical structure to wood char and thus different thermal gradient pattern were found (see Fig. IV.1).
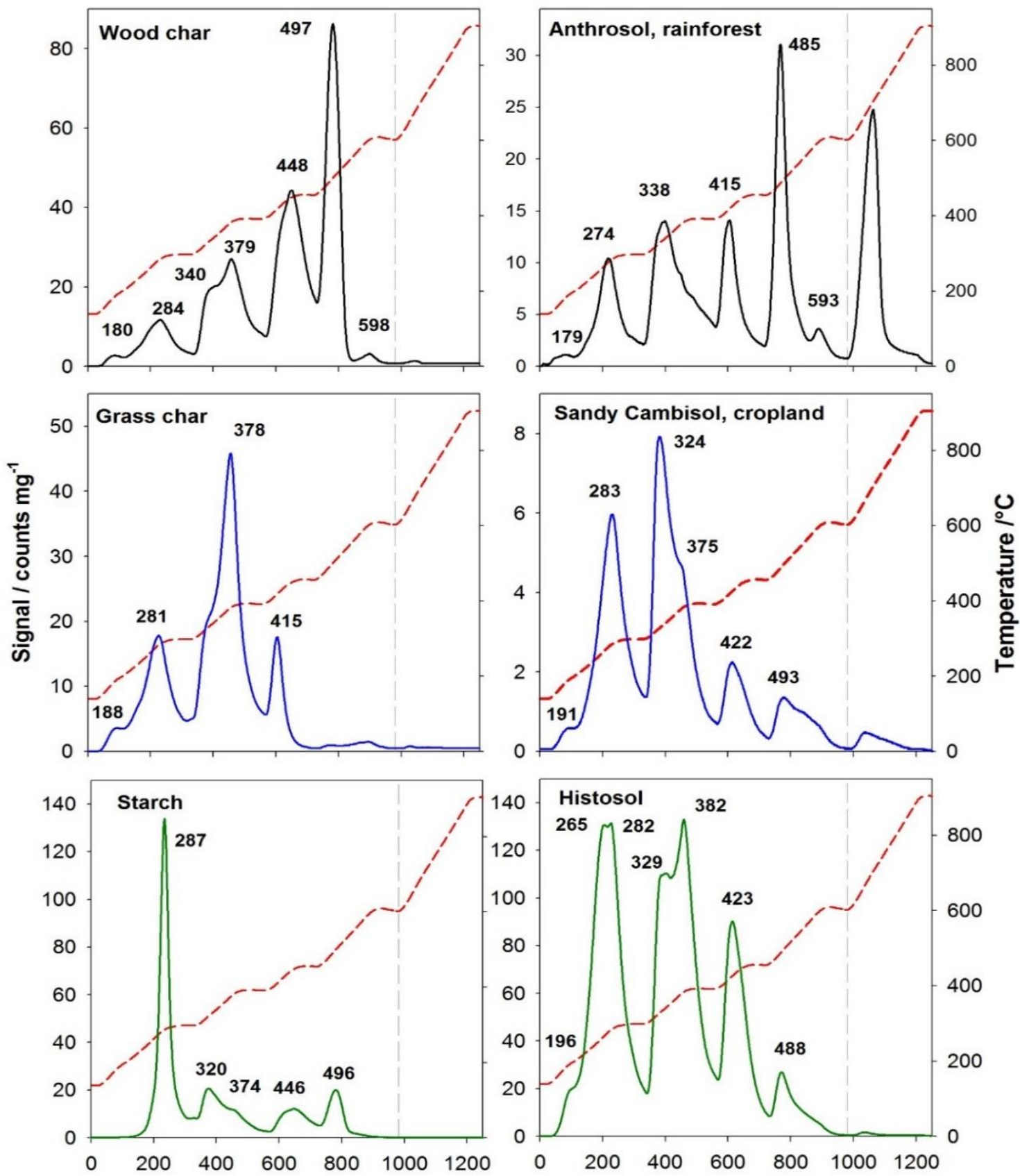

Time / s

Fig. IV.1 Thermograms of material and soil samples. The peak above $600^{\circ} \mathrm{C}$ was proven to be inorganic carbon and is therefore delimited by the dashed grey line. The numbers represent the temperatures for peaks and shoulders. 
The largest peak area of grass char occurred in the range between $300-400^{\circ} \mathrm{C}$ indicating that grass char is more prone to decomposition than wood char, which was recently shown by Hilscher and Knicker (2011). Leifeld (2007) analysed the same grass and wood char with DSC and reported similar temperature ranges of the highest peaks. Moreover, Fernández et al. (2012) showed that $\mathrm{CO}_{2}$ - and DSC-profiles were highly correlated. Therefore, the ThG method produced reasonable results for the different chars regarding the distribution of $\mathrm{C}$ among fractions of different thermo-stability.

According to our expectations, large peak areas were detected for the temperature ranges of $400-450^{\circ} \mathrm{C}$ and $450-600^{\circ} \mathrm{C}$ and lower peak areas in the temperature range of $300-400^{\circ} \mathrm{C}$. However, small but significant peaks were also detected for the temperature range of 140Highest peak areas for starch were found at temperatures $<300^{\circ} \mathrm{C}$ as expected. However, relevant amounts were still detected at higher temperatures, which indicates that analysis of highly labile materials may be biased as was shown for wood (Leifeld. 2007). Nevertheless, SOM normally does not contain high proportions of such pure and labile materials due to their fast turnover and microbial decomposition in any soil environment.

High proportions of thermo-stable $\mathrm{C}$ were expected in the Anthrosol, due to high proportions of black carbon and other highly condensed aromatics (humified material) frequently found in such soils (Glaser and Birk. 2012). In the cropland soils, especially labile SOM should be depleted due to cultivation (Heitkamp et al. 2012). Expectations were met for both soils, since highest signals occurred in the range of $450-600^{\circ} \mathrm{C}$ and $300-400^{\circ} \mathrm{C}$ for the Anthrosol and the cropland soil, respectively. The cropland soil additionally had a sandy texture ( $85 \%$ sand) and, therefore, relatively low amounts of SOM were stabilised in organo-mineral complexes (Heitkamp et al. 2011). Consequently, only low signals for stable carbon were found (Fig. IV.1). Large amounts of labile organic carbon due to water logging preservation were expected for the wetland soil which was basically confirmed (Figure IV.1). Additionally, rather high amounts of C were registered for the regions 300 - 400 and 400 $450^{\circ} \mathrm{C}$. In the Drakensberg of South Africa, the wetlands usually run dry during the dry season in winter. Furthermore, surrounding grassland of the sampling location were burnt every other year (Hammes et al. 2008). Therefore, relevant amounts of grass char and/or soot particles are likely to be present in the wetland sample as well as a higher degree of humification, which both explain the high proportion of more stable organic carbon.

The ability to isolate SOC fractions of different stability was further tested by using density fractions from a long-term fertilisation experiment (Heitkamp et al. 2011). Our results show 
that the heavy fraction contained consistently less carbon, which evolved at temperatures below $400^{\circ} \mathrm{C}$ as compared to the light fractions (Table IV.6). Specifically, proportions of $\mathrm{C}_{140-300}$ (34.5 and $41.2 \%$ of OC in heavy and light fractions, respectively) and $\mathrm{C}_{300-400}$ (34.4 and 39.7 in heavy and light fractions, respectively) were significantly lower and proportions of $\mathrm{C}_{400-450}$ (15.0 and 10.1 in heavy and light fractions, respectively) and $\mathrm{C}_{450-600}$ (16.1 and 8.9 in heavy and light fractions, respectively) were significantly higher as compared to light fraction carbon (Table IV.6). Carbon in the heavy fraction was shown to be more decomposed, as revealed by ${ }^{13} \mathrm{C}$ nuclear magnetic resonance (NMR) measurements (Helfrich et al. 2006). Therefore, it is reasonable to assume that the results of the ThG are related to the higher degree of decomposition of carbon in the heavy fraction. Both organo-mineral association, as well as a higher recalcitrance are likely responsible for the higher thermal stability of SOM in the heavy fraction as compared to the light fraction.

Overall, the measurements indicated that clear and repeated differences in OC of thermal fractions in differing soil samples can be detected. The distribution among peaks largely fulfilled the expectations in an ecological meaningful sense. This is a first indication, that ThG is a suitable tool to identify differences in organic carbon fractions of soil units in a landscape.

\section{IV.4.2 Standard additions}

The thermo-grams of four soil samples and quartz sand added with standard materials (wheat starch and wood char) were shown in figure IV.2. The recovery of starch-derived OC was in the range of 36 to $189 \%$ (Table IV.3). Recovery rates for the low starch spike were poorer as compared to the high starch spike (51-102\%). Similar results were found for the wood char spike (Table IV.4, recovery 55-194\%), where results for high char spikes were satisfying (79-96\%). Roth et al. (2012) reported recovery of TC in spiked samples of 80 to $104 \%$. The OC contents of their soil samples, however, had a maximum of $21 \mathrm{~g} \mathrm{~kg}^{-1}$, whereas OC contents of our samples was up to $164 \mathrm{~g} \mathrm{~kg}^{-1}$ in the WET sample (Table IV.2). The larger OC background may explain the poor recovery in some cases. For instance, recovery of starch and wood char (spike at high rate) were 83-95 and 87-89\% (Table IV.3 and IV.4), respectively, when omitting the wetland and forest topsoil. 


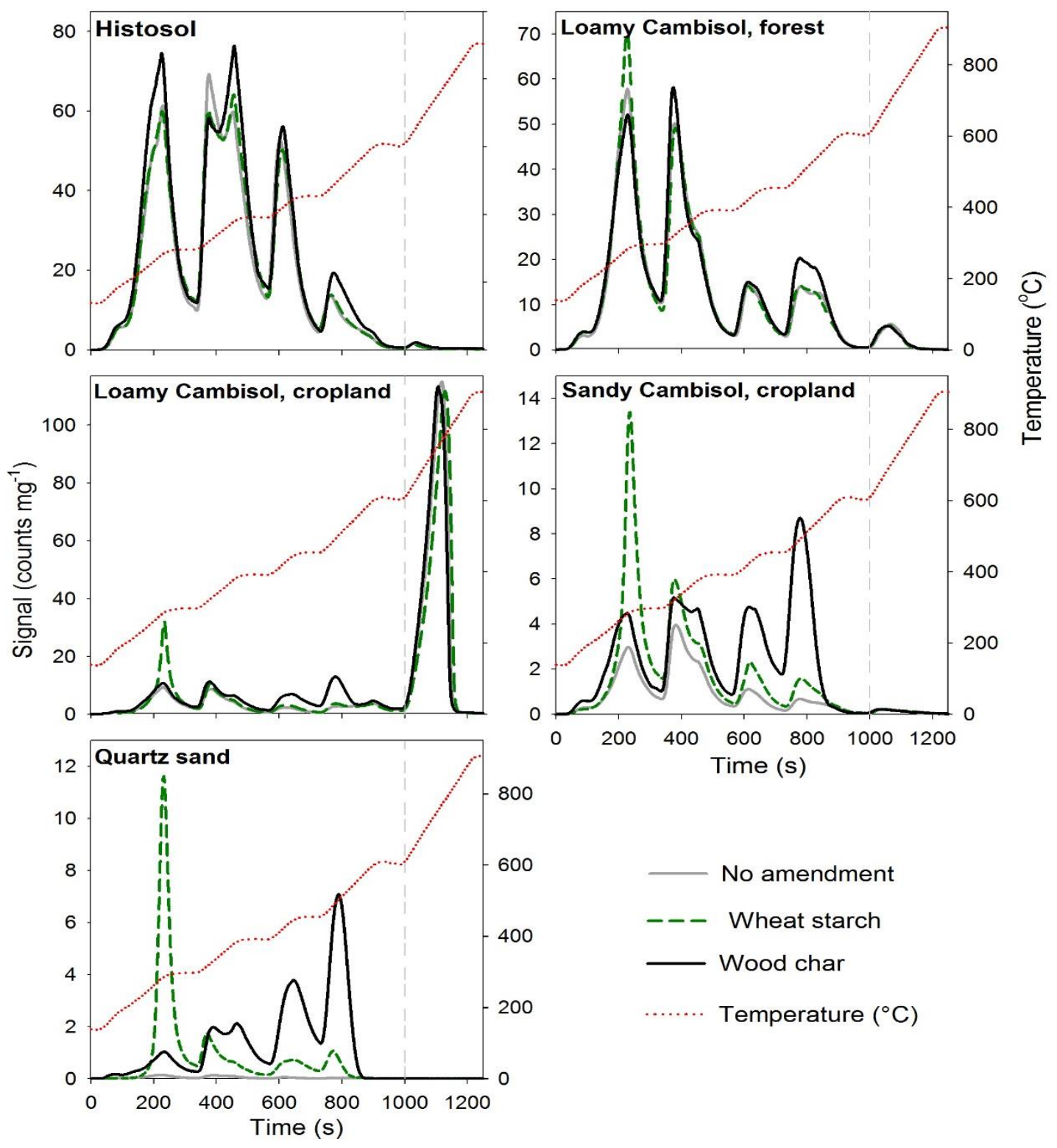

Fig. IV.2. Thermograms of different samples spiked with $16 \mathrm{~g} \mathrm{~kg}^{-1}$ wheat starch or wood char in comparison to the blank samples. The peak above $600^{\circ} \mathrm{Cw}$ as proven to be inorganic carbon and is therefore delimited by the dashed line. 
Table IV.3 Organic carbon concentrations in thermal fractions of four soil samples and changes in the concentrations in comparison to the unspiked sample after starch spiking. Mean values and standard errors $(\mathrm{n}=3)$.

\begin{tabular}{|c|c|c|c|c|c|c|c|c|c|}
\hline \multirow[b]{2}{*}{ Sample } & \multicolumn{2}{|l|}{$130-300^{\circ} \mathrm{C}$} & \multicolumn{2}{|l|}{$300-400^{\circ} \mathrm{C}$} & \multicolumn{2}{|l|}{$400-450^{\circ} \mathrm{C}$} & \multicolumn{2}{|l|}{$450-600^{\circ} \mathrm{C}$} & \multirow[b]{2}{*}{$\begin{array}{l}\text { Recovery } \\
1 \%\end{array}$} \\
\hline & $\begin{array}{l}\text { OC content } \\
/ \mathrm{g} \mathrm{kg}^{-1}\end{array}$ & $p$ & $\begin{array}{l}\text { OC content } \\
/ \mathrm{g} \mathrm{kg}^{-1}\end{array}$ & $p$ & $\begin{array}{l}\text { OC content } \\
/ \mathrm{g} \mathrm{kg}^{-1}\end{array}$ & $p$ & $\begin{array}{l}\text { OC content } \\
/ \mathrm{g} \mathrm{kg}^{-1}\end{array}$ & $p$ & \\
\hline WET & $54.45(3.12)$ & - & $69.66(0.59)$ & - & $29.06(2.73)$ & - & $10.32(2.73)$ & - & \\
\hline$\Delta \mathrm{WET}^{+}$ & $3.91(5.88)$ & 0.945 & $1.11(1.65)$ & 0.996 & $\begin{array}{r}-2.99 \\
(6.20)\end{array}$ & 0.627 & $-1.54(1.54)$ & 0.330 & 49 \\
\hline$\Delta \mathrm{WET}^{++}$ & $6.07(1.46)$ & 0.215 & $5.57(1.61)$ & 0.109 & $\begin{array}{r}-4.10 \\
(1.71)\end{array}$ & 0.113 & $-0.60(0.72)$ & 0.290 & 102 \\
\hline FOR & $43.11(1.35)$ & - & $33.82(1.67)$ & - & $9.86(0.24)$ & & $13.30(0.45)$ & & \\
\hline$\Delta \mathrm{FOR}^{+}$ & $-0.89(2.98)$ & 0.718 & $1.90(3.48)$ & 0.664 & $\begin{array}{r}-0.04 \\
(0.75)\end{array}$ & 0.926 & $0.71(1.08)$ & 0.604 & 189 \\
\hline$\Delta \mathrm{FOR}^{++}$ & $3.83(1.10)$ & 0.765 & $3.39(2.03)$ & 0.367 & $0.59(0.52)$ & 0.927 & $0.08(0.65)$ & 0.651 & 52 \\
\hline CRloam & $6.61(0.18)$ & - & $6.18(0.32)$ & - & $1.66(0.10)$ & & $4.18(0.33)$ & & \\
\hline$\Delta$ CRloam $^{+}$ & $0.54(0.38)$ & 0.658 & $0.08(0.38)$ & 0.888 & $\begin{array}{r}-0.11 \\
(0.09)\end{array}$ & 0.184 & $-0.21(0.31)$ & 0.485 & 36 \\
\hline$\Delta$ CRloam $^{++}$ & $4.34(0.50)$ & 0.225 & $1.31(0.33)$ & 0.632 & $0.48(0.12)$ & 0.664 & $0.21(0.26)$ & 0.501 & 95 \\
\hline CRsand & $2.54(0.11)$ & - & $2.87(0.12)$ & - & $0.65(0.04)$ & & $0.59(0.01)$ & & \\
\hline$\Delta$ CRsand $^{+}$ & $0.51(0.12)$ & 0.153 & $0.06(0.25)$ & 0.618 & $0.10(0.10)$ & 0.341 & $0.08(0.02)$ & 0.330 & 90 \\
\hline$\Delta$ CRsand $^{++}$ & $3.23(0.70)$ & 0.649 & $1.84(0.36)$ & 0.08 & $0.63(0.03)$ & 0.068 & $0.64(0.01)$ & 0.009 & 95 \\
\hline $\mathrm{CON}$ & $0.14(0.01)$ & - & $0.14(0.02)$ & - & $0.06(0.02)$ & - & $0.04(0.02)$ & - & \\
\hline$\Delta \mathrm{CON}^{+}$ & $0.35(0.01)$ & - & $0.14(0.04)$ & - & $0.04(0.04)$ & - & $0.05(0.04)$ & & 70 \\
\hline$\Delta \mathrm{CON}^{++}$ & $3.45(0.16)$ & - & $1.12(0.05)$ & - & $0.53(0.06)$ & - & $0.42(0.03)$ & & 83 \\
\hline
\end{tabular}

$\Delta$ : difference between the sample and the corresponding control $\left(\mathrm{CON}^{+}, \mathrm{CON}^{++}\right) ;{ }^{+}$: spike at low rate; ${ }^{++}$spike at high rate; WET: wetland; FOR: forest soil; $\mathrm{CR}_{\text {loam}}$ : loamy cropland soil; $\mathrm{CR}_{\text {sand }}$ : sandy cropland soil; $\mathrm{CON}$ : control with quartz sand; $p$-values indicate the probability that $\Delta$ sample is not different from the corresponding $\triangle \mathrm{CON}$. 
Table IV.4 Organic carbon concentrations in thermal fractions of four soil samples and changes in the concentrations as compared to the unspiked sample after wood char spiking. Mean values and standard errors $(\mathrm{n}=3)$.

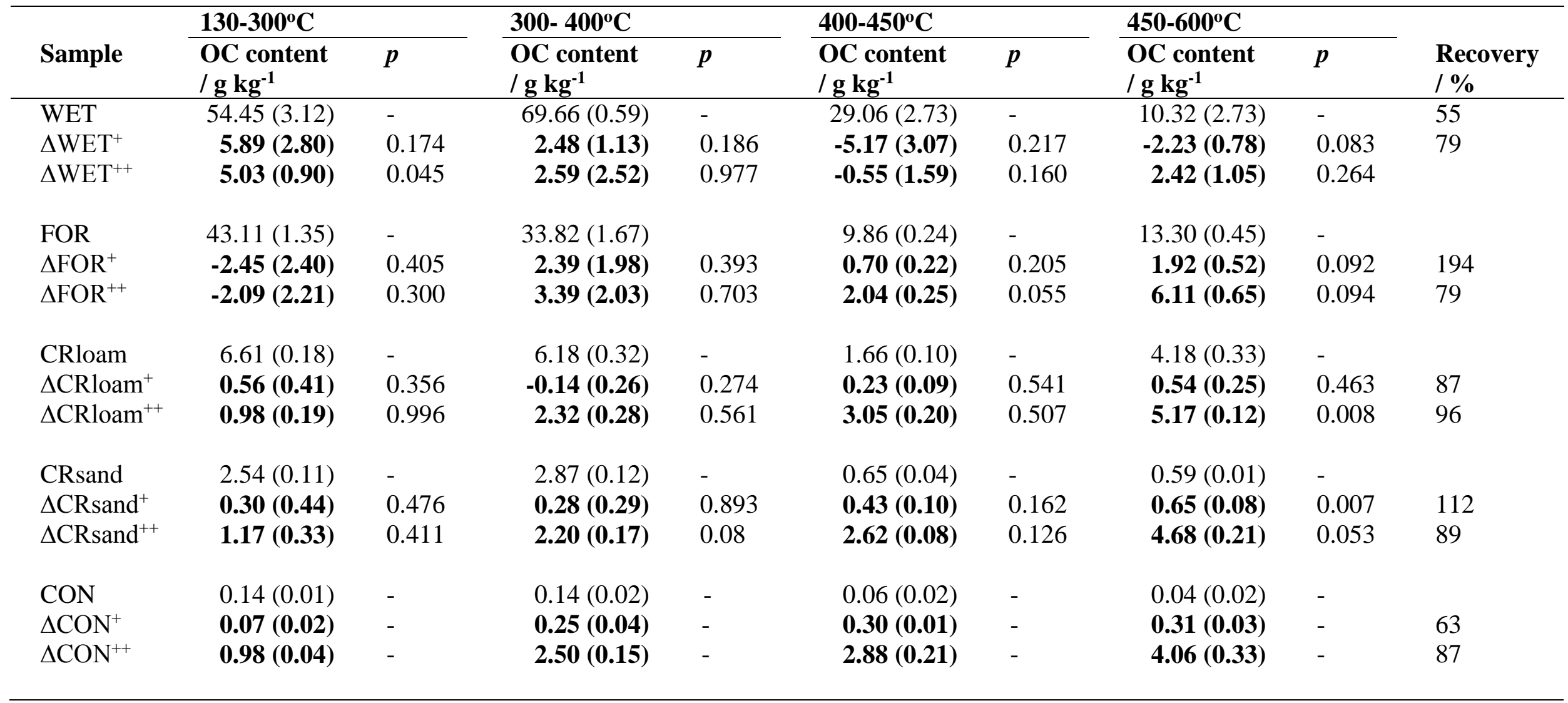

$\Delta$ : difference between the sample and the corresponding control $\left(\mathrm{CON}^{+}, \mathrm{CON}^{++}\right) ;{ }^{+}$: spike at low rate; ${ }^{++}$spike at high rate; WET: wetland; FOR: forest soil; $\mathrm{CR}_{\text {loam: }}$ loamy cropland soil; $\mathrm{CR}_{\text {sand: }}$ sandy cropland soil; $\mathrm{CON}$ : control with quartz sand; $p$-values indicate the probability that $\Delta$ sample is not different from the corresponding $\triangle \mathrm{CON}$ 
In most samples (Table IV.3 and IV.4), the distribution of both starch and wood char among thermal fractions in soil samples did not differ significantly from the distribution in the control (CON). The only significant differences were found for the starch spike, at $\mathrm{C}_{300-400}$ and $\mathrm{C}_{450-600}$ concentrations of $\Delta \mathrm{CR}_{\text {sand }}{ }^{++}$. However, this may be attributed to the higher recovery in $\Delta \mathrm{CR}_{\text {sand }}{ }^{++}(95 \%)$ as compared to $\Delta \mathrm{CON}^{++}(83 \%)$. The standard deviations of the different thermal fractions for the spiked FOR and WET samples were very high (Table IV.3 and IV.4). This led to unsatisfying (although not significant) deviations of the mean from the reference values, especially for $\triangle \mathrm{WET}$ (starch and char) and for $\triangle \mathrm{FOR}$ (mainly char). One reason maybe that the baseline between the thermal fractions was not reached due to high C-concentrations. This could be overcome by increasing the hold-times (Table IV.1), but increasing the ramp may lead to incomplete combustion of labile OC, as reported by Roth et al. (2012). In conclusion, the standard additions showed, that highly labile and more stable (starch and wood char) materials could be well quantified in loamy and sandy cropland soils.

\section{IV.4.3 Methodological comparison}

Selected fractions of the ThG method were compared to established methods. It was shown that hot water extractable $\mathrm{C}$ is mainly composed of carbohydrates and microbial residue (Leinweber et al. 1995; von Lützow et al. 2007) and it was often used to measure labile C in soils. The correlation between HWC and the $\mathrm{C}_{140-300}$ fraction was highly significant $(\mathrm{p}<$ 0.001 , Fig. IV.3). The correlation between $\mathrm{C}_{140-300}$ and $\mathrm{HWC}$ was very good $(\mathrm{r}=0.885, \log$ $\log$ transformed data). The recovery of, theoretically well bioavailable, starch (Table IV.5) in HWC was very low. 
Table IV.5 Mean concentrations (with standard errors, $n=3$ ) of hot water extractable carbon (with starch spike) and oxidisable carbon (with wood char spike) including the respective recovery rates. The letters indicate differences at a level of significance of $p \leq 0.05$ and are entered for convenience. Results of the ANOVA are given in the supporting information.

\begin{tabular}{|c|c|c|c|c|c|c|}
\hline \multirow[t]{2}{*}{ Sample } & \multicolumn{3}{|c|}{$\begin{array}{l}\text { Hot water extraction \& starch } \\
\text { spike }\end{array}$} & \multicolumn{3}{|c|}{$\begin{array}{l}\text { Wet oxidation \& wood char } \\
\text { spike }\end{array}$} \\
\hline & $\begin{array}{l}\text { HWC } \\
/ \mathrm{g} \mathrm{kg}^{-1}\end{array}$ & $\begin{array}{l}\Delta \mathrm{HWC} \\
/ \mathrm{g} \mathrm{kg}^{-1}\end{array}$ & $\begin{array}{l}\text { Recovery } \\
/ \%\end{array}$ & $\begin{array}{l}\text { Cox } \\
/ \mathbf{g ~ k g}^{-1}\end{array}$ & $\begin{array}{l}\Delta \operatorname{Cox}^{-} \\
/ \mathrm{g} \mathrm{kg}^{-}\end{array}$ & $\begin{array}{l}\text { Recovery } \\
/ \%\end{array}$ \\
\hline WET & $1.92(0.04)^{\mathrm{a}}$ & & & $3.40(0.11)^{\mathrm{a}}$ & & \\
\hline $\mathrm{WET}^{+}$ & $2.25(0.06)^{b}$ & 0.33 & 40 & $3.72(0.09)^{\mathrm{a}}$ & 0.32 & 22 \\
\hline $\mathrm{WET}^{++}$ & $4.04(0.14)^{\mathrm{c}}$ & 2.12 & 32 & $4.78(0.21)^{\mathrm{b}}$ & 1.37 & 12 \\
\hline FOR & $5.75(0.08)^{\mathrm{a}}$ & & & $3.49(0.12)^{\mathrm{a}}$ & & \\
\hline $\mathrm{FOR}^{+}$ & $6.24(0.90)^{\mathrm{b}}$ & 0.49 & 59 & $3.69(0.18)^{\mathrm{a}}$ & 0.20 & 13 \\
\hline $\mathrm{FOR}^{++}$ & $6.99(0.09)^{\mathrm{c}}$ & 1.24 & 19 & $5.76(0.60)^{\mathrm{b}}$ & 2.27 & 19 \\
\hline $\mathrm{CR}_{\text {loam }}$ & $0.65(0.05)^{\mathrm{a}}$ & & & $3.25(0.07)^{\mathrm{a}}$ & & \\
\hline $\mathrm{CR}_{\text {loam }}{ }^{+}$ & $0.87(0.07)^{\mathrm{a}}$ & 0.22 & 27 & $3.81(0.11)^{\mathrm{a}}$ & 0.55 & 38 \\
\hline $\mathrm{CR}_{\text {loam }}{ }^{++}$ & $1.57(0.13)^{b}$ & 0.92 & 14 & $7.35(0.68)^{\mathrm{b}}$ & 4.10 & 35 \\
\hline $\mathrm{CR}_{\text {sand }}$ & $0.50(0.00)^{\mathrm{a}}$ & & & $2.46(0.07)^{\mathrm{a}}$ & & \\
\hline $\mathrm{CR}_{\text {sand }}{ }^{+}$ & $0.57(0.01)^{\mathrm{b}}$ & 0.07 & 9 & $2.70(0.28)^{\mathrm{a}}$ & 0.24 & 16 \\
\hline $\mathrm{CR}_{\text {sand }}{ }^{++}$ & $1.01(0.03)^{\mathrm{c}}$ & 0.51 & 8 & $2.74(0.14)^{\mathrm{a}}$ & 0.28 & 2 \\
\hline $\mathrm{CON}$ & $0.09(0.02)^{\mathrm{a}}$ & & & $1.90(0.07)^{\mathrm{a}}$ & & \\
\hline $\mathrm{CON}^{+}$ & $0.23(0.02)^{b}$ & 0.14 & 17 & $2.20(0.03)^{b}$ & 0.30 & 19 \\
\hline $\mathrm{CON}^{++}$ & $0.26(0.02)^{\mathrm{b}}$ & 0.18 & 3 & $2.71(0.16)^{\mathrm{c}}$ & 0.81 & 7 \\
\hline
\end{tabular}

$\Delta$ : difference between the spiked sample and the control; ${ }^{+}$: spike at low rate; ${ }^{++}$spike at high

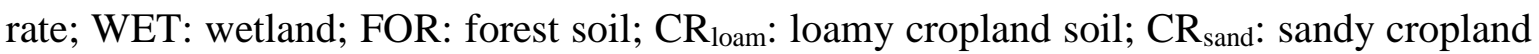
soil; CON: control with quartz sand.

Recovery rates ranged from only 3 to $59 \%$ and were lower for a high rate of spiking. Therefore, the measure of HWC may not always be well suited to indicate labile C. Moreover, the recovery of starch depended on the matrix: it was markedly higher in the loamy and wetland soils (WET, FOR, $\mathrm{CR}_{\text {loam}}$ ) as compared to the sandy matrices (CON,

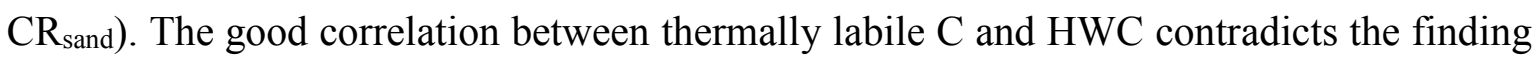
of Plante et al. (2011). They reported that HWC and indices for thermo-labile C were not well correlated. However, thermally labile SOM was defined as mass loss at temperatures < $400^{\circ} \mathrm{C}$, which may well explain the contradictory findings. Our method offers the advantage of (1) direct $\mathrm{CO}_{2}$ measurements, instead of mass loss and (2) a better resolution due to temperature ramps. Overall, the comparison of $\mathrm{C}_{140-300}$ with hot water extractable carbon strongly indicates the suitability of ThG to measure labile C. 

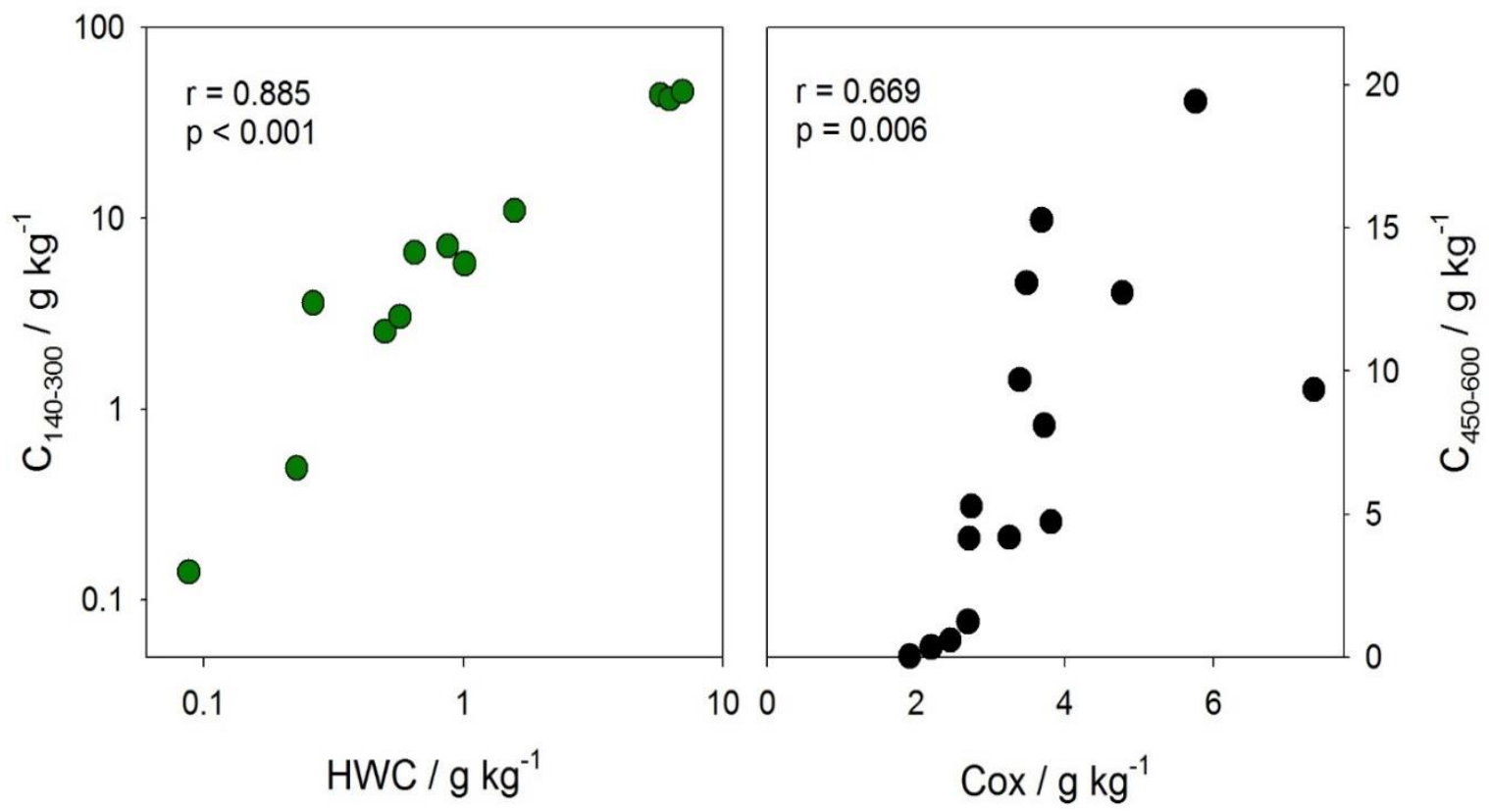

Fig. IV.3 Scatter plots of spiked samples for comparison of (left) labile carbon evolved between 140 and $300^{\circ} \mathrm{C}\left(\mathrm{C}_{140-300}\right)$ and hot water extractable carbon (HWC) and (right) stable carbon evolved between 450 and $600^{\circ} \mathrm{C}\left(\mathrm{C}_{450-600}\right)$ and wet oxidation resistant carbon $\left(\mathrm{C}_{\mathrm{OX}}\right)$.

A wet oxidation by $\mathrm{Na}_{2} \mathrm{~S}_{2} \mathrm{O}_{8}$ was performed as a measure for the stable SOC fraction. The relationship of the oxidation residue $\left(\mathrm{C}_{\mathrm{ox}}\right)$ with the $\mathrm{C}_{450-600}$ fraction was quite good $(\mathrm{r}=$ 0.669). That large amounts of wood char were oxidised (recovery after oxidation: $2-38 \%$ ) is also fitting to the results of the ThG measurements. The recovery of wood char seemed to depend on the samples matrix, which was not the case for the ThG-method. Therefore, the results of the two methods are not very well comparable.

\section{IV.4.4 Examples for applications}

\section{a. Land use effects.}

These measurements are highly valuable for determining spatial variations particularly at the landscape scale where other, maybe more sophisticated methods, fail to produce such detailed $\mathrm{C}$ analyses at reasonable time. For detecting soil carbon changes in ecosystems (Schrumpf et al., 2011), which are an important measure for developing management options, information about changes of different fraction rather than solely bulk carbon measurements could be both more easy to detect and bear more ecological information (Olk \& Gregorich, 2006; Heitkamp et al., 2012). Such studies, where spatial explicit information will require large sample numbers, are in need for quick and potentially rather inexpensive methods. In the end it will be the landscape scale information that determines decision making processes (Burt \& Pinay, 2005). Therefore, a rationale use of such ThG method will probably be for studies at the landscape scale. Most established fractionation methods are 
time consuming or reveal limited information (e.g. only one or two fractions). In consequence, little information on spatial variability of SOM fractions is available (Kravchenko and Hao. 2008; Herbst et al. 2012). For example, spatial and temporal modelling of soil respiration is still challenging, because there is lack of accompanying measurements of available substrate (Ryan and Law. 2005; Herbst et al. 2012).

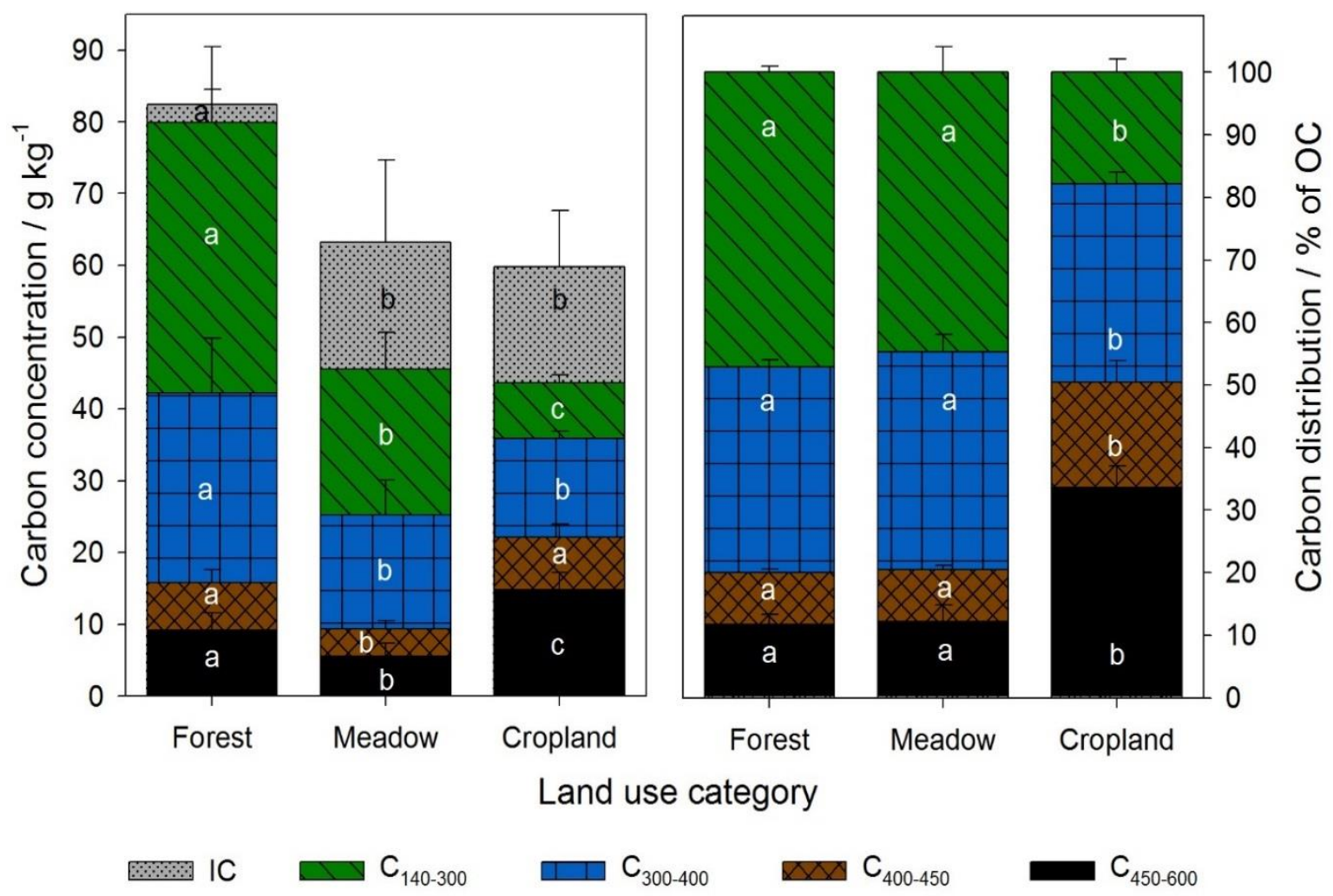

Fig. IV.4 Land use effects on soil total carbon, inorganic carbon organic carbon and its four thermal fractions. Left: absolute values, right: fractions in relation to organic carbon (mean values and standard deviations, $\mathrm{n}=9$ ). The letters indicate differences at a level of significance of $p \leq 0.05$ and are entered for convenience. Results of the ANOVA are given in the supporting information.

In this context, we present a small set of results from different land use (forest, meadow and cropland on loamy soils near Göttingen, Germany; sample set 3, Figure IV.4). According to Guo and Gifford (2002) SOC stocks declined on a global average of $42 \%$ when natural forests were converted to cropland. The organic carbon concentration differ in a very similar magnitude between the forest and the agricultural sites represented by meadow and cropland (Figure IV.4). The significant differences in the topsoil to forest topsoil are for $\mathrm{C}_{140-300} 17.5$ and $30.0 \mathrm{~g} \mathrm{~kg}^{-1}$ and for $\mathrm{C}_{300-400} 10.5$ and $12.6 \mathrm{~g} \mathrm{~kg}^{-1}$ for meadow and cropland, respectively. A step forward are the results showing the differences in the relative distribution of carbon among fractions between the land use types (Figure IV.4). Despite the differences in bulk 
SOC do forest and meadow reveal a similar distribution of the organic carbon fractions, while in cropland there was a strong and significant shift towards more stable fractions (Figure IV.4 right side). Depletion of labile C and relative enrichment of stable C by cropland cultivation is likely part of the explanation. Moreover, extensive grasslands received no fertiliser, whereas the cropland was fertilised with organic manures, which has the effect to increase amounts of thermo-stable carbon, as was demonstrated by this study (Table IV.6). In any case, this small example of comparing different land use within a region according to their soil organic carbon fractions demonstrates how much more information can be withdrawn from a thermal gradient method in comparison to regular bulk $\mathrm{C}$ measurement.

b. Management effects in density fractions.

Different composition and turnover times of carbon between different density fractions were often reported and are well known (Baldock and Skjemstad, 2000; von Lützow et al. 2007). Differences in the composition of organic matter within one fraction induced by different management or vegetation (e.g. farmyard manure and straw; litter of coniferous and broadleaf species) are often too subtle to be significant (Randall et al. 1995; Heitkamp et al. 2011). These findings fit well to our results for the light fraction, where neither fertiliser type (farmyard manure vs. mineral fertiliser) nor rate $\left(50\right.$ and $150 \mathrm{~kg} \mathrm{~N} \mathrm{ha}^{-1}$ with manure or mineral fertiliser) had significant effects on distribution of OC among thermal fractions (Table IV.6). For the heavy fraction however, the ThG method revealed significantly smaller proportions of $\mathrm{C}_{140-300}$, a trend to higher proportions in the $\mathrm{C}_{300-400}$ as well as significantly higher proportions in the $\mathrm{C}_{450-600}$ fraction in soils receiving farmyard manure as compared to those receiving mineral fertiliser and straw (i.e., different types of fertiliser). This fits to the results of Heitkamp et al. (2009) who showed for the same site that fertilisation with farmyard manure increased the intermediate $\mathrm{C}$ pool. By using differential scanning calorimetry, Leifeld et al. (2006) showed that SOM depletion in cropland soils (no fertiliser, $\mathrm{N}$-fertiliser, manure) led to higher proportions of thermo-stable SOM. From our analysis, we argue that such pattern can result either from a depletion of $\mathrm{C}$ from the light fraction, which was shown to be more thermo-labile and is depleted faster than heavy fraction $\mathrm{C}$ (Christensen. 2001), or from the application of farmyard manure, which seem to increase thermal stability of $\mathrm{C}$ in the heavy fraction (Table IV.6) or potentially both. 
Table IV.6 Thermal characterisation of light $\left(\rho \leq 2.0 \mathrm{~g} \mathrm{~cm}^{-3}\right)$ and heavy $\left(\rho>2.0 \mathrm{~g} \mathrm{~cm}^{-3}\right)$ fractions of soil samples from sites with different fertilisation history. Means of four field replicates with standard deviations in brackets (upper part of the table). The lower part of the table presents the $p$-values obtained by the mixed model (factors Type, Rate and their interaction) and the t-test (comparison between light and heavy fractions).

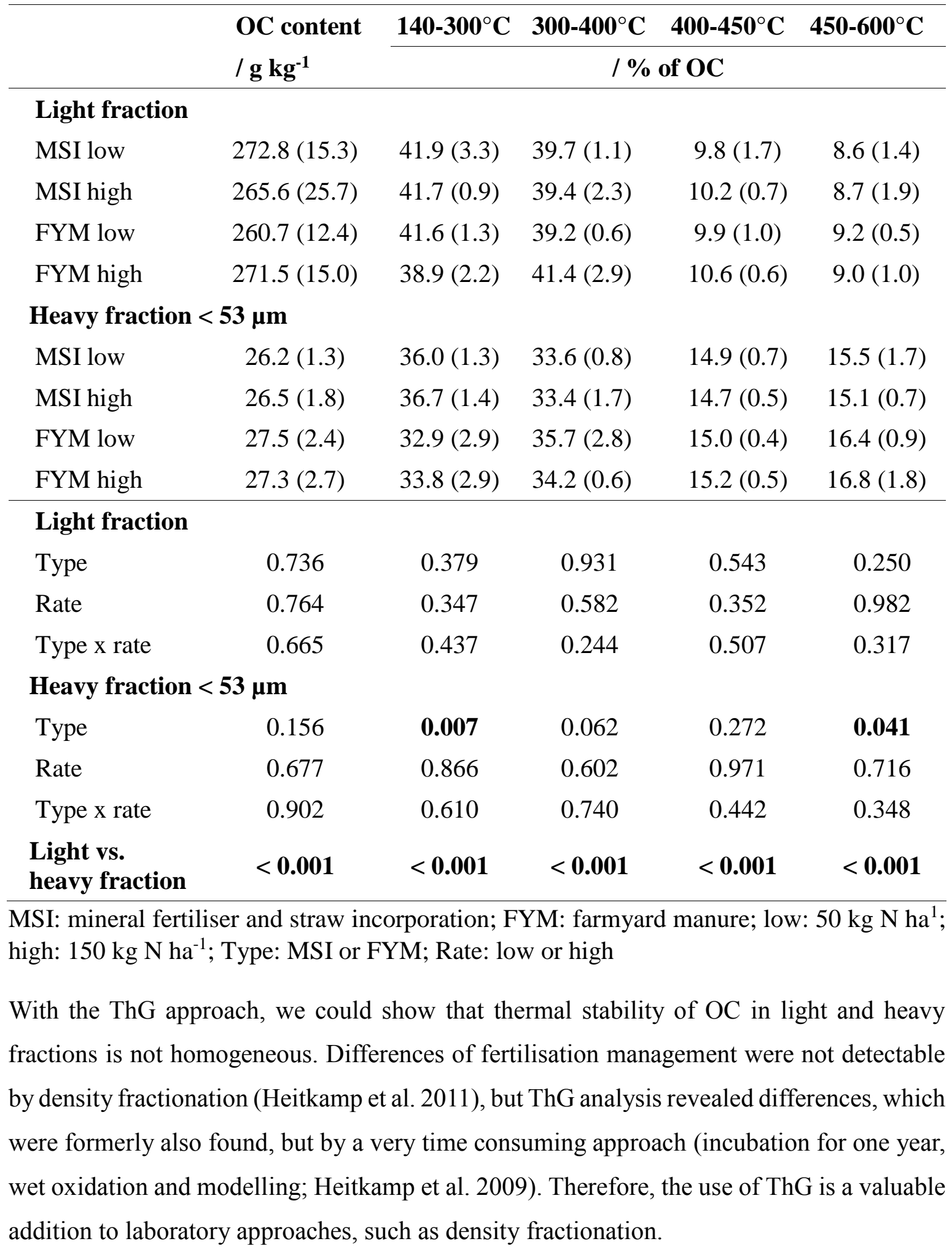




\section{IV.5 Conclusions}

It was demonstrated that ThG can constantly identify four organic carbon fractions in a highly diverse set of soil and artificial samples at an adequate precision and without the need of applying different methods. It appears likely that these thermally differently stable carbon fractions are mirroring ecologically differently stable organic carbon fractions and it is proposed to term them labile, intermediate labile, intermediate stable and stable soil organic carbon fractions. Separation of fractions in one single analytical run for one specific soil sample is appealing and has the potential to be a routine method in addition to bulk $\mathrm{C}$ soil measurements. The latter is realistic as the used device is a standard machine that can be bought and therefore these methods will not be restricted to specialists making their own machine. The analysis of one sample is roughly $20 \mathrm{~min}$ and other $20 \mathrm{~min}$ is needed for the next analysis (time to cool down). Consequently it is possible to analyse at least 10 samples a day, which allows for larger scaled studies at landscapes and regional scales. An autoloader can theoretically increase sample throughput to ca. 36 samples per 24 hours. Consequently much more information can be withdrawn from a thermal gradient method in comparison to regular bulk $\mathrm{C}$ measurement for comparing the effects of different land use systems or active land use changes on soil organic carbon and detect soil carbon changes with time in any given ecosystem and relationships to other biogeochemical cycles (e.g. greenhouse gas fluxes). 


\section{Acknowledgements}

Truong Xuan Vuong was supported by the German Academic Exchange Service (DAAD) and project 322 of Vietnamese Ministry of Training and Education. F. Heitkamp and H.F Jungkunst designed the experiment; V.T Xuan and A. Reimer performed setup and measurements; V.T Xuan and F. Heitkamp analysed data; V.T Xuan, F. Heitkamp and H.F Jungkunst wrote the manuscript; G. Gerold and A. Reimer contributed significantly with writing and discussions. 


\section{Supplementary Materials}

\section{Supporting information}

In this appendix, detailed information is provided to underline the validity of the used setup. For instance, the effect of (1) different heating rates (ramp), (2) sample amount and (3) of including constant temperatures for better peak-separation (holds) was tested. Moreover, detailed information on the statistical analysis are given.

\section{Ramp}

The effect of ramp speed was tested on samples of starch, Histosol, Anthrosol and loamy Cambisol from cropland (see main manuscript). Two different ramps were used, one of $12^{\circ} \mathrm{C}$ $\min ^{-1}$ and the other of $35^{\circ} \mathrm{C} \mathrm{min}^{-1}$. Heating was performed from $140^{\circ} \mathrm{C}$ to $600^{\circ} \mathrm{C}$ to include the whole range of organic carbon. The lower ramp was used because it was the longest possible analysis time and close to the most frequently applied value of $10^{\circ} \mathrm{C}$. With the ramp of $35^{\circ} \mathrm{C} \mathrm{min}-1$ it would also be possible to include the temperature range needed for inorganic carbon determination $\left(600-900^{\circ} \mathrm{C}\right)$, as well as the holds (see below). In this test, no holds were included. For the calculation of peak areas, the program PeakFit 4.12 (SeaSolve Software Inc.) was used. This was done instead of setting fixed temperature (as in the final set up), because shifts of the signal among temperature regions may occur (Fernández et al. 2011). Figure S1 shows, that the shape of the thermograms was remarkable similar. Differentiation of peaks is clearer at $35^{\circ} \mathrm{C}$ as compared to $12^{\circ} \mathrm{C}$, especially in the wetland sample (Figure S1, left side). The calculated peak areas are compared in Figure S2 (left side). Neither intercept nor slope differed significantly from 0 or 1 , respectively (Table S1). Therefore, the use of the faster ramp is well justified.

Table S.1 Statistical parameters for the relationship between the peak areas of different ramps as well as for hold and continuous ramp. Standard errors of intercept and slope are given in brackets. T-statistics show the probability (p-value) that the null-hypothesis (no difference) is accepted.

\begin{tabular}{|c|c|c|c|c|c|c|c|c|}
\hline & Intercept & Slope & \multirow[t]{2}{*}{$\mathrm{R}^{2}$} & \multirow{2}{*}{\multicolumn{2}{|c|}{$\frac{\mathrm{df} \text { Intercept }}{\mathrm{t} \text {-value }}$}} & \multicolumn{3}{|c|}{ Slope } \\
\hline & \multicolumn{2}{|c|}{ (\% of peak area) } & & & & p-value & t-value & p-value \\
\hline $12^{\circ} \mathrm{C} v s .35^{\circ} \mathrm{C}$ ramp & $0.15(3.15)$ & $0.996(0.094)$ & 0.90 & 12 & 0.05 & 0.961 & 0.04 & 0.969 \\
\hline $\begin{array}{l}\text { Continuous } \\
\text { ramp vs. hold }\end{array}$ & $-1.40(1.14)$ & $1.081(0.042)$ & 0.95 & 30 & 1.22 & 0.232 & 1.90 & 0.067 \\
\hline
\end{tabular}




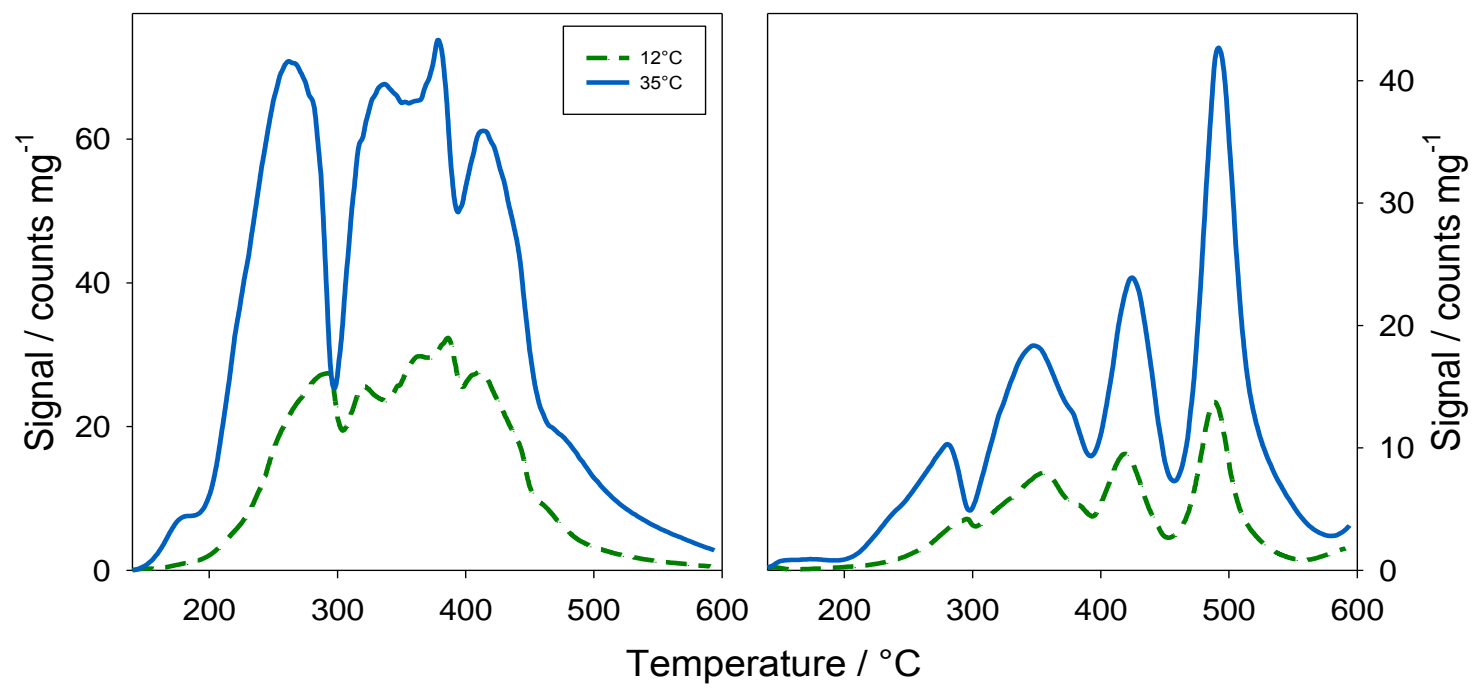

Fig. S1 Examples for thermograms recorded with different ramps $\left(12^{\circ} \mathrm{C} \mathrm{min}^{-1}\right.$ : dashed line; $35^{\circ} \mathrm{C} \mathrm{min}{ }^{-1}$ : solid line). Left side: Histosol, right side: Anthrosol. Note that temperature is on the $\mathrm{x}$-axis, whereas time is on the $\mathrm{x}$-axis in the main manuscript.
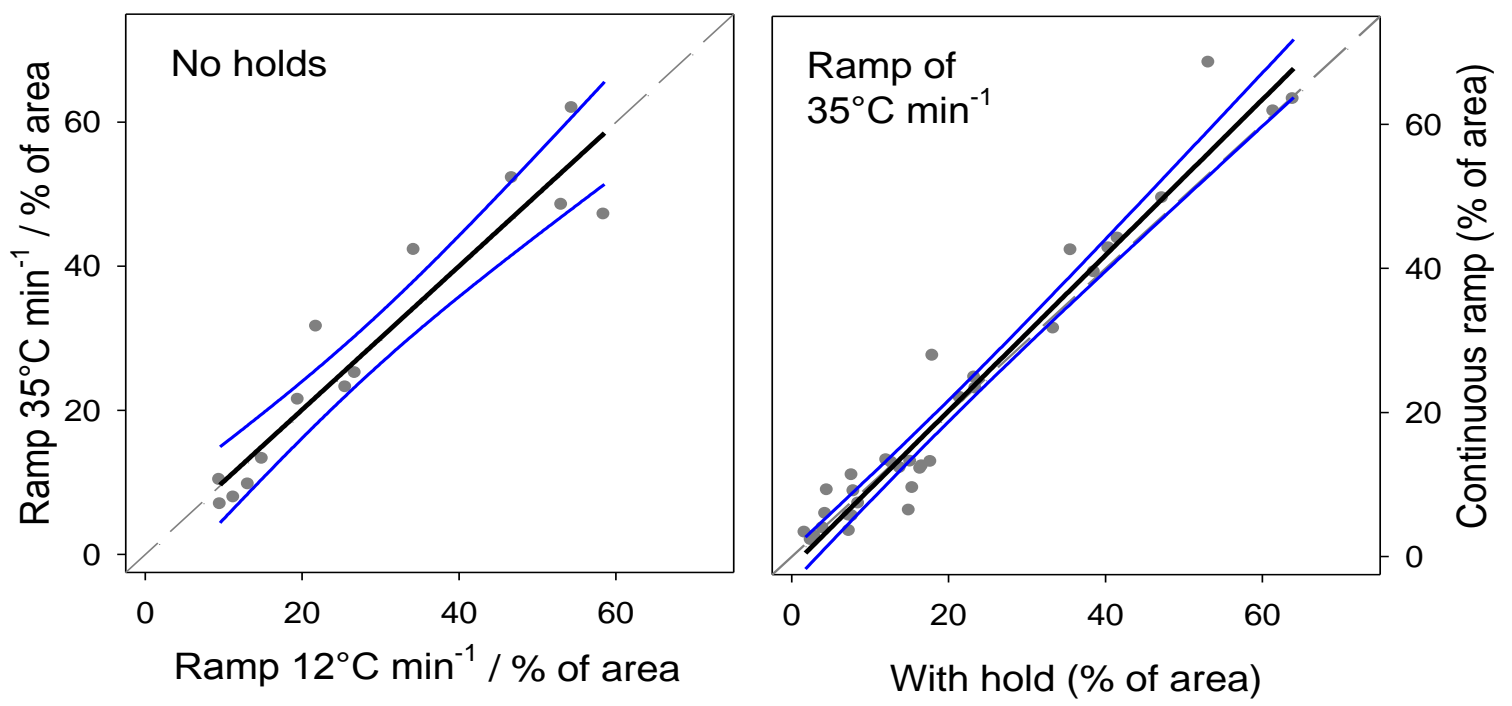

Fig. S2 Relationships between the peak areas of different ramps (left) as well as of hold and continuous ramp (right). Comparison of different ramps without hold and comparison of hold and continuous ramp at $35^{\circ} \mathrm{C} \mathrm{min}^{-1}$. The $1: 1$ line is dashed and $95 \%$ confidence intervals are visualized. 
Table S2 Statistical parameters for the relationship between the sample weight and measured concentrations for the Histosol and Anthrosol. Measurements with holds and a ramp of $35^{\circ} \mathrm{C}$ $\min ^{-1}$. Standard errors of intercept and slope are given in brackets.

\begin{tabular}{|c|c|c|c|c|c|c|c|c|}
\hline & \multicolumn{4}{|l|}{ Histosol } & \multicolumn{4}{|l|}{ Anthrosol } \\
\hline & $\frac{\text { Intercept }}{\left(\mathrm{g} \mathrm{kg}^{-1}\right)}$ & Slope & $\mathrm{R}^{2}$ & $\mathrm{p}$ & $\frac{\text { Intercept }}{\left(\mathrm{g} \mathrm{kg}^{-1}\right)}$ & Slope & $\mathrm{R}^{2}$ & $\mathrm{p}$ \\
\hline \multicolumn{9}{|c|}{$10-40 \mathrm{mg}(\mathrm{df}=9)$} \\
\hline Total C & $175.1(1.3)$ & $\mathbf{- 0 . 4 5}(0.05)$ & 0.94 & $<0.001$ & $63.2(0.9)$ & $0.03(0.04)$ & 0.07 & 0.466 \\
\hline $140-300^{\circ} \mathrm{C}$ & $60.7(1.0)$ & $\mathbf{- 0 . 1 2}(0.04)$ & 0.45 & 0.017 & $7.7(0.4)$ & $\begin{array}{r}-0.01 \\
(0.02)\end{array}$ & 0.04 & 0.594 \\
\hline $300-400^{\circ} \mathrm{C}$ & $76.1(0.7)$ & $\mathbf{- 0 . 3 3}(0.03)$ & 0.93 & $<0.0$ & $16.5(0.2)$ & $\begin{array}{r}-0.02 \\
(0.01)\end{array}$ & 0.19 & 0.214 \\
\hline $400-450^{\circ} \mathrm{C}$ & $28.3(1.1)$ & $-0.02(0.04)$ & 0.01 & 0.731 & $8.9(0.2)$ & $0.00(0.01)$ & 0.00 & 0.865 \\
\hline $450-600^{\circ} \mathrm{C}$ & $9.3(0.4)$ & $0.01(0.02)$ & 0.04 & 0.529 & $17.3(0.2)$ & $\begin{array}{r}\mathbf{- 0 . 0 5} \\
(0.03)\end{array}$ & 0.79 & 0.001 \\
\hline \multicolumn{9}{|c|}{$10-20 \mathrm{mg}(\mathrm{df}=5)$} \\
\hline Total C & $168.0(0.6)$ & $0.04(0.04)$ & 0.16 & 0.426 & $65.1(0.8)$ & $\begin{array}{r}-0.09 \\
(0.05)\end{array}$ & 0.43 & 0.158 \\
\hline $140-300^{\circ} \mathrm{C}$ & $61.0(2.6)$ & $-0.15(0.16)$ & 0.17 & 0.417 & $8.3(0.4)$ & $\begin{array}{r}-0.05 \\
(0.03)\end{array}$ & 0.56 & 0.088 \\
\hline $300-400^{\circ} \mathrm{C}$ & $73.8(1.5)$ & $-0.16(0.10)$ & 0.40 & 9 & 16.5( & $\begin{array}{r}-0.01 \\
(0.02)\end{array}$ & 0.07 & 0.613 \\
\hline $400-450^{\circ} \mathrm{C}$ & $25.6(1.6)$ & $0.17(0.10)$ & 0.42 & 0.168 & $8.5(0.4)$ & $0.03(0.02)$ & 0.29 & 0.272 \\
\hline $450-600^{\circ} \mathrm{C}$ & $7.5(0.6)$ & $\mathbf{0 . 1 4}(0.04)$ & 0.80 & 0.016 & $17.6(0.6)$ & $\begin{array}{r}-0.07 \\
(0.04) \\
\end{array}$ & 0.45 & 0.146 \\
\hline
\end{tabular}

Df: degrees of freedom

\section{Holds}

When examining a large sample set, it was apparent that peaks were distributed very similar across repeating temperature ranges for all samples. This finding was recently mechanistically explained by Demyan et al. (2013), who could show, that the given temperature ranges could be assigned to certain functional groups. The outcome of peakfitting procedures to assign fractions of organic carbon depends strongly on parameter settings. To (1) overcome this problem, (2) to make a more wide-spread application possible (i.e. for researchers without detailed knowledge about peak fitting) and (3) to enable a clearer separation of the peaks, we decided to introduce holds in the temperature profile. Figure S3 shows the comparison of the thermograms with hold and continuous ramp. The shapes of the thermograms were very similar, differences can mainly be attributed to a better separation of peaks. This visual impression is corroborated by results shown in Figure S2 (right side). Intercept and slope of the relationship did not differ significantly from 0 and 1 , respectively (Table $\mathrm{S} 1)$. There was a trend for the slope to differ from $1(\mathrm{p}=0.067)$. This trend, however, can largely be attributed to a single $\mathrm{x}-\mathrm{y}$ pair, representing data of the first 
peak of starch (upper left, Figure S2). Deleting this single data pair changes the level of significance to $\mathrm{p}=0.38$. Problems with analyzing samples with high proportions of labile $\mathrm{C}$ are discussed in the main manuscript.

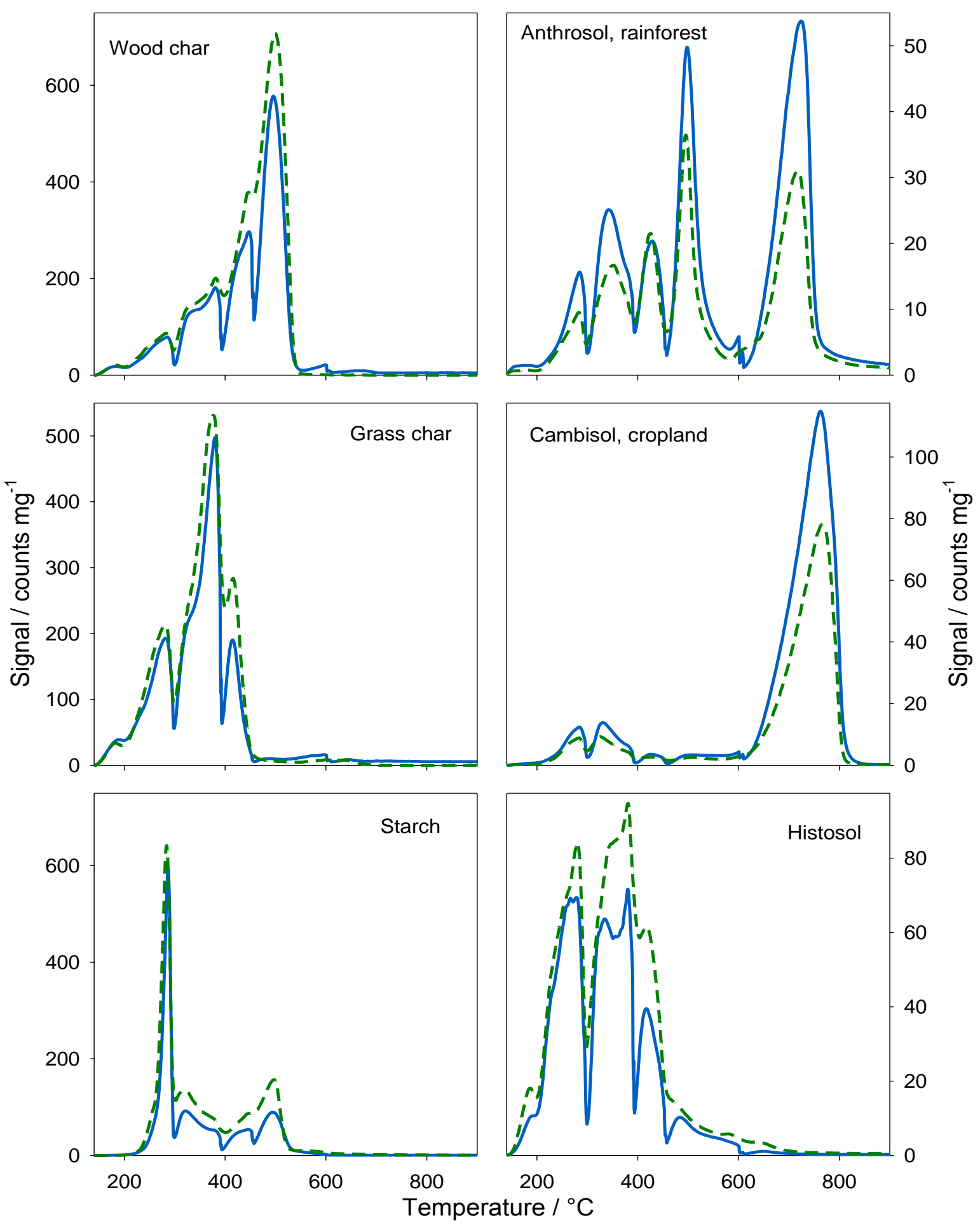

Fig. S3 Comparison of thermograms with holds (solid line) and continuous ramp (dashed line). The ramp was $35^{\circ} \mathrm{C} \mathrm{min}{ }^{-1}$. The figure is the equivalent of Figure IV.1 in the main manuscript, but temperature instead of time is used on the $\mathrm{x}$-axis. This may lead in the holdregions to apparently clinched signals. 


\section{Amount of sample}

The amount of sample material can have an effect on the outcome of thermal analysis (Fernández et al., 2011). Therefore, the effect of the sample amount was tested with the Histosol and Anthrosol with weights of 10, 15, 20, 25 and 30 and $40 \mathrm{mg}$. Figure S4 shows, that there was an effect of the amount on all fractions and total $\mathrm{C}$ in the Histosol. This can, however, be attributed to measurements close to the calibration limit. Effects were lower for the Anthrosol. Nevertheless, a significant decrease in the fraction $450-600^{\circ} \mathrm{C}$ was found (Table S2). The results shown in Figure S4 and Table S2 indicated that the amount of sample may affect the results, but the bias between 10 and $20 \mathrm{mg}$ sample weight was very low (Histosol) or not significant (Anthrosol). Therefore, the amount of 10-20 mg sample is recommended and used throughout.

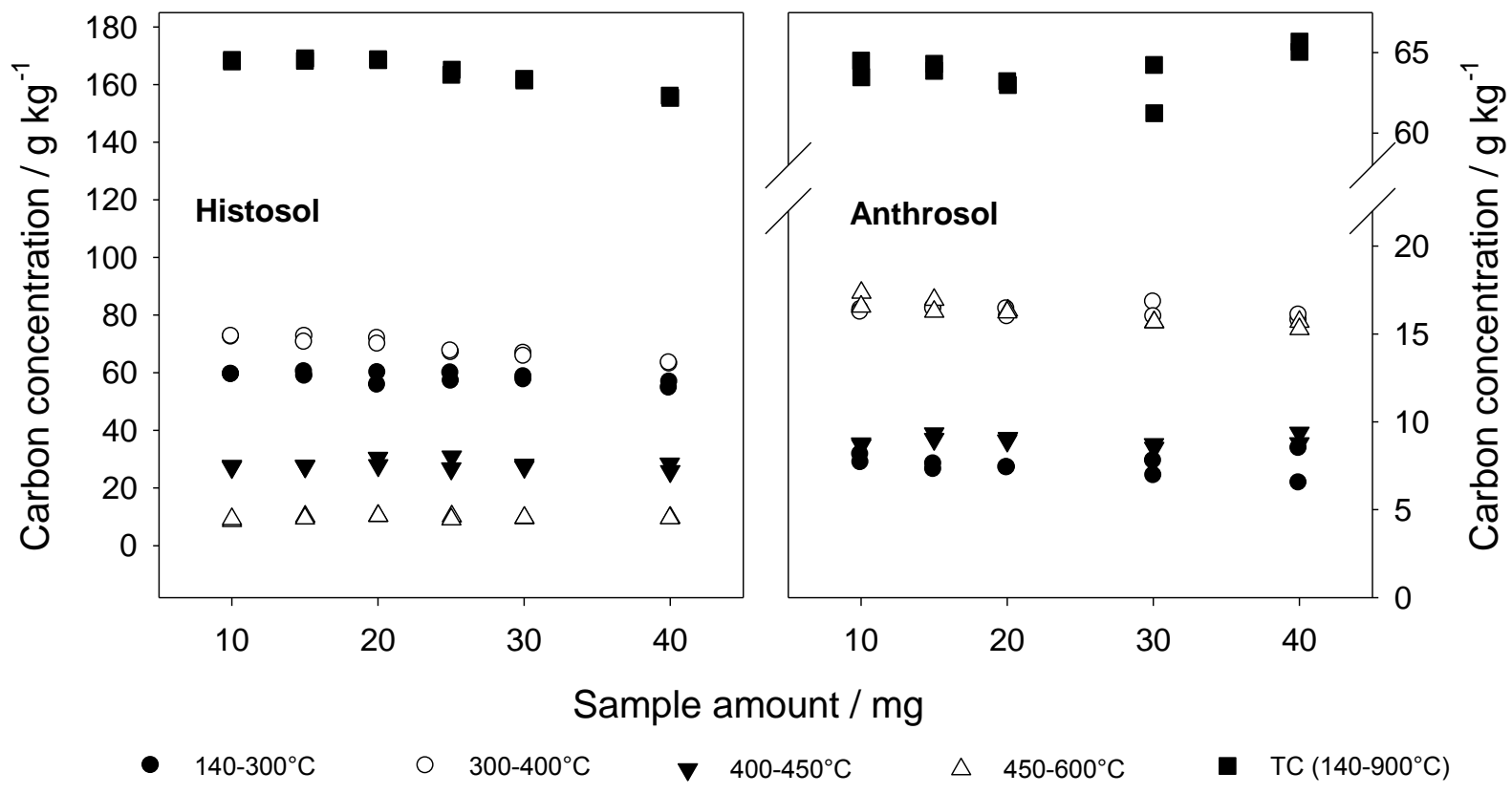

Fig. S4 Scatter plots showing results for organic carbon concentrations in different thermal fractions as well as total carbon concentrations in relation to sample amount. Analysis with hold and ramp of $35^{\circ} \mathrm{C} \mathrm{min}^{-1}$. Analysis was done in duplicate. 


\section{Supporting information for statistics}

Table S3 F- and t-statistics ( $\mathrm{n}=3,2$ degrees of freedom) for Table IV.3 of the main manuscript.

\begin{tabular}{|c|c|c|c|c|c|c|c|c|}
\hline \multirow[t]{2}{*}{ Sample } & \multicolumn{4}{|c|}{$F$-values } & \multicolumn{4}{|c|}{$t$-values } \\
\hline & $140-300^{\circ} \mathrm{C}$ & $300-400^{\circ} \mathrm{C}$ & $400-450^{\circ} \mathrm{C}$ & $450-600^{\circ} \mathrm{C}$ & $140-300^{\circ} \mathrm{C}$ & $300-400^{\circ} \mathrm{C}$ & $400-450^{\circ} \mathrm{C}$ & $450-600^{\circ} \mathrm{C}$ \\
\hline$\Delta \mathrm{WET}^{+}$ & 3934 & 3967 & 33340 & 6256 & 0.078 & 0.006 & 0.568 & 1.276 \\
\hline$\Delta \mathrm{WET}^{++}$ & 241 & 3747 & 2540 & 1357 & 1.792 & 2.770 & 2.710 & 1.425 \\
\hline$\Delta \mathrm{FOR}^{+}$ & 205588 & 27711 & 1286 & 2412 & 0.416 & 0.505 & 0.104 & 0.609 \\
\hline$\Delta \mathrm{FOR}^{++}$ & 138.6 & 7832 & 232 & 1127 & 0.341 & 1.155 & 0.103 & 0.526 \\
\hline$\Delta \mathrm{CR}_{\text {loam }}^{+}$ & 108.96 & 48.46 & 7.55 & 2.41 & 0.514 & 0.159 & 0.849 & 1.604 \\
\hline$\Delta \mathrm{CR}_{\text {loam }}^{++}$ & 18.37 & 64.21 & 3.92 & 9.97 & 1.703 & 0.560 & 0.468 & 0.815 \\
\hline$\Delta \mathrm{CR}_{\text {sand }^{+}}$ & 3305 & 334.4 & 18.03 & 196.8 & 2.258 & 0.584 & 1.078 & 1.161 \\
\hline$\Delta \mathrm{CR}_{\text {sand }^{++}}{ }^{++}$ & 28.84 & 159.3 & 11.55 & 183.57 & 0.530 & 3.378 & 2.490 & 10.49 \\
\hline
\end{tabular}

Critical $F$-value $=19$ and critical $t$-value $=4.303$ for $p=0.05$. 
Table S4 F- and t-statistics ( $\mathrm{n}=3,2$ degrees of freedom) for Table IV.4 of the main manuscript.

\begin{tabular}{|c|c|c|c|c|c|c|c|c|}
\hline \multirow[t]{2}{*}{ Sample } & \multicolumn{3}{|c|}{$F$-values } & \multirow[b]{2}{*}{$450-600^{\circ} \mathrm{C}$} & \multicolumn{3}{|c|}{$t$-values } & \multirow[b]{2}{*}{$450-600^{\circ} \mathrm{C}$} \\
\hline & $140-300^{\circ} \mathrm{C}$ & $300-400^{\circ} \mathrm{C}$ & $400-450^{\circ} \mathrm{C}$ & & $140-300^{\circ} \mathrm{C}$ & $300-400^{\circ} \mathrm{C}$ & $400-450^{\circ} \mathrm{C}$ & \\
\hline$\Delta \mathrm{WET}^{+}$ & 34898 & 1886 & 160434 & 2061 & 2.074 & 1.979 & 1.780 & 3.258 \\
\hline$\Delta \mathrm{WET}^{++}$ & 1309 & 811 & 167 & 29.98 & 4.528 & 0.033 & 2.187 & 1.535 \\
\hline$\Delta \mathrm{FOR}^{+}$ & 29318 & 5840 & 787.7 & 921.99 & 1.047 & 1.079 & 1.853 & 3.072 \\
\hline$\Delta \mathrm{FOR}^{++}$ & 7962 & 524 & 4.03 & 11.41 & 1.388 & 0.440 & 3.061 & 3.026 \\
\hline$\Delta \mathrm{CR}_{\text {loam }}{ }^{+}$ & 1716.6 & 42.11 & 61.92 & 7.78 & 1.191 & 1.492 & 0.730 & 0.901 \\
\hline$\Delta \mathrm{CR}_{\text {loam }}{ }^{++}$ & 58.14 & 1.18 & 6.65 & 2.50 & 0.006 & 0.633 & 0.728 & 4.874 \\
\hline$\Delta \mathrm{CR}_{\text {sand }^{+}}$ & 861.8 & 99.69 & 140.76 & 217.27 & 0.870 & 0.152 & 2.176 & 6.571 \\
\hline$\Delta \mathrm{CR}_{\text {sand }}{ }^{++}$ & 57.07 & 9.89 & 2.69 & 2.43 & 1.030 & 2.334 & 1.929 & 2.729 \\
\hline
\end{tabular}

Critical $F$-value $=19$ and critical $t$-value $=4.303$ for $p=0.05$. 
Table S5 Results of the one-way ANOVA calculated for the dataset of hot water extractable carbon with starch spike (Table IV.5).

\begin{tabular}{|c|c|c|c|c|c|c|}
\hline Sample & Source & $\begin{array}{l}\text { Degrees of } \\
\text { freedom }\end{array}$ & $\begin{array}{c}\text { Sum of } \\
\text { squares }\end{array}$ & $\begin{array}{l}\text { Mean } \\
\text { square }\end{array}$ & $F$-value & $p$-value \\
\hline WET & $\begin{array}{l}\text { Between group } \\
\text { Within group } \\
\text { Total }\end{array}$ & $\begin{array}{l}\mathrm{K}-1=2 \\
\mathrm{~N}-\mathrm{k}=6 \\
\mathrm{~N}-1=8\end{array}$ & $\begin{array}{l}\mathrm{SS}_{\mathrm{B}}=7.824 \\
\mathrm{SS}_{\mathrm{W}}=0.139 \\
\mathrm{SS}_{\mathrm{T}}=7.962\end{array}$ & $\begin{array}{l}\mathrm{B}=3.912 \\
\mathrm{~W}=0.023\end{array}$ & 169.264 & $<0.001$ \\
\hline FOR & $\begin{array}{l}\text { Between group } \\
\text { Within group } \\
\text { Total }\end{array}$ & $\begin{array}{l}\mathrm{K}-1=2 \\
\mathrm{~N}-\mathrm{k}=6 \\
\mathrm{~N}-1=8\end{array}$ & $\begin{array}{l}\mathrm{SS}_{\mathrm{B}}=2.327 \\
\mathrm{SS}_{\mathrm{W}}=0.134 \\
\mathrm{SS}_{\mathrm{T}}=2.461\end{array}$ & $\begin{aligned} B & =1.163 \\
W & =0.022\end{aligned}$ & 52.122 & $<0.001$ \\
\hline $\mathrm{CR}_{\text {cloam }}$ & $\begin{array}{l}\text { Between group } \\
\text { Within group } \\
\text { Total }\end{array}$ & $\begin{array}{l}\mathrm{K}-1=2 \\
\mathrm{~N}-\mathrm{k}=6 \\
\mathrm{~N}-1=8\end{array}$ & $\begin{array}{l}\mathrm{SS}_{\mathrm{B}}=1.385 \\
\mathrm{SS}_{\mathrm{W}}=0.146 \\
\mathrm{SS}_{\mathrm{T}}=1.531\end{array}$ & $\begin{array}{c}\mathrm{B}=0.692 \\
\mathrm{~W}=0.024\end{array}$ & 28.416 & 0.001 \\
\hline $\mathrm{CR}_{\text {sand }}$ & $\begin{array}{l}\text { Between group } \\
\text { Within group } \\
\text { Total }\end{array}$ & $\begin{array}{l}\mathrm{K}-1=2 \\
\mathrm{~N}-\mathrm{k}=6 \\
\mathrm{~N}-1=8\end{array}$ & $\begin{array}{l}\mathrm{SS}_{\mathrm{B}}=0.465 \\
\mathrm{SS}_{\mathrm{W}}=0.005 \\
\mathrm{SS}_{\mathrm{T}}=0.470\end{array}$ & $\begin{array}{c}\mathrm{B}=0.232 \\
\mathrm{~W}=0.001\end{array}$ & 298.900 & $<0.001$ \\
\hline $\mathrm{CON}$ & $\begin{array}{l}\text { Between group } \\
\text { Within group } \\
\text { Total }\end{array}$ & $\begin{array}{l}\mathrm{K}-1=2 \\
\mathrm{~N}-\mathrm{k}=6 \\
\mathrm{~N}-1=8\end{array}$ & $\begin{array}{l}\mathrm{SS}_{\mathrm{B}}=0.036 \\
\mathrm{SS}_{\mathrm{W}}=0.002 \\
\mathrm{SS}_{\mathrm{T}}=0.038\end{array}$ & $\begin{array}{c}\mathrm{B}=0.018 \\
\mathrm{~W}=0.001\end{array}$ & 32.147 & 0.009 \\
\hline
\end{tabular}


Table S6 Results of the one-way ANOVA calculated for the dataset of oxidisable carbon with wood char spike (Table IV.5).

\begin{tabular}{|c|c|c|c|c|c|c|}
\hline Sample & Source & Degrees of freedom & Sum of squares & $\begin{array}{l}\text { Mean } \\
\text { square }\end{array}$ & $\begin{array}{c}F- \\
\text { value }\end{array}$ & $\begin{array}{c}p- \\
\text { value }\end{array}$ \\
\hline WET & $\begin{array}{l}\text { Between group } \\
\text { Within group } \\
\text { Total }\end{array}$ & $\begin{array}{l}\mathrm{K}-1=2 \\
\mathrm{~N}-\mathrm{k}=6 \\
\mathrm{~N}-1=8\end{array}$ & $\begin{array}{l}\mathrm{SS}_{\mathrm{B}}=0.031 \\
\mathrm{SS}_{\mathrm{W}}=0.004 \\
\mathrm{SS}_{\mathrm{T}}=0.035\end{array}$ & $\begin{array}{l}\mathrm{B}=0.016 \\
\mathrm{~W}=0.001\end{array}$ & 24.905 & 0.001 \\
\hline FOR & $\begin{array}{l}\text { Between group } \\
\text { Within group } \\
\text { Total }\end{array}$ & $\begin{array}{l}\mathrm{K}-1=2 \\
\mathrm{~N}-\mathrm{k}=6 \\
\mathrm{~N}-1=8\end{array}$ & $\begin{array}{l}\mathrm{SS}_{\mathrm{B}}=0.095 \\
\mathrm{SS}_{\mathrm{W}}=0.025 \\
\mathrm{SS}_{\mathrm{T}}=0.120\end{array}$ & $\begin{array}{l}B=0.048 \\
W=0.004\end{array}$ & 11.498 & 0.009 \\
\hline $\mathrm{CR}_{\text {cloam }}$ & $\begin{array}{l}\text { Between group } \\
\text { Within group } \\
\text { Total }\end{array}$ & $\begin{array}{l}\mathrm{K}-1=2 \\
\mathrm{~N}-\mathrm{k}=6 \\
\mathrm{~N}-1=8\end{array}$ & $\begin{array}{l}\mathrm{SS}_{\mathrm{B}}=0.297 \\
\mathrm{SS}_{\mathrm{W}}=0.029 \\
\mathrm{SS}_{\mathrm{T}}=0.326\end{array}$ & $\begin{array}{l}\mathrm{B}=0.148 \\
\mathrm{~W}=0.005\end{array}$ & 31.072 & 0.001 \\
\hline $\mathrm{CR}_{\text {sand }}$ & $\begin{array}{l}\text { Between group } \\
\text { Within group } \\
\text { Total }\end{array}$ & $\begin{array}{l}\mathrm{K}-1=2 \\
\mathrm{~N}-\mathrm{k}=6 \\
\mathrm{~N}-1=8\end{array}$ & $\begin{array}{l}\mathrm{SS}_{\mathrm{B}}=0.001 \\
\mathrm{SS}_{\mathrm{W}}=0.006 \\
\mathrm{SS}_{\mathrm{T}}=0.007\end{array}$ & $\begin{array}{c}\mathrm{B}=0.001 \\
\mathrm{~W}=0.001\end{array}$ & 0.653 & 0.554 \\
\hline $\mathrm{CON}$ & $\begin{array}{l}\text { Between group } \\
\text { Within group } \\
\text { Total }\end{array}$ & $\begin{array}{l}\mathrm{K}-1=2 \\
\mathrm{~N}-\mathrm{k}=6 \\
\mathrm{~N}-1=8\end{array}$ & $\begin{array}{l}\mathrm{SS}_{\mathrm{B}}=0.010 \\
\mathrm{SS}_{\mathrm{W}}=0.002 \\
\mathrm{SS}_{\mathrm{T}}=0.012\end{array}$ & $\begin{array}{l}\mathrm{B}=0.005 \\
\mathrm{~W}=0.000\end{array}$ & 15.799 & 0.004 \\
\hline
\end{tabular}


Table S7a Results of the one-way ANOVA calculated for the dataset of absolute C-concentrations under different land-use (Figure IV.4).

\begin{tabular}{|c|c|c|c|c|c|c|}
\hline Fraction & Source & Degree of freedom & Sum of squares & Mean square & $F$-value & $p$-value \\
\hline $\mathrm{TC}$ & $\begin{array}{l}\text { Between group } \\
\text { Within group } \\
\text { Total }\end{array}$ & $\begin{array}{l}\mathrm{K}-1=2 \\
\mathrm{~N}-\mathrm{k}=24 \\
\mathrm{~N}-1=26\end{array}$ & $\begin{array}{l}\mathrm{SS}_{\mathrm{B}}=26.687 \\
\mathrm{SS}_{\mathrm{W}}=68.992 \\
\mathrm{SS}_{\mathrm{T}}=95.680\end{array}$ & $\begin{array}{l}\mathrm{B}=13.344 \\
\mathrm{~W}=2.875\end{array}$ & 4.642 & 0.020 \\
\hline $\mathrm{OC}$ & $\begin{array}{l}\text { Between group } \\
\text { Within group } \\
\text { Total }\end{array}$ & $\begin{array}{l}\mathrm{K}-1=2 \\
\mathrm{~N}-\mathrm{k}=24 \\
\mathrm{~N}-1=26\end{array}$ & $\begin{array}{l}\mathrm{SS}_{\mathrm{B}}=75.081 \\
\mathrm{SS}_{\mathrm{W}}=52.001 \\
\mathrm{SS}_{\mathrm{T}}=127.082\end{array}$ & $\begin{array}{l}B=37.541 \\
W=2.167\end{array}$ & 17.326 & $<0.001$ \\
\hline SIC & $\begin{array}{l}\text { Between group } \\
\text { Within group } \\
\text { Total }\end{array}$ & $\begin{array}{l}\mathrm{K}-1=2 \\
\mathrm{~N}-\mathrm{k}=24 \\
\mathrm{~N}-1=26\end{array}$ & $\begin{array}{l}\mathrm{SS}_{\mathrm{B}}=3130.464 \\
\mathrm{SS}_{\mathrm{W}}=2714.576 \\
\mathrm{SS}_{\mathrm{T}}=5845.040\end{array}$ & $\begin{array}{l}B=1565.232 \\
W=113.107\end{array}$ & 13.838 & $<0.001$ \\
\hline $\mathrm{C}_{140-300}$ & $\begin{array}{l}\text { Between group } \\
\text { Within group } \\
\text { Total }\end{array}$ & $\begin{array}{l}\mathrm{K}-1=2 \\
\mathrm{~N}-\mathrm{k}=24 \\
\mathrm{~N}-1=26\end{array}$ & $\begin{array}{l}\mathrm{SS}_{\mathrm{B}}=40.769 \\
\mathrm{SS}_{\mathrm{W}}=11.070 \\
\mathrm{SS}_{\mathrm{T}}=51.839\end{array}$ & $\begin{array}{l}B=20.384 \\
W=0.461\end{array}$ & 44.192 & $<0.001$ \\
\hline $\mathrm{C}_{300-400}$ & $\begin{array}{l}\text { Between group } \\
\text { Within group } \\
\text { Total }\end{array}$ & $\begin{array}{l}\mathrm{K}-1=2 \\
\mathrm{~N}-\mathrm{k}=24 \\
\mathrm{~N}-1=26\end{array}$ & $\begin{array}{l}\mathrm{SS}_{\mathrm{B}}=8.177 \\
\mathrm{SS}_{\mathrm{W}}=6.663 \\
\mathrm{SS}_{\mathrm{T}}=14.840\end{array}$ & $\begin{array}{l}\mathrm{B}=4.089 \\
\mathrm{~W}=0.278\end{array}$ & 14.727 & $<0.001$ \\
\hline $\mathrm{C}_{400-450}$ & $\begin{array}{l}\text { Between group } \\
\text { Within group } \\
\text { Total }\end{array}$ & $\begin{array}{l}\mathrm{K}-1=2 \\
\mathrm{~N}-\mathrm{k}=24 \\
\mathrm{~N}-1=26\end{array}$ & $\begin{array}{l}\mathrm{SS}_{\mathrm{B}}=0.628 \\
\mathrm{SS}_{\mathrm{W}}=0.639 \\
\mathrm{SS}_{\mathrm{T}}=1.267\end{array}$ & $\begin{array}{l}B=0.314 \\
W=0.027\end{array}$ & 11.806 & $<0.001$ \\
\hline $\mathrm{C}_{450-600}$ & $\begin{array}{l}\text { Between group } \\
\text { Within group } \\
\text { Total }\end{array}$ & $\begin{array}{l}\mathrm{K}-1=2 \\
\mathrm{~N}-\mathrm{k}=24 \\
\mathrm{~N}-1=26\end{array}$ & $\begin{array}{l}\mathrm{SS}_{\mathrm{B}}=3.864 \\
\mathrm{SS}_{\mathrm{W}}=1.182 \\
\mathrm{SS}_{\mathrm{T}}=5.046\end{array}$ & $\begin{array}{l}B=1.932 \\
W=0.049\end{array}$ & 39.238 & $<0.001$ \\
\hline
\end{tabular}


Table S7b Results of the one-way ANOVA calculated for the dataset of relative OC-concentrations under different land-use (Figure IV.4).

\begin{tabular}{|c|c|c|c|c|c|c|}
\hline Sample & Source & Degree of freedom & Sum of squares & Mean square & F value & P value \\
\hline $\mathrm{C}_{140-300}$ & $\begin{array}{l}\text { Between group } \\
\text { Within group } \\
\text { Total }\end{array}$ & $\begin{array}{l}\mathrm{K}-1=2 \\
\mathrm{~N}-\mathrm{k}=24 \\
\mathrm{~N}-1=26\end{array}$ & $\begin{array}{l}\mathrm{SS}_{\mathrm{B}}=4763.382 \\
\mathrm{SS}_{\mathrm{W}}=178.762 \\
\mathrm{SS}_{\mathrm{T}}=4942.144\end{array}$ & $\begin{array}{l}\mathrm{B}=2381.691 \\
\mathrm{~W}=7.448\end{array}$ & 319.758 & $<0.001$ \\
\hline $\mathrm{C}_{300-400}$ & $\begin{array}{l}\text { Between group } \\
\text { Within group } \\
\text { Total }\end{array}$ & $\begin{array}{l}\mathrm{K}-1=2 \\
\mathrm{~N}-\mathrm{k}=24 \\
\mathrm{~N}-1=26\end{array}$ & $\begin{array}{l}\mathrm{SS}_{\mathrm{B}}=42.103 \\
\mathrm{SS}_{\mathrm{W}}=100.727 \\
\mathrm{SS}_{\mathrm{T}}=142.829\end{array}$ & $\begin{array}{l}\mathrm{B}=21.051 \\
\mathrm{~W}=4.197\end{array}$ & 5.016 & 0.015 \\
\hline $\mathrm{C}_{400-450}$ & $\begin{array}{l}\text { Between group } \\
\text { Within group } \\
\text { Total }\end{array}$ & $\begin{array}{l}\mathrm{K}-1=2 \\
\mathrm{~N}-\mathrm{k}=24 \\
\mathrm{~N}-1=26\end{array}$ & $\begin{array}{l}\mathrm{SS}_{\mathrm{B}}=426.459 \\
\mathrm{SS}_{\mathrm{W}}=103.488 \\
\mathrm{SS}_{\mathrm{T}}=529.946\end{array}$ & $\begin{array}{l}\mathrm{B}=213.229 \\
\mathrm{~W}=4.312\end{array}$ & 49.450 & $<0.001$ \\
\hline $\mathrm{C}_{450-600}$ & $\begin{array}{l}\text { Between group } \\
\text { Within group } \\
\text { Total }\end{array}$ & $\begin{array}{l}\mathrm{K}-1=2 \\
\mathrm{~N}-\mathrm{k}=24 \\
\mathrm{~N}-1=26\end{array}$ & $\begin{array}{l}\mathrm{SS}_{\mathrm{B}}=2837.803 \\
\mathrm{SS}_{\mathrm{W}}=172.034 \\
\mathrm{SS}_{\mathrm{T}}=3009.837\end{array}$ & $\begin{array}{l}\mathrm{B}=1418.902 \\
\mathrm{~W}=7.168\end{array}$ & 197.947 & $<0.001$ \\
\hline
\end{tabular}




\section{Synthesis of Results and Outlook}

Soil carbon plays a key role in carbon cycling and climate change. It is one of the main five $\mathrm{C}$-stores of global carbon cycling, which is a key factor in retaining the balance of ecosystem C fluxes (as aforementioned in chapter I). It is also important in soil quality assessment and sustainability of agriculture. Increasing SOC will provide nutrients for soil, increase available water capacity, and improve soil structure and soil physical properties that will increase agricultural yields significantly (Lal. 2006).

Carbon modelling has been widely used for understanding soil $\mathrm{C}$ dynamic, the relation between soil $\mathrm{C}$ stock and climate change, and accessing the effect of land use and management change on soil $\mathrm{C}$ stock. Some researchers used model to explain the effect of temperature changes on soil organic carbon amounts (Schimel et al. 1990; Kirschbaum 1993), humus balance (Brock et al. 2012) and soil respiration (Ryan and Law. 2005). Knowledge of humification and mineralization processes in different soil types is essential for carbon modelling. Besides, soil organic carbon contains two major components that are the inert or recalcitrant carbon fraction and the labile or active carbon fraction. When inert carbon fraction depends on climate, soil type and land-use history; labile OC fraction is dependent on management and has a strong relation with soil quality. Since labile organic carbon fraction is decomposed rapidly, therefore, changes in land use and management induce changes in labile OC fraction significantly (Lal. 2006). Knowledge of soil fractions and the amount of labile soil fraction (fast pool) is necessary to analyze natural or human induced changes in humus horizons. Consequently, it is necessary to find a suitable method that is precise, economic and possible to measure and isolate SOM fractions.

In this study, we used different sets of soil sample and artificial materials, specific methods to analyze SOM fractions. The results showed that ThG has potential in quantifying and separating SOM fractions. Main task of this research was to prove the suitability of ThG for quantifying TC, OC, IC and separating OC fractions. Here are the conclusions:

\section{V.1 ThG: direct method for soil carbon characterization:}

\section{V.1.1 Advantages}

i ThG is a simple method that does not need complicated pretreatments for carbonate, noncarbonated and dolomite soil samples in determining TC, IC and OC. Besides, ThG is a precise method compared to other standard methods (Dry 
combustion, Calcimeter, Acidification and Loss on Ignition) in quantifying TC, IC and OC in carbonate, non-carbonate and dolomite soils.

ii Hot water extraction can separate only LC fraction and wet oxidation can isolate SC fraction. Our results demonstrated that ThG can constantly identify four organic carbon fractions (labile, intermediate labile, intermediate stable and stable carbon fractions at $140-300^{\circ} \mathrm{C}, 300-390^{\circ} \mathrm{C}, 390-450^{\circ} \mathrm{C}$ and $450-600^{\circ} \mathrm{C}$, respectively) in a highly diverse set of soil and artificial samples at an adequate precision and without the need of applying different methods. It appears that these thermally differently stable carbon fractions are mirroring ecologically differently organic carbon fractions. For instance, the wetland soil sample with high labile carbon, ThG showed that the wetland sample has very high peaks at the temperature range of $140-300^{\circ} \mathrm{C}$ and $300-390^{\circ} \mathrm{C}$ (labile and intermediate labile OC). Wood char that is more thermally stable than normal soil has a low peak at the range of $140-300^{\circ} \mathrm{C}$, but has high peaks at the ranges of $390-450^{\circ}$ and $450-600^{\circ} \mathrm{C}$ (intermediate stable and stable OC). Therefore, these thermally differently stable carbon fractions of ThG can be used to identify labile, intermediate labile, intermediate stable and stable soil organic carbon fractions.

iii ThG is a precise and economic method that can analyze many soil samples without complicated pretreatment. It can separate SOC fractions in one single analytical run for one specific soil sample that is appealing and has the potential to be a routine method in addition to bulk-C soil measurements. Moreover, ThG can provide not only information of TC, OC, and IC values and SOC fractions concurrently, but also information of decomposed temperature range of SOM and the shift of peaks of decomposed LC and SC of different samples. Therefore, much more information can be obtained from ThG method in comparison to regular bulk $\mathrm{C}$ measurement for comparing the effects of different land use systems or active land use changes on soil organic carbon and detect soil carbon changes with time in any given ecosystem and relationships to other biogeochemical cycles (e.g. greenhouse gas fluxes). For instance, ThG can not only provide the information of TC, OC and IC values, but also the different decomposed temperature of SOC fractions of different soil samples with different disturbances or environments through themogram. It also can provide valuable 
information for identification and characterization of SOM change by fire impacts. For instances, two soil samples were taken in the same forest and same depth, but different fired effects. One sample was taken in a place that had intensive fire and the other without fire. When analyzing them with ThG, the thermo-gram showed that the intensively fired sample had a peak, which was higher than that of the non-fire samples at the temperature range $450-600^{\circ} \mathrm{C}$ (stable OC fraction). It means that SOM in the intensively fired sample were burnt and that soil was intensively mineralized by the fire. Therefore, it has more stable OC fraction than that in the non-fired sample.

\section{V.1.2 Limitations}

i ThG can determine TC, OC and IOC simultaneously. However, it cannot provide $\mathrm{N}$ content and the $\mathrm{C} / \mathrm{N}$ ratio of soil sample, which are very necessary to estimate the quality of soil. It would be better when ThG can provide information of $\mathrm{C}$ and $\mathrm{N}$ contents in a single run.

ii For inorganic carbon soil samples, ThG has a slightly overestimate of determining SOC compared to that of acidification methods, especially for carbonate soil samples. Therefore, care has to be taken when comparing SOC contents in soil samples with markedly different carbonate contents analyzed by ThG.

iii For samples that have high organic carbon contents, it is difficult for ThG to detect the changes of SOC fractions. This can be explained that the peat or humic soils have high $\mathrm{C}$-contents and are rich of labile OC. Therefore, the time to increase temperature from $140-300^{\circ} \mathrm{C}$ was not enough for all labile $\mathrm{OC}$ fraction to be completely combusted. Consequently, the labile SOC was not completely combusted when the temperature increases to the coming temperature range (300-390 ${ }^{\circ} \mathrm{C}$ intermediate labile). This can be seen in the thermo-gram that after the first fraction (labile OC fraction) the curve is still much higher than the baseline in these cases. Besides, care has taken when soil samples have high labile $\mathrm{C}$ content and two high neighbor peaks in the thermo-gram. This can be explained that when samples have two high neighbor peaks, they will be overlap and cannot be completely separated. Therefore, it might cause some errors in results even 
peak separation and analysis software was used to separate hide and overlap peaks. To solve this problem, we have to separate all neighbor peaks by slowing down the ramp speed of the device that will take longer time to analyze samples. It will not be optimal for ThG, because of the limitation of analysis time of the device. The maximum analysis time of ThG for one sample is only 30 minutes. The next generation device might solve this problem. Therefore, care has to be taken for the separation of SOC fractions by ThG with samples of high $\mathrm{C}$ content (above 15\%), for examples peat and humic soils.

iv ThG has limitation to explain the individual peaks of SOC fractions by itself. It should be combined with other devices (i.e. carbon isotope analysis, mass spectrometry. etc.) to provide more information about the peaks of its thermogram. However, these devices are expensive and not available in many labors.

\section{V.2 Outlook for future research}

i It is necessary to test ThG with various kinds of soil samples before applying it widely in soil analysis. For examples, ThG should be tested for soil samples of deferent depths. When the depth of soil increase, the ratios of LC/SC will decrease. ThG should be used to test this issue.

ii ThG can provide many information of IC, OC, TC and SOC fractions in a single run without complicated pretreatment. Therefore, ThG should be a useful method in landscape scale, where the number of sample is high, to quantify the change of SOC with time of different given environments, and to compare the effects of different land-use changes on SOC. ThG also can be used to detect the SOC changes of long term farm experiments.

iii Soil respiration plays an important part in the global carbon cycle (Ryan. 2005). Labile carbon fraction might contribute an important part in soil respiration because of its short turnover rate (Gu et al. 2004). Therefore, finding the relation between soil respiration and labile organic carbon fraction is necessary. ThG can be used to provide information of LC fraction and thus it might be a useful input for finding the relation of soil respiration and LC fraction.

iv To understand the dynamic of SOM, SOM models should use a continuous quality distribution (Bruun et al. 2010). Thermogram of thermal analysis, which 
provide information of continuous decomposition of SOM with temperature, can be useful to identity a continuous distribution of SOM in a distributional model. Therefore, ThG can provide useful inputs for distributional SOM modelling (Bruun et al. 2010).

v ThG cannot clarify the peaks of its thermograph by itself. However, radiocarbon analysis and mass spectrometry are effective tools in determining turnover rate, dynamic and structure of SOM in ecosystem (Plante et al.2013; Trumbore. 2009; Dell'Abate et al.2003; Lopez-Capel et al. 2005). Consequently, isotope analysis and mass spectrometry have been frequently applied to analyze chemical characteristics and turnover rates of SOM (Bernoux et al. 1998; Kujawinski et al. 2002; Kögel- Knabner. 1997; Schweizer et al. 1999), or connected to thermal devices (Lopez-Capel et al. 2005; Kuzyakov et al. 2006; Dorodnikov et al. 2007, Dell'Abate et al. 2003). For example, Plante et al. (2013) combined TG and DSC with ${ }^{14} \mathrm{C}$ isotope to test if thermal labile carbon fraction has more ${ }^{14} \mathrm{C}$ than thermal stable carbon fraction or not. Meanwhile, Doronikov et al. (2007) coupled TG and DSC to stable isotope $\left({ }^{13} \mathrm{C}\right.$ and $\left.{ }^{15} \mathrm{~N}\right)$ to distinguish SOM pools with different thermal stability. Therefore it is necessary to combine ThG with these devices (e.g. isotope analysis, mass spectrophotometry) to explain all the peaks of $\mathrm{ThG}$ clearly and to assign isotopic signatures to SIC and SOC that may be a valuable future advancement of the thermal gradient method. 


\section{References}

Amundson, R. 2001. The carbon budget in soils. Annual Review of Earth and Planetary Sciences, 29, 535-562.

Baldock J.A and Skjemstad J.O. 2000. Role of the soil matrix and minerals in protecting natural organic materials against biological attack. Organic Geochemistry, 31, 697710.

Baldock J.A and Skjemstad J.O. 1999. Soil organic carbon/soil organic matter. In 'Soil Analysis: an Interpretation Manual. (Eds K. I. Peverill, L. A. Sparrow, and D. J. Reuter.): 159-170. (CSIRO Publishing: Collingwood).

Baldock, J.A., Masiello, C.A., Gelinas, Y. and Hedges, J.I. 2004. Cycling and composition of organic matter in terrestrial and marine ecosystems. Marine Chemistry, 92, 39-64.

Batjes N.H and Sombroek W.G. 1997. Possibilities for carbon sequestration in tropical and subtropical soils. Global Change Biology, 3, 161-173.

Biermayer G and Rehfuess K.E. 1985. Holozäne Terrae fuscae aus Carbonatgesteinen in den Nördlichen Kalkalpen. Zeitschrift für Pflanzenernährung und Bodenkunde, 148, 405416.

Bisutti I, Hilke I, Raessler M. 2004. Determination of total organic carbon - an overview of current methods. Trac-Trends Anal. Chem, 23, 716-726.

Bisutti I, Hilke I, Schumacher J, Raessler M. 2007. A novel single-run dual temperature combustion (SRDTC) method for the determination of organic, in-organic and total carbon in soil samples. Talanta, 71, 521-528.

Breulmann M. 2011. Functional soil organic matter pools and soil organic carbon stocks in grasslands - An ecosystem perspective. Ph.D Dissertation. Gottfried Wilhelm Leibniz Hannover University, Germany.

Brevik E.C. 2012. Soils and Climate Change: Gas Fluxes and Soil Processes. Soil society of America. doi:10.2136/sh12-04-0012

Broos K and Baldock J. 2008. 'Building soil carbon for productivity and implications for carbon accounting', in 2008South Australian GRDC Grains Research Update

Bruun S, Agren G.I, Christensen B.T and Jensen L.S. 2010. Measuring and modeling continuous quality distributions of soil organic matter. Biogeosciences, 7, 27-41.

Burt T.P and Pinay G. 2005. Linking hydrology and biogeochemistry in complex landscapes. Progress in Physical Geography, 29, 297-316.

Chatterjee A, Lal R, Wielopolski L, Martin M. Z, Ebinger M.H. 2009. Evaluation of different soil carbon determination methods. Crit Rev Plant Sci, 28: 164-178. 
Chaudhari P.R, Ahire D.V, Ahire V.D, Chkravarty M, Maity S. 2013. Soil Bulk Density as related to Soil Texture, OrganicMatter Content and available total Nutrients of Coimbatore Soil. International Journal of Scientific and Research Publications, Volume 3, Issue 2, ISSN 2250-3153.

Chichester F.W and Chaison R.F. 1992. Analysis of carbon in calcareous soils using a two temperatures dry combustion infrared instrumental procedure. Soil Science 153: 237241.

Christensen B.T. 1992. Physical fractionation of soil and organic matter in primary particle size and density separates. Advances in Soil Science, 20,1-90.

Christensen B.T. 2001. Physical fractionation of soil and structural and functional complexity in organic matter turnover. Eur J Soil Sci, 52, 345-353.

Craswell E.T and Lefroy R.D.B. 2001. The rolle and function of organic matter in tropical soils. Nutrient Cycling in Agroecosystems, 61, 7-18.

De la Rosa J.M, González-Pérez J.A, González-Vázquez R, Knicker H, López-Capel E, Manning D.A.C, González-Vila F.J. 2008. Use of pyrolysis/GCeMS combined with thermal analysis to monitor $\mathrm{C}$ and $\mathrm{N}$ changes in soil organic matter from a Mediterranean fire affected forest. Catena, 74, 296-303.

Dell'Abate M.T, Benedetti A, Trinchera A and Dazzi C. 2002. Humic substances along the profile of two Typic Haploxerert. Geoderma, 107, 281-296.

Demyan M.S, Rasche F, Schütt M, Smirnova N, Schulz E and Cadisch G. 2013. Combining a coupled FTIR-EGA system and in situ DRIFTS for studying soil organic matter in arable soils. Biogeosciences, 10, 2897-2913.

Dorodnikov, M, Fangmeier, A, Kuzyakov, Y. 2007. Thermal stability of soil organic matter pools and their $\delta^{13} \mathrm{C}$ values after $\mathrm{C} 3-\mathrm{C} 4$ vegetation change. Soil Biology and Biochemistry, 39, 1173-1180.

Elmquist M, Cornelissen G, Kukulska Z, Gustafsson, Ö. 2006. Distinct oxidative stabilities of char versus soot black carbon: Implications for quantification and environmental recalcitrance. Global Biogeochemical cycles, 20: GB2009, doi: 10.1029/2005GB002629, 2006.

Fernández J.M, Plante A, Leifeld J, Rasmussen C. 2011. Methodological considerations for using thermal analysis in the characterization of soil organic matter. Journal of Thermal Analysis and Calorimetry, 104, 389-398.

Fernández J.M, Peltre C, Craine J.M, Plante A.F. 2012. Improved characterization of soil organic matter by thermal analysis using $\mathrm{CO}_{2} / \mathrm{H}_{2} \mathrm{O}$ evolved gas analysis. 
Environmental Science and Technology, 46, 8921-8927.

Ghani A, Dexter M, Perrott K.W. 2003. Hot-water extractable carbon in soils: a sensitive measurement for determining impacts of fertilisation, grazing and cultivation. Soil Biology and Biochemistry, 35, 1231-1243.

Glaser B and Birk J.J. 2012. State of the scientific knowledge on properties and genesis of Anthropogenic Dark Earths in Central Amazonia (terra preta de Índio). Geochimica et Cosmochimica Acta, 82, 39-51.

GRDC. 2004. Function of soil organic matter and the effect on soil properties. http://www.grdc.com.au/ /media/05FC0F23498E4129AC216A06B2C804E3.pdf

GRDC. 2009. Carbon farming (fact sheet), Grains Research and Development Corporation. http://www.grdc.com.au/uploads/documents/GRDC_CarbonFarming_4pp.pdf

GRDC $^{1}$. 2013. Managing soil organic matter. Part 1. http://www.grdc.com.au/GRDC-Guide-ManagingSoilOrganicMatter

GRDC $^{2}$.2013. Managing soil organic matter. Part 2. http://www.grdc.com.au/GRDC-Guide-ManagingSoilOrganicMatter

Gregorich E.G, Beare M.H, McKim U.F, Skjemstad J.O. 2006. Chemical and biological characteristics of physically uncomplexed organic matter. Soil Sci Soc Am J 70:975985.

Guo L.B and Gifford R.M. 2002. Soil carbon stocks and land use change: a meta analysis. Global Change Biology, 8, 345-360.

Hafner S and Bisobni J. 2007. A simple method for measurement of inorganic carbon concentration and carbonate system alkalinity in anaerobic digesters. Agricultural Engineering International, IX, Manuscript EE 06008.

Hammes K, Schmidt M.W.I, Smernik R.J, Currie L.A, Ball W.P, Nguyen T.H, Louchouarn P, Houel S, Gustafsson Ö, Elmquist M, Cornelissen G, Skjemstad J O, Masiello C A, Song J, Peng P A, Mitra S, Dunn J C, Hatcher P G, Hockaday W C, Smith D M, Hartkopf-Fröder C, Böhmer A, Lüer B, Huebert B J, Amelung W, Brodowski S, Huang L, Zhang W, Gschwend P M, Flores-Cervantes D X, Largeau C, Rouzaud J-N, Rumpel C, Guggenberger G, Kaiser K, Rodionov A, Gonzalez-Vila F J, GonzalezPerez J A, de la Rosa J M, Manning D A C, López-Capél E, Ding L. 2007. Comparison of quantification methods to measure fire-derived (black/elemental) carbon in soils and sediments using reference materials from soil, water, sediment and the atmosphere. Global Biogeochem Cycles, 21: GB3016. 
Hammes K, Smernik R.J, Skjemstad J.O, Schmidt M.W.I. 2008. Characterisation and evaluation of reference materials for black carbon analysis using elemental composition, colour, BET surface area and ${ }^{13} \mathrm{C}$ NMR spectroscopy. Applied Geochemistry, 23, 2113-2122.

Harris D, Horwath W.R, van Kessel C. 2001. Acid fumigation of soils to remove carbonates prior to total organic carbon or carbon-13 analysis. Soil Sci Soc Am J, 65, 1853-1856.

Heimann M and Reichstein M. 2008. Terrestrial ecosystem carbon dynamics and climate feedbacks. Nature, 451, doi:10.1038/nature06591.

Heitkamp F, Jacobs A, Jungkunst H.F, Heinze S, Wendland M, Kuzyakov Y. 2012. Processes of soil carbon dynamics and ecosystem carbon cycling in a changing world. In: Lal R, Lorenz K, Hüttl RF, Schneider BU, von Braun J (eds) Recarbonization of the biosphere. Springer, Dordrecht, pp 395-428.

Heitkamp F, Raupp J, Ludwig B. 2011. Effects of fertilizer type and rate on labile soil fractions of a sandy Cambisol - long term and short-term dynamics. J Plant Nutr Soil Sci 174:121-127.

Heitkamp F. 2010. Effects of fertilizer type and rate on partitioning of soil organic matter into pools of different stability. PhD Dissertation. Kassel University, Germany. http://d-nb.info/1003392407/34/

Heitkamp F, Raupp J, Ludwig B. 2009. Impact of fertilizer type and rate on carbon and nitrogen pools in a sandy Cambisol. Plant and Soil, 319, 259-275.

Heitkamp F, Raupp J, Ludwig B. 2011. Effects of fertilizer type and rate on labile soil fractions of a sandy Cambisol - long term and short-term dynamics. Journal of Plant Nutrition and Soil Science, 174, 121-127.

Helfrich M, Flessa H, Mikutta R, Dreves A, Ludwig B. 2007. Comparison of chemical fractionation methods for isolating stable soil organic carbon pools. European Journal of Soil Science, 58, 1316-1329.

Helfrich M, Ludwig B, Buurman P, Flessa H. 2006. Effect of land use on the composition of soil organic matter in density and aggregate fractions as revealed by solid-state C13 NMR spectroscopy. Geoderma, 136, 331-341. 
Helfrich M. 2006. Composition and stability of organic matter fractions in soils under different land use regimes. PhD Dissertation. Kassel University, Germany. http://wwwuser.gwdg.de/ mhelfri/abstract/Dissertation\%20Helfrich\%202007.pdf

Herbst M, Bornemann L, Graf A, Welp G, Vereecken H, Amelung W. 2012. A geostatistical approach to the field-scale pattern of heterotrophic soil $\mathrm{CO}_{2}$ emission using covariates. Biogeochemistry, 111, 377-392.

Hilscher A and Knicker H. 2011. Degradation of grass-derived pyrogenic organic material, transport of the residues within a soil column and distribution in soil organic matter fractions during a 28-month microcosm experiment. Organic Geochemistry, 42, 4254.

Horváth B, Opara-Nadi O, Beese F. 2005. A simple method for measuring the carbonate content of soils. Soil Sci Soc Am J, 69, 1066-1068.

IPCC. 2007. Climate Change 2007: Synthesis Report Intergovernmental Panel on Climate Change, an Assessment of the Intergovernmental Panel on Climate Change, 1-52.

ISO 10390. 2005. Soil Quality - Determination of $\mathrm{pH}$. International Organization for Standardization. Geneva, Switzerland. 5 pp.

ISO 10693. 1995. Soil Quality - Determination of carbonate content - Volumetric method. International Organization for Standardization. Geneva, Switzerland. 7 pp.

ISO 10694. 1995. Soil Quality - Determination of organic and total carbon after dry combustion (elementary analysis). International Organization for Standardization. Geneva, Switzerland. 7 pp.

Jagadamma S, Lal R, Ussiri D.A.N, Trumbore S.E, Mestelan S. 2010. Evaluation of structural chemistry and isotopic signatures of refractory soil organic carbon fraction isolated by wet oxidation methods. Biogeochemistry, 98, 29-44.

Jungkunst H and Fiedler S. 2007. Latitudinal differentiated water table control of carbon dioxide, methane and nitrous oxide fluxes from hydromorphic soils: feedbacks to climate change: Global Change Biology. 13, 2668-2683.

Kabala C and Zapart J. 2012. Initial soil development and carbon accumulation on moraines of the rapidly retreating Werenskiold Glacier, SW Spitsbergen, Svalbard archipelago. Geoderma 175-176, 9-20.

Kalbitz K, Kaiser K, Fiedler S, Kölbl A, Amelung W, Bräuer T, Cao Z, Don A, Grootes P, Jahn R, Schwark L, Vogelsang V, Wissing L, Kögel-Knabner I. 2012. The carbon count of 2000 years of rice cultivation. Glob Change Biol: in press, DOI: 10.1111/gcb.12080. 
Kalbitz K, Kaiser K, Fiedler S, Kölbl A, Amelung W, Bräuer T, Cao Z, Don A, Grootes P, Jahn R, Schwark L, Vogelsang V, Wissing L, Kögel-Knabner I. 2013. The carbon count of 2000 years of rice cultivation. Global Change Biology, 19, 1107-1113.

Karhu K. 2010. Temperature sensitivity of soil organic matter decomposition in boreal soils. $\mathrm{PhD}$ Dissetation. University of Helsinki, Finland.

Kiem R. 2002. Characterization of refractory soil organic matter in long-term agroecosystem experiments. PhD Dissetation. University of Technique München, Germany. https://mediatum.ub.tum.de/doc/603290/document.pdf

Kirschbaum. 2000. Will changes in soil organic carbon act as a positive or negative feedback on global warming? Biogeochemistry 48, 21-51.

Kirschbaum. 2006. The temperature dependence of organic-matter decomposition - still a topic of debate. Soil Biology and Biochemistry 38, 2510-2518.

Körschens M, Weigel A, Schulz E. 1998. Turnover of soil organic matter (SOM) and longterm balances - Tools for evaluating sustainable productivity of soils. J Plant Nutr Soil Sci 161:409-424.

Köster J, Wehner H, Hufnagel H. 1988. Organic geochemistry and organic petrology of organic rich sediments within the "Hauptdolomit" formation (Triassic, Norian) of the Northern Calcareous Alps. Organic Geochemistry, 13, 377-386.

Kravchenko A.N and Hao X. 2008. Management practice effects on spatial variability characteristics of surface mineralizable C. Geoderma, 144, 387-394.

Krüger J.P, Beckedahl H, Gerold G, Jungkunst H.F. 2013. Greenhouse gas emission peaks following natural rewetting of two wetlands in the southern Ukhahlamba-Drakensberg Park, South Africa. South African Geographical Journal, 1-6.

Kuzyakov Y, Mitusov A, Schneckenberger K. 2006. Effect of C3-C4 vegetation change on $\delta 13 \mathrm{C}$ and $\delta 15 \mathrm{~N}$ values of soil organic matter fractions separated by thermal stability. Plant and Soil. 283, 229-238.

Lal R. 2002. Soil carbon dynamics in cropland and rangeland. Environmental Pollution. 116, 353-362.

Lal R. 2004. Soil carbon sequestration impacts on global climate change and food security. Science, 304, 1623-1627.

Leifeld J. 2007. Thermal stability of black carbon characterised by oxidative differential scanning calorimetry. Organic Geochemistry, 38, 112-127. 
Leifeld J and Kögel-Knabner I. 2004. Soil organic matter fractions as early indicator for carbon stock changes under different land-use? Geoderma. 124, 143-155.

Leifeld J. and von Lützow M. 2014. Chemical and microbial activation energies of soil organic matter decomposition. Biology and Fertility of Soils, 50, 147-153.

Leifeld J, Franko U, Schulz E. 2006. Thermal stability responses of soil organic matter to long-term fertilization practices. Biogeosciences, 3, 371-374.

Leinweber P, Schulten, H.R, Körschens, M. 1995. Hot water extracted organic matter: chemical composition and temporal variations in a long-term field experiment. Biology and Fertility of Soils, 20, 17-23.

Loeppert R.H and Suarez D.L., 1996. Carbonate and gypsum. in: Sparks, D.L. et al. (Eds.), Methods of soil analysis. Part 3 - chemical methods. SSSA and ASA, Madison, WI.

Lopez-Capel E.L, Arranz J, Gonzalez-Vila F.J, Gonzalez-Perez J.A, Manning D.A.C. 2006b. Elucidation of different forms of organic carbon in marine sediments from the Atlantic coast of Spain using thermal analysis coupled to isotope ratio and quadrupole mass spectrometry. Organic Geochemistry 37, 1983-1994.

Lopez-Capel E, Sohi S.P, Gaunt J.L, Manning D.A.C. 2005. Use of thermogravimetrydifferential scanning calorimetry to characterize modelable soil organic matter fractions. Soil Science Society of America Journal 69, 136-140.

Maharaj S, Barton C.D, Karathanasis T.A.D, Rowe H.D, Rimmer S.M. 2007. Distinguishing "new" from "old" organic carbon on reclaimed coal mine sites using thermogravimetry: I. Method development. Soil Science, 172, 292-301

Manlay R.J, Feller C, Swift M.J. 2007. Historical evolution of soil organic matter concepts and their relationships with the fertility and sustainability of cropping systems. Agricultural Ecosystem Environment 119, 217-233.

Marin-Spiotta E, Chaopricha N.T, Plante A.F, Diefendorf A.F, Mueller C.W, Grandy A.S, Mason, J.A. 2014. Long-term stabilization of deep soil carbon by fire and burial during early Holocene climate change. Nature Geoscience, 7, 428-432.

Martin AE and Reeve R. 1954. A rapid manometric method for determining soil carbonate. Soil Science, 79, 187-197.

Midwood A.J and Boutton T.W. 1998. Soil carbonate decomposition by acid has little effect on $\delta^{13} \mathrm{C}$ of organic matter. Soil Biol Biochem 30, 1301-1307.

Mikutta R, Kleber M, Kaiser K, Jahn R. 2005. Review: Organic matter removal from soils using hydrogenperoxide, sodium hypochlorite, and disodium peroxodisulfate. Soil Science Society of America, 69, 120-135. 
Müller D. 2010. Das Ökosystem „Kerstlingeröder Feld“ - Ehemaliger Truppenübungsplatz und späteres Naturschutzgebiet mit FFH-Gebiet. In: Schauplätze und Themen der Umweltgeschichte (eds. Herrmann, B. and Kruse, U.), pp. 205-2014. Universitätsdrucke Göttingen, Göttingen.

Murphy B.W. 2014. Soil organic matter and soil function- Review of the literature and underlying data. Department of environment, Canberra, Australia. http://www.environment.gov.au/system/files/resources/20051db1-51ba-49e1-9758$\underline{66 \mathrm{bd} 2 \mathrm{c} 8 \mathrm{c} 1 \mathrm{cc} 5 / \text { files/soil-organic-matter.pdf }}$

Mutsch F. 2001. Soil chemical characterisation of the Mühleggerköpfl within the frame of investigations concerning the nitrogen fluxes in the Limestone Alps. in: Herman, F., Smidt, S., Englisch, M. (Eds.), Nitrogen fluxes at the Mühleggerköpfl in the Northern Tyrolean Limestone Alps. FBVA-Berichte 119, Wien, pp. 33-40.

Nguyen T.H, Roberta A.B, Ball W.P. 2004. An evaluation of thermal resistance as a measure of black carbon content in diesel soot, wood char and sediment. Organic Geochemistry $35,217-234$.

Oades J.M. 1984. Soil organic matter and structural stability: mechanisms and implications for management. Plant and Soil. 76, 319-337.

Olk D.C and Gregorich E.G. 2006. Overview of the symposium proceedings, "Meaningful Pools in Determining Soil Carbon and Nitrogen Dynamics". Soil Science Society of America Journal, 70, 967-974.

Paul E.A, Morris S.J, Conant R.T, Plante A.F. 2006. Does the acid hydrolysis-incubation method measure meaningful soil organic carbon pools? Soil Sci Soc Am J 70, 10231035.

Peltre C, Fernandez J.M, Craine J.M, Plante A.F. 2013. Relationships between biological and thermal indices of soil organic matter stability differ with soil organic carbon level. Soil Science Society of America Journal, 77, 2020-2028.

PIRSA. 2010. Soil carbon and climate change. Discussion paper. http://www.pir.sa.gov.au/_data/assets/pdf_file/0006/137904/PIRSA_soil_carbon_an d_climate_change.pdf

Plante AF, Pernes M, Chenu C. 2005. Changes in clay-associated organic matter quality in a $\mathrm{C}$ depletion sequence as measured by differential thermal analysis. Geoderma 129,186-199.

Plante A.F, Beaupre S.R, Roberts M.L, Baisden T. 2013. Distribution of radiocarbon ages in soil organic matter by thermal fractionation. Radiocarbon, 55, 1077-1083. 
Plante A.F, Fernandez J.M, Leifeld J. 2009. Application of thermal analysis techniques in soil science. Geoderma, 153, 1-10.

Plante A.F, Fernández J.M, Haddix M.L, Steinweg J.M, Conant, R.T. 2011. Biological, chemical and thermal indices of soil organic matter stability in four grassland soils. Soil Biology and Biochemistry, 43, 1051-1058.

Preutenborbeck J. 2009. Landnutzungswandel und Biodiversität - eine historischökologische Analyse am Beispiel des Naturraumes Göttinger Wald. Ph.D. thesis, Georg-August-Universität, Göttingen.

Prietzel J, and Christophel D. 2014. Organic carbon stocks in forest soils of the German Alps. Geoderma, 221-222, 28-39.

Prietzel J, Dechamps N and Spielvogel S. 2013. Analysis of non-cellulosic polysaccharides helps to reveal the history of thick organic surface layers on calcareous Alpine soils. Plant and Soil, 365, 93-114.

Provenzano M.R and Senesi N. 1999. Thermal properties of standard and reference humic substances by differential scanning calorimetry. Journal of Thermal Analysis and Calorimetry, 57,517-526.

Randall E.W, Mahieu N, Powlson D.S, Christensen B.T. 1995. Fertilization effects on organic matter in physically fractionated soils as studied by ${ }^{13} \mathrm{C}$ NMR: Results from two long-term field experiments. European Journal of Soil Science, 46, 557-565.

Reeves D.W. 1997. The role of soil organic matter in maintaining soil quality in continuous cropping systems. Soil and Tillage research, 43, 131-167.

Roth P.J, Lehndorff E, Brodowski S, Bornemann L, Sanchez-García L, Gustafsson Ö, Amelung W. 2012. Differentiation of charcoal, soot and diagenetic carbon in soil: Method comparison and perspectives. Organic Geochemistry, 46, 66-75.

Rovira P, Kurz-Besson C, Couteaux M.M, Vallejo R.V. 2008. Changes in litter properties during decomposition: A study by differential thermogravimetry and scanning calorimetry. Soil Biology and Biochemistry, 40, 172-185.

Rozzi A and Brunetti A. 1981. Direct bicarbonate determination in anaerobic digester liquors. Environmental Technology Letters, 2, 385-392.

Ryan M.G. and Law B.E. 2005. Interpreting, measuring, and modeling soil respiration. Biogeochemistry, 73, 3-27.

Schlesinger W.H. 1990. Evidence from chronosequence studies for a low carbon-storage potential of soils. Nature 348, 232-234. 
Schmidt A, Smernik R.J, McBeath T.M. 2012. Measuring organic carbon in Calcarosols: understanding the pitfalls and complications. Soil Research, 50, 397-405.

Schnitzer M. 1991. Soil Organic matter - the next 75 years. Soil Science, 151, 41-58.

Schnitzer M and Hoffman I. 1966. A thermogravimetric approach to the classification of organic soils. Proceedings-Soil Science Society of America, 30, 63-66.

Schnitzer M, Turner R.C, Hoffman I. 1964. A thermogravimetric study of organic matter of representative Canadian podzol soils. Canadian Journal of Soil Science, 44, 7-13.

Schrumpf M, Schulze E.D, Kaiser K, Schumacher J. 2011. How accurately can soil organic carbon stocks and stock changes be quantified by soil inventories? Biogeosciences, 8 , 1193-1212.

Shurygina E.A, Larina N.K, Chubarov M.A, Kononova M.M. 1971. Differential thermal analysis (DTA) and thermogravimetry (TG) of soil humus substances. Geoderma, 6, 169-177.

Skjemstad J.O and Baldock J.A. 2008. Total and organic carbon. In: Carter MR, Gregorich EG (eds) Soil sampling and methods of analysis. Taylor and Francis, Boca Raton, pp 225-238.

Sollins P, Homann P, Caldwell B.A. 1996. Stabilisation and destabilisation of soil organic matter: Mechanisms and controls. Geoderma 74, 65-105.

Tatzber M, Stemmer M, Spiegel H, Katzlberger C, Haberhauer G, Gerzabek M.H. 2007. An alternative method to measure carbonate in soils by FT-IR spectroscopy. Environmental Chemistry Letters, 5, 9-12.

Tivet F, Carlos de Moraes Sà J, Borszowskei P.R, Letourmy P, Briedis C, Ferreira A.O, Burkner dos Santos Thiago Massao Inagaki J. 2012. Soil carbon inventory by wet oxidation and dry combustion methods: Effects of land use, soil texture gradients, and sampling depth on the linear model of C-equivalent correction factor. Soil Sci Soc Am J 76, 1048-1059.

Trumbore S.E, Oliver A, Amundson R. 1996. Rapid Exchange between Soil Carbon and Atmospheric Carbon Dioxide Driven by Temperature Change. Science. 272. 393-396.

Van Keulen Herman. 2001. Tropical soil organic matter modelling: problems and prospects. Nutrient cycling in Agro-ecosystems, 61,33-39.

van Reeuwijk L.P and Houba V.J.G. 1998. Guidelines for quality management in soil and plant laboratories. ISRIC, FAO, Rome.

von Lützow M, Kogel-Knabner I, Ekschmitt K, Flessa H, Guggenberger G, Matzner E, Marschner B. 2007. SOM fractionation methods: Relevance to functional pools and to 
stabilization mechanisms. Soil Biology and Biochemistry, 39, 2183-2207.

von Lutzow M, Kogel-Knabner I., Ekschmitt K, Matzner E, Guggenberger G, Marschner, B, Flessa H. 2006. Stabilization of organic matter in temperate soils: mechanisms and their relevance under different soil conditions - A review. EuropeanJournal of Soil Science, 57, 426-445.

von Lützow M, Kögel-Knabner I., Ludwig B, Matzner E, Flessa H, Ekschmitt K, Guggenberger G, Marschner B, Kalbitz K. 2008. Stabilization mechanisms of organic matter in four temperate soils: Development and application of a conceptual model. Journal of Plant Nutrition and Soil Science, 171, 111-124.

Vuong T.X, Heitkamp F, Jungkunst H.F, Reimer A, Gerold G. 2013. Simultaneous measurement of soil organic and inorganic carbon: evaluation of a thermal gradient analysis. Journal of Soils and Sediments, 13, 1133-1140.

Walthert L, Graf U, Kammer A, Luster J, Pezzotta D, Zimmermann S, Hagedorn F. 2010. Determination of organic and inorganic carbon, $\delta^{13} \mathrm{C}$, and nitrogen in soils containing carbonates after acid fumigation with $\mathrm{HCl}$. J Plant Nutrient Soil Science, 173, 207 216.

Wang X, Wang J, Zhang J. 2012. Comparisons of three methods for organic and inorganic carbon in calcareous soils of Northwestern China. PLoS ONE 7: e44334 EP.

Wang Q, Li Y, Wang Y. 2011. Optimizing the weight loss-on-ignition methodology to quantify organic and carbonate carbon of sediments from diverse sources. Environmental Monitoring and Assessment, 174, 241-257.

Webster R. 1997. Regression and functional relations. European Journal of Soil Science, 48, 557-566.

Williams D.E. 1948. A rapid manometer method for the determination of carbonate in soils. Proceedings-Soil Science Society of America, 13, 127-129. 


\section{Curriculum Vitae}

\section{Truong Xuan Vuong}

\section{Personal data}

Date of birth: 31.07.1979

Place of birth: Thai Nguyen city, Vietnam.

\section{Professional career}

2010 - Present: Graduate student (PhD), Georg-August-University Göttingen.

Topic: Highly resolved thermal analysis as a tool for simultaneous quantification of total carbon, organic carbon, inorganic carbon and soil organic carbon fractions in landscapes.

Supervisors: Prof. Dr. Gerhard Gerold, Prof. Dr. Hermann F. Jungkunst, Dr. Felix Heitkamp.

2005 - 2010: Working as a lecturer at Chemistry faculty of College of Sciences- Thai Nguyen University.

2003 - 2005: Master degree of analytical chemistry, Hanoi University of Education.

Master's thesis: 'Study on the complexation of the mono and multiligand complexes of $\mathrm{Nd}$ (III) with 4-(2-pyridilazo) - rezocinol (PAR) and $\mathrm{HX}\left(\mathrm{HX}: \mathrm{CH}_{2} \mathrm{ClCOOH}, \mathrm{CHCl}_{2} \mathrm{COOH}\right.$, $\left.\mathrm{CCl}_{3} \mathrm{COOH}\right)$.' (Written in Vietnamese).

Supervisor: Assoc. Prof. Dr. Tran Thi Hong Van.

1998 - 2002: Undergraduate student (BSc in chemistry), Thai Nguyen University of Education.

Bachelor's thesis: The first studying some groups of natural organic compounds in the 'Bo Khai' plant ( Erythropalum scandens blume) in the mountainous areas. (Written in Vietnamese).

Supervisor: MSc. Hua Van Thao. 


\section{Awards \& Grants}

1. Thai Nguyen college of Education's (TNCE) scholarship for academic years from 1999 to 2002 .

2. Award for excellent students in studying of Thai Nguyen College of Education (TNCE) in 2000 .

3. In 2010, PhD scholarship (4 years) of Vietnamese Ministry of Training and Education and the German Academic Exchange Service (DAAD).

\section{Publications}

\section{Submitted}

4. Truong Xuan Vuong, Jörg Prietzel and Felix Heitkamp. Simultaneous measurement of organic and inorganic carbon in dolomite-containing soils.

Submitted to CATENA Journal of Elsevier. (Submitted).

5. Vuong T.X, Jungkunst H.F, Reimer A, Gerold G, Heitkamp F. Highly resolved thermal analysis as a tool for soil organic carbon fractionation in landscapes.

Submitted in European Journal of Soil Science. (Submitted).

\section{Other publications}

1 The first studying some groups of natural organic compounds in Erythropalum Scandent Blume plant. Journal of science and technology, Thai Nguyen University, 2004, 3, 66-70.

2 Study on the complex formation of the mono and multiligand complexes of Nd (III) with 4-(2-pyridilazo) - rezocinol (PAR) and $\mathrm{HX}(\mathrm{HX}: \mathrm{CH} 2 \mathrm{ClCOOH}, \mathrm{CHCl} 2 \mathrm{COOH}$, $\mathrm{CCl} 3 \mathrm{COOH})$. Journal of science, Ha Noi University of Education, 2006, 4, 89-93.

3 Vuong, T.X., Heitkamp, F., Jungkunst, H.F., Reimer, A., Gerold, G. 2013. Simultaneous measurement of soil organic and inorganic carbon: evaluation of a thermal gradient analysis. Journal of Soils and Sediments, 13, 1133-1140. 